\title{
Comunicación y Sistematización de experiencias: aprendizajes sobre una política ambiental territorial, Rafaela Más Sustentable
}

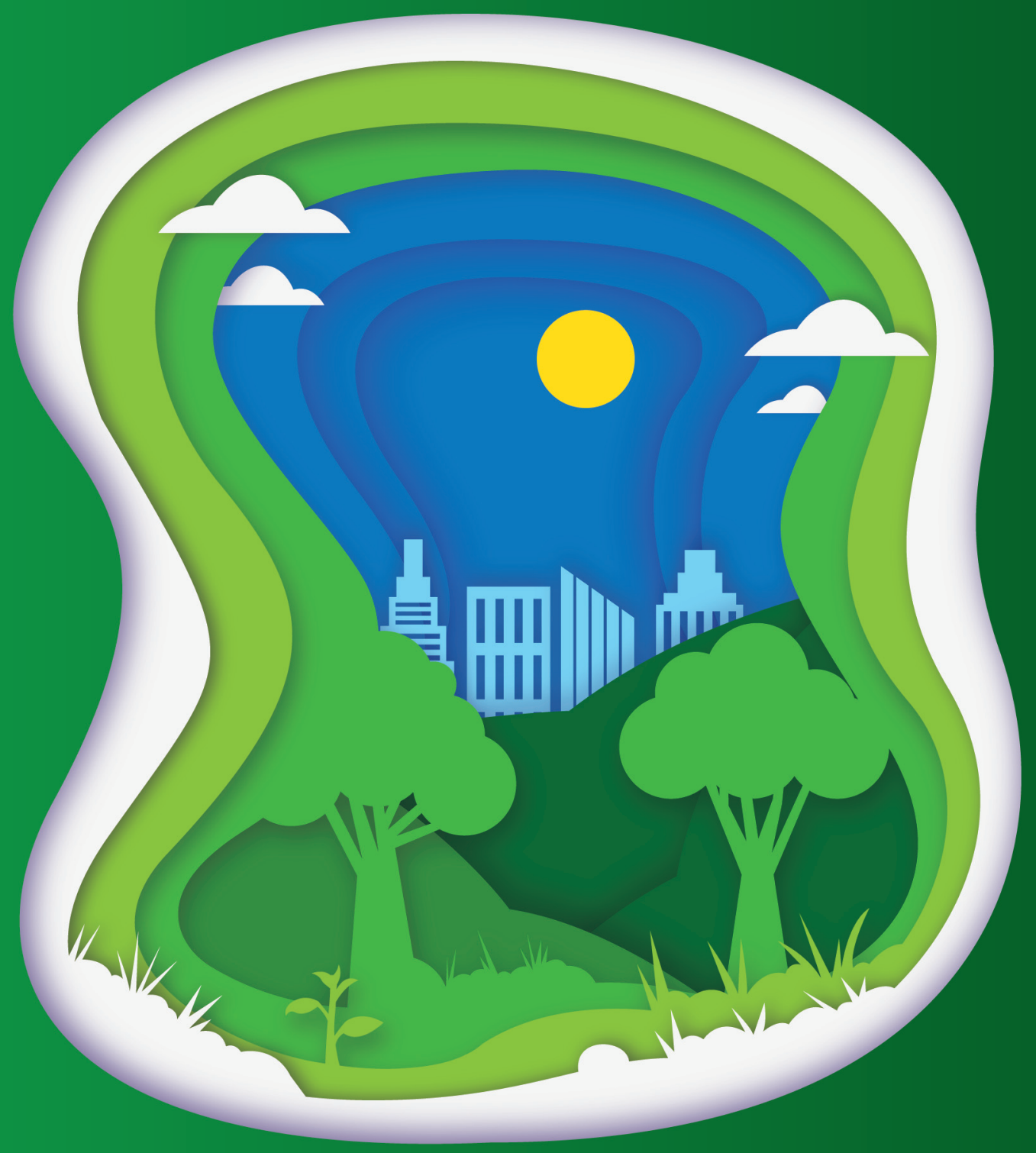

Eleonora Spinelli 


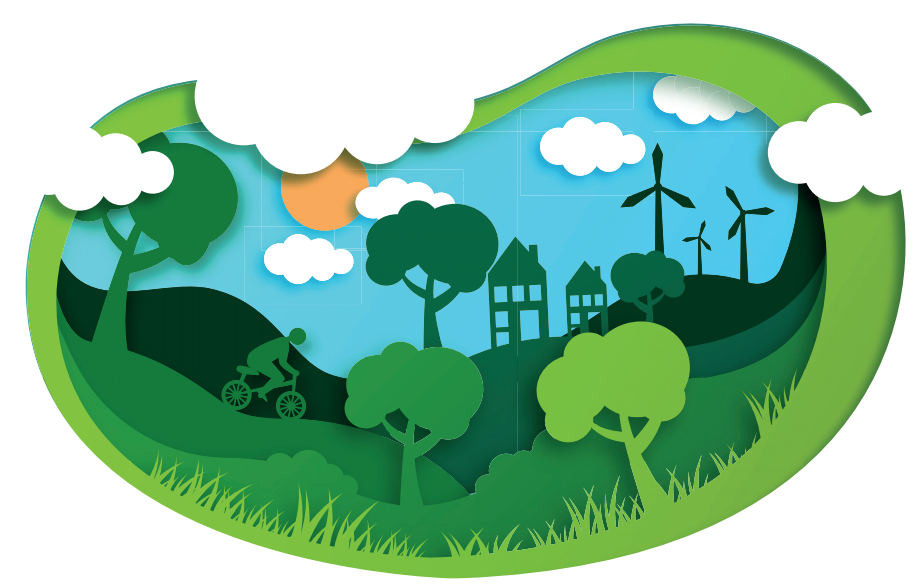

\section{Agradecimientos:}

A Sebastián, mi compañero adorable y paciente.

A mis hijas Catalina y Helena que me enseñaron que el amor es la energía más poderosa para cambiar el mundo.

A mi papá y a mi mamá, Ricardo y María Ángela, que siempre están amorosamente presentes y que me alientan a ir detrás de mis sueños. Mi eterno agradecimiento porque gracias a su esfuerzo me dejaron el mejor legado, transitar por el maravilloso camino de la educación pública.

A mis hermanas, Carolina y Luciana, con ellas la vida es más linda, más fácil y más feminista.

A Pablo Costamagna, mi director de tesis, pero fundamentalmente mi maestro y mi amigo, sin su impulso y su energía permanente este trabajo nunca hubiera sido posible.

A mi querida Facultad de Periodismo y Comunicación Social en donde tuve y tengo el gusto de formarme y crecer, enseñando, investigando, construyendo.

A toda la maravillosa gente de Rafaela, especialmente a Diego Peiretti y a todos mis compañeros y compañeras de la Maestría en Desarrollo Territorial y del Instituto Praxis que desde hace años me hacen sentir como en casa. 


\section{Índice:}

Presentación

Capítulo 1: Las perspectivas conceptuales para el abordaje de la experiencia 12

1. Conceptos centrales como marco de la sistematización de la experiencia

1.1 La articulación Comunicación / Educación

1.2 La articulación de la Comunicación con los procesos de Desarrollo Territorial

1.3 El enfoque del Desarrollo Territorial

1.4 Enfoque pedagógico en el Desarrollo Territorial y su aporte a la sistematización de experiencias.

1.5 Los aportes de la Investigación Acción en la sistematización de experiencias en Desarrollo Territorial

1.6 La sistematización de experiencias en procesos de Desarrollo Territorial:

1.7 La perspectiva de la Maestría en Planificación y Gestión de procesos comunicacionales (PLANGESCO)

Capítulo 2. Perspectivas metodológicas para la sistematización de la experiencia 33

1. Consideraciones generales sobre el enfoque metodológico

2. La metodología como un camino en construcción

3. El enfoque de la sistematización de experiencias

3.1 Las definiciones para el abordaje metodológico.

4. La sistematización de experiencias como método de trabajo

4.1 Las "etapas" de la Sistematización de Experiencias

4.2 ¿Cuáles son esos momentos del proceso de sistematización de experiencias que propusimos en este trabajo de tesis?

5. Algunas consideraciones finales sobre la dimensión metodológica:

Capítulo 3. El inicio y la puesta en marcha de la sistematización

1. La conformación el equipo de sistematización.

2. El diseño del proyecto de sistematización de la experiencia (plan de trabajo). 
Capítulo 4. Memoria de la experiencia "Rafaela más Sustentable"

1. Antecedentes para la creación, origen y surgimiento del Programa Rafaela Más Sustentable.

2. Alianzas e instituciones involucradas para la creación y realización de Rafaela Más Sustentable

3. Localización y contexto

4. Objetivos generales y específicos de Rafaela Más Sustentable

5. Fundamentos y enfoque general de Rafaela Más Sustentable

6. Mapa de actores

7. Líneas de acción planteadas

8. Resultados alcanzados según las y los responsables de Programa

9. Estrategias de intervención

Capítulo 5. Análisis y aprendizajes del proceso

1. Ejes de análisis para la identificación de los aprendizajes del proceso

1.1 La relevancia del tema ambiental, el contexto y la política de gestión en el territorio

1.2 El enfoque de la transversalidad

1.3 El rol y el liderazgo del Estado Local

1.4 El modelo de gestión

1.5 La construcción de la agenda ambiental: anticipación y oportunidad

1.6 La relevancia de los procesos participativos

1.7 El componente educativo y la formación de capacidades

2. Las propuestas de transformación: nuevos temas, roles y desafíos

2.1 Sobre los temas a futuro, la discusión de la agenda ambiental de la ciudad y el rol de Instituto para el Desarrollo Sustentable

2.2 Sobre las y los actores participantes del Consejo Ambiental

2.3 Sobre el modo de participación en el Consejo Ambiental

3. La comunicación de la experiencia

4. La "vuelta a la academia". 
Capítulo 6. Conclusiones y consideraciones finales

1. Aprendizajes vinculados a la perspectiva de comunicación / educación y su articulación con el enfoque del desarrollo territorial.

2. Aprendizajes sobre la metodología de sistematización de experiencias desde el enfoque del desarrollo territorial.

3. Aprendizajes vinculados a los diálogos con la academia

4. Aprendizajes vinculados a la planificación y gestión de políticas públicas socioambientales.

Bibliografía 


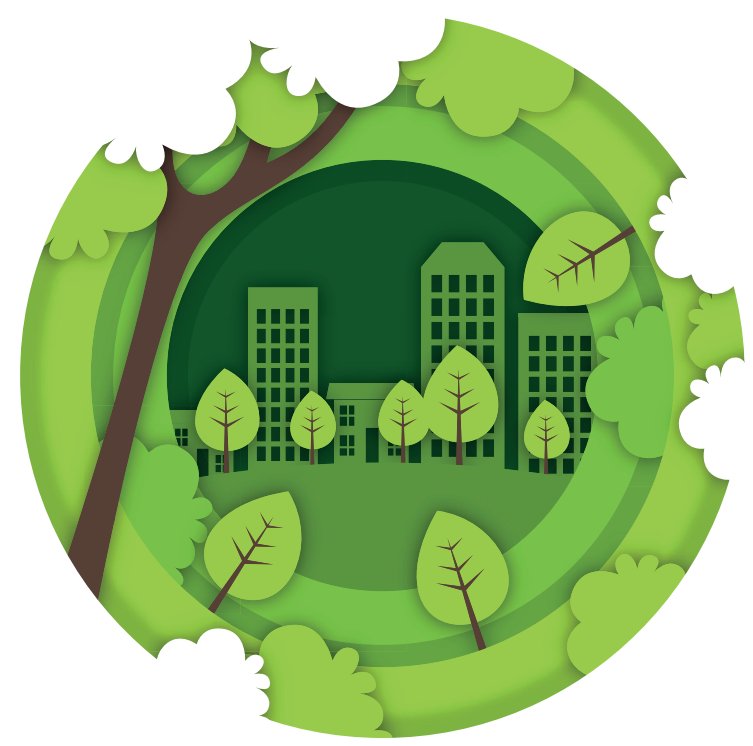

\section{Presentación:}

El trabajo de tesis que aquí desarrollamos parte de recuperar múltiples procesos y pertenencias en el marco de un recorrido académico, profesional y personal desde la propia biografía. Esa biografía, sobre la que profundizaremos más adelante, se va tejiendo anudada con los espacios formativos en el encuentro con otras y otros como ha sido el tránsito como estudiante por la Licenciatura y el Profesorado en Comunicación Social en la Facultad de Periodismo y Comunicación Social de la Universidad Nacional de La Plata, la experiencia docente y de investigación en el marco de las cátedras de Comunicación y Educación y, especialmente, la Maestría PLANGESCO con su particular impronta de abordaje de los procesos comunicativos desde una perspectiva latinoamericana, crítica y emancipadora.

Al recorrido por estos itinerarios se suma el trabajo profesional en otros territorios, como es el caso de la ciudad de Rafaela, en proyectos e iniciativas que nos acercaron a las temáticas del Desarrollo Territorial y que confluyen en la participación como docente / facilitadora de los Talleres de Reflexión sobre la Praxis I y II de la Maestría en Desarrollo Territorial de la Universidad Tecnológica Nacional y en la pertenencia, como Investigadora externa, al Instituto Praxis de Investigaciones Tecnológicas y Sociales para el Desarrollo Territorial. A esos escenarios se suman también otros lugares que siempre tienen el valor de lo colectivo, del estar juntos y juntas pensando, dialogando, construyendo.

Desde esa perspectiva es que a continuación desarrollamos nuestro proceso que se basa en la sistematización de una experiencia territorial, Rafaela Más Sustentable, que iniciamos sobre fines del año 2016 y continuamos en 2017 y desde el cual recuperamos en su devenir los elementos y dimensiones que se plasman en estas páginas. En ese camino hemos intentado poner en diálogo una perspectiva metodológica (y estratégica), como lo es la práctica de 
sistematizar, con un conjunto de dimensiones conceptuales que fundamentalmente se posicionan desde la mirada de Comunicación / Educación como horizonte político. De ahí que no ha sido un camino lineal sino más bien sinuoso, de ida y vuelta, para revisar los conceptos, las dinámicas y prácticas; con el horizonte puesto en los aprendizajes que vuelven y se actualizan con otros y nuevos sentidos.

Para alcanzar este propósito, hemos avanzado en el análisis y recuperación histórica de esta experiencia de gestión territorial y en la generación de espacios de diálogos multiactorales para detectar aprendizajes y desafíos colectivos tanto para la tesista, para distintos espacios académicos y para las y los actores de la experiencia. La intención con esto último fue propiciar una reflexión que permitiera construir una mirada de políticas ambientales a futuro, así como también introducir transformaciones en la propia perspectiva de la sistematización de experiencias como metodología, estrategia y enfoque.

Para darle orden y sentido a la escritura de este documento, en principio desarrollamos el marco teórico, donde se da cuenta inicialmente de una perspectiva que fue nuestro norte, nuestros "anteojos" para entender, abordar y reflexionar la práctica. Las categorías conceptuales presentadas allí, son aquellas que a modo de caja de herramienta fuimos articulando entre sí, para construir un prisma desde el cual reconstruir y analizar la experiencia desarrollada.

En el marco metodológico, explicitamos fuertemente el enfoque de la sistematización de experiencias que construimos también en vinculación con la perspectiva del desarrollo territorial y el enfoque pedagógico. Aquí la metodología también se hace corpus conceptual y hay un intertexto que nos ha permitido avanzar hacia una interpretación donde la propia metodología y los propios conceptos se van transformando en el "hacer", casi como un artesanado.

La sistematización de experiencias, fue para nosotros y nosotras un proceso de trabajo que nos ha permitido recuperar el conocimiento construido en la práctica, dejando no sólo una reflexión sobre lo acontecido, sino principalmente dimensiones para problematizar desde allí aspectos que hacen a la planificación y la gestión de políticas públicas locales.

Posteriormente, abordamos cada capítulo de acuerdo a las etapas metodológicas que definimos en relación con la sistematización de experiencias que abarcaron desde la preparación, el proyecto y la conformación de la sistematización, la recuperación histórica del proceso (que denominamos "Memoria") y la identificación de los aprendizajes y generación de propuestas de transformación a futuro en diálogo con las y los actores involucrados.

Finalmente presentamos las conclusiones identificadas a lo largo del proceso como ejes y dimensiones que reflexionan sobre la propia práctica, sobre la metodología y sobre los diálogos entre la comunicación, la educación, las perspectivas del desarrollo territorial y la planificación y gestión de las políticas públicas socioambientales. 


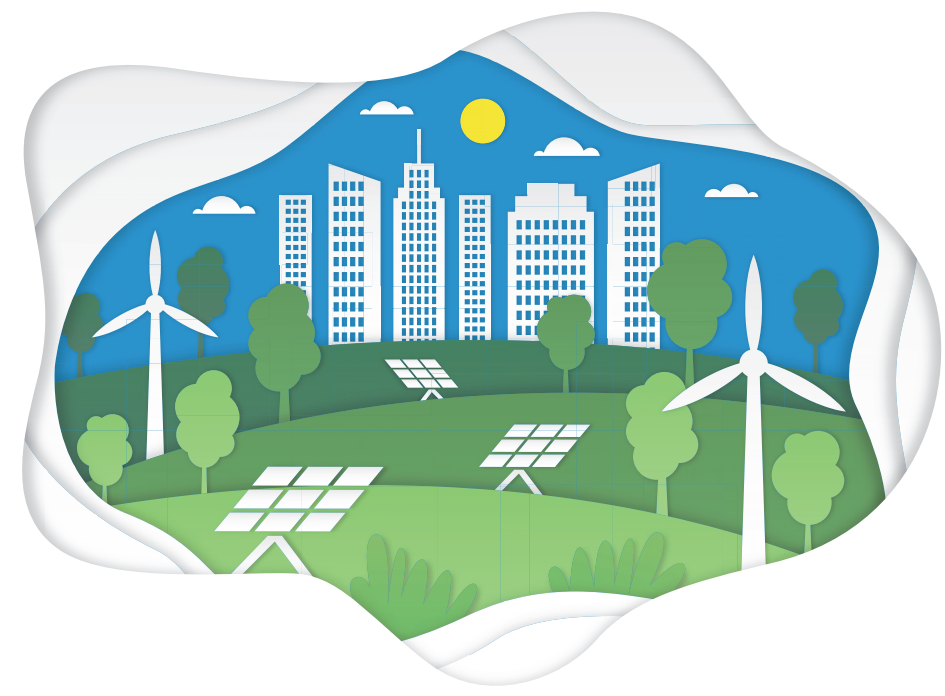

\section{Introducción}

Nos proponemos entonces, tal como anticipamos en las páginas precedentes, sistematizar y construir aprendizajes en torno a la experiencia del "Programa Rafaela más Sustentable" desarrollado en la ciudad de Rafaela, Provincia de Santa Fe, Argentina y liderado por el gobierno municipal. Para ello nos situaremos desde sus orígenes en el año 2009, tomando como hito fundamental su transformación en "Instituto para el Desarrollo Sustentable" a fines de 2015, que da cuenta de la consolidación y permanencia de esta política pública en el territorio.

Como elementos fundamentales, reconocemos la necesidad de sistematizar esta experiencia, desde una mirada compleja que permita analizar el desarrollo de esta política pública socioambiental, el modo en que se ha transformado en una iniciativa innovadora y de avanzada en la región y en el país y que nuevas reflexiones podemos devolver al "mundo académico". La intencionalidad de este trabajo se basa en la importancia de recuperar los marcos conceptuales, las metodologías, las modalidades de gestión en el territorio y la lógica de construcción conjunta y de diálogo con diversos actores, actoras y sectores, enfatizando también en los escenarios de tensiones y disputas, mirando y comprendiendo sus principales nudos problemáticos.

Asimismo, apuntamos no sólo al análisis (complejo) de la experiencia, sino que aparecen como centrales en este trabajo dos objetivos, vinculados con la perspectiva que propone la Maestría PLANGESCO.

El primero de ellos tiene que ver con la idea de praxis, siguiendo el planteo de Paulo Freire (1999), que implica poner en diálogo la reflexión y la acción para que, a partir de los aprendizajes identificados en la sistematización, se generen procesos transformadores de las 
propias prácticas de planificación y gestión de políticas públicas ambientales, profundizando las iniciativas que contribuyan a mejorar la calidad de vida de las personas.

El segundo objetivo se asocia directamente con la metodología de sistematización de experiencias, vinculada con los procesos de desarrollo territorial, como herramienta analítica que nos permita construir y aportar nuevos modos de reflexionar sobre los procesos del territorio: la construcción conjunta de los problemas, las estrategias y los aprendizajes con las y los actores partícipes de esas experiencias. Y, fundamentalmente, la sistematización como práctica que colabora con la construcción de modalidades comunicativas que contribuyan a generar nuevos conocimientos y a enlazarnos con otros y otras.

Si bien ahondaremos más adelante acerca de la experiencia elegida, a modo de introducción y para situar a las y los lectores de este trabajo nos gustaría presentar algunos rasgos y características propias de la misma que nos proponemos abordar.

Rafaela Más Sustentable, nace como una línea de trabajo en el año 2009, en el marco del Programa de Competitividad Territorial de la Región Central de Santa Fe (BID - FOMIN) ${ }^{1}$. En ese entonces uno de los ejes de dicho Programa estaba liderado por temas ambientales que habían surgido a partir de diagnósticos compartidos sobre su importancia en relación al desarrollo territorial de la región. En esta etapa la línea de trabajo adquiere un especial protagonismo dado el carácter transversal de los temas abordados y se transforma en el Programa Rafaela Más Sustentable (R+S).

En el año 2010 la Municipalidad de Rafaela asume el desafío y el compromiso de liderar estas políticas e incorpora al Programa Rafaela + Sustentable $(R+S)$ a su propia estructura, específicamente en el ámbito de la Secretaría de Servicios, Espacios Públicos y Ambiente. Uno de los aspectos interesantes para señalar es que permanece la impronta que traía consigo el Programa $R+S$ basado en el trabajo colaborativo, interinstitucional y transversal. Se suma a este enfoque la importancia de la sostenibilidad de las acciones a través del liderazgo del estado local, en este caso la Municipalidad de Rafaela, que toma esta línea para profundizar una política pública.

En esta etapa se profundizan y acentúan las acciones en base a la identidad y al espíritu que ya traía consigo el Programa bajo la definición de líneas temáticas que eran consideradas estratégicas en materia de política ambiental: gestión y transformación integral de residuos sólidos urbanos, energías renovables y eficiencia energética, verde urbano y biodiversidad, movilidad sustentable, economía verde y educación ambiental. Fueron unos cinco años de consolidación con una multiplicidad de acciones en temas muy relevantes y sensibles.

Con este marco, el territorio avanza y el gobierno municipal decide que el Programa Rafaela Más Sustentable se transforme en el Instituto para el Desarrollo Sustentable como resultado

\footnotetext{
1 Programa financiado por el Banco Interamericano de Desarrollo y el Fondo Multilateral de Inversiones y ejecutado en Rafaela y la región por la Agencia de Innovación y Desarrollo de Rafaela (ACDICAR), asociación civil sin fines de lucro de constitución público- privada e impulsado a partir de la iniciativa del Centro Comercial e Industrial de Rafaela y Región (CCIRR) y la Municipalidad de Rafaela.
} 
de los diálogos, debates y acciones conjuntas y bajo la necesidad de conformar un ente autárquico, dependiente de la Municipalidad de Rafaela, con mayores posibilidades de actuar. Tal como lo define su Ordenanza de creación (Ord. 4785, 2015) se crea con:

"el objetivo de promover un modelo de desarrollo sustentable para la ciudad de Rafaela a partir de la preservación y mejora de la calidad ambiental desde y en la utilización de los recursos naturales y la participación de la ciudadanía de los procesos de toma de decisiones, en condiciones equitativas".

Esta figura le otorga otro status para una gestión vinculada a las posibilidades de construir una nueva gobernanza del tema. Más allá de las dimensiones formales, el Instituto se crea como un espacio destinado a promover la innovación y la participación con la meta de transformarse en un referente como espacio de diseño, gestión y evaluación de políticas públicas socioambientales.

Ahora bien, ¿por qué la importancia de analizar, sistematizar y construir aprendizajes sobre esta experiencia desde la articulación comunicación / educación en procesos de desarrollo territorial, como el que se toma para el desarrollo de esta tesis?

En este punto se ponen en diálogo varias dimensiones y para explicarlas retomaremos la idea de la propia biografía, esa biografía que está formada por una trama de experiencias y que, en este caso, hacen posible la intencionalidad de esta tesis.

Por un lado, aparece la biografía laboral en donde, como ya fue descripto, desde hace casi diez años nos vinculamos con el territorio de Rafaela, en donde comenzamos a desarrollarnos profesionalmente, en mi caso como comunicadora y más tarde como investigadora en donde el eje de la sistematización de experiencias posee una relevancia como tema de análisis, de reflexión y de producción académica. Aquí entonces, nos convoca una cercanía con ese territorio, con su gente, un aprendizaje vinculado no sólo al enfoque conceptual sino a las experiencias de gestión de procesos de desarrollo territorial, que Rafaela viene teniendo desde el liderazgo del Estado local desde hace por lo menos 25 años en la gestión de gobierno con continuidad de gobernanza.

En este contexto, también se suma como elemento una demanda institucional del nuevo y reciente Instituto para el Desarrollo Sustentable de contar con algún material que pueda historizar su propia política y accionar en el territorio a modo de visibilizar la política ambiental que se venía gestando en la ciudad y en ese marco, con otros matices, se articulará la reflexión de esta tesis de Maestría.

Un segundo elemento es la biografía conceptual que tiene que ver con el propio recorrido en el campo de la comunicación y el modo que se articula con la experiencia de la formación de grado y posgrado. Sin lugar a duda un hito fundante en esta biografía lo constituyen los diecisiete años de docencia universitaria e investigación en el marco de las cátedras de Comunicación y Educación en la Facultad de Periodismo y Comunicación Social, de la Universidad Nacional 
de La Plata. Ahí se conjuga una mirada de la comunicación como producción social de sentidos en articulación con la formación de sujetos (Huergo, 2002) entendiendo el carácter formativo que tienen las prácticas sociales, más allá de las que transcurren en las instituciones educativas formales.

Esta confluencia de la perspectiva de Comunicación / Educación marca un modo de entender, abordar y mirar las prácticas que seguramente aparecerá explícitamente y también entrelíneas en este trabajo de tesis.

El último elemento, vinculado a las biografías que confluyen en estas páginas, es la biografía PLANGESCO y el particular enfoque conceptual, metodológico y pedagógico de la Maestría, enriquecido por el cuerpo de las y los docentes y también por los aprendizajes generados en el marco del intercambio con los compañeros y compañeras, provenientes de diversas disciplinas, experiencias profesionales y espacios de pertenencia de nuestro país y de Latinoamérica.

La perspectiva PLANGESCO se va pregnando en el modo de entender y abordar la planificación y la gestión de procesos comunicacionales y en este sentido es que pretendemos dar cuenta cómo se van articulando estos trayectos con las prácticas profesionales, intentando tal como los objetivos de la maestría lo persiguen "sistematizar los conocimientos en materia de planificación y gestión de la comunicación a través de la investigación e intervención para el desarrollo. La comunicación como dimensión estratégica para la ideación de procesos de cambio social, supera la instancia de la lectura para convertirse en perspectiva orientativa de personas y organizaciones que en base a objetivos político-culturales pueden diseñar, planificar y gestionar procesos de comunicación que favorecen transformaciones sociales en contextos micro y macro sociales"2

Esta experiencia entonces contiene un sinnúmero de dimensiones de análisis para poner en tensión, unas vinculadas a las categorías conceptuales: la dimensión política, la planificación y gestión de políticas públicas, la perspectiva socioambiental, las modalidades de gestión y la transversalidad, el diálogo multiactoral, la perspectiva del desarrollo (en nuestro caso del desarrollo territorial), el enfoque pedagógico del desarrollo y la articulación con la comunicación desde una perspectiva cultural.

Otras relacionadas con lo metodológico, como la propia perspectiva de sistematización de experiencias en donde nos proponemos aprehender, reflexionar y construir nuestros propios modos de sistematizar, entendiendo a la comunicación como una dimensión central en este proceso para generar nuevos relatos y modalidades comunicativas, para aprender de nuestras prácticas y transformarlas, para ponernos en relación con otros y otras, para generar procesos más emancipatorios y vinculados con nuestras propias identidades culturales y territoriales, para producir nuevos conocimientos y por qué no, para hacernos nuevas y mejores preguntas.

\footnotetext{
2 Documento Proyecto curricular y plan de estudios. Maestría en Planificación y Gestión de Procesos Comunicacionales (PLANGESCO). Facultad de Periodismo y Comunicación Social. Universidad Nacional de La Plata.
} 


\section{CAPÍTULO 1}

Las perspectivas conceptuales para el abordaje de la experiencia 


\section{CAPÍTULO 1.}

\section{Las perspectivas conceptuales para el abordaje de la experiencia}

El presente capítulo, pretende abordar las principales nociones teóricas y conceptuales que permitan construir un diálogo analítico con la experiencia que estamos sistematizando. Es decir, que lo que se propone, como un primer desafío, es la conformación de una matriz conceptual, que contribuya a atravesar la práctica, repensarla, darle nuevas formas y trabajar en la construcción de nuevos conocimientos y aprendizajes a partir de la experiencia.

Otro de los desafíos que reconocemos en este recorrido, tiene que ver con que consideramos que ni el objeto está allí a la espera de ser analizado, ni los conceptos cerrados, aguardando ser puestos a trabajar sobre un fenómeno en particular. La praxis entendida como el encuentro entre acción y reflexión (Freire, 1991) apunta a reconstruir la experiencia desde una trama conceptual teniendo en cuenta dos dimensiones: las características propias de la práctica y los modos en que se ha puesto en marcha en el territorio, por un lado, y la reflexividad del sujeto que reelabora, construye y analiza esa práctica por el otro.

Además, el desarrollo conceptual que aquí desplegamos incorpora la impronta clara de las matrices de pensamiento que, a través de la Licenciatura en Comunicación Social, el Profesorado en Comunicación Social, la Maestría en Planificación y Gestión de procesos comunicacionales (PLANGESCO), el recorrido personal por el campo de Comunicación y Educación y el enfoque del Desarrollo Territorial, se han logrado recuperar. Entonces, aparece otro elemento que desafía cuando se hace referencia a la idea de un diálogo analítico y se propone el encuentro entre formas de conocimiento provenientes del campo de Comunicación / Educación y la reconstrucción, la historización y la sistematización de un proceso en particular, como lo es el caso de una política ambiental territorial localizada en Rafaela.

Antes de continuar con este desarrollo, es necesario aclarar que la lógica de la construcción conceptual en relación a este trabajo de tesis, no pretende ceñirse a conceptos cerrados sino más bien se apunta a trazar un recorrido que dé cuenta de los enfoques y las perspectivas desde las cuales se interpelará la práctica y se sistematizará la experiencia de Rafaela Más Sustentable.

En tal sentido, como categorías teóricas para la sistematización y el análisis desarrollaremos en las páginas que siguen la articulación Comunicación / Educación, la perspectiva de la comunicación desde los procesos de desarrollo, el enfoque del Desarrollo Territorial como marco para abordar la política ambiental de Rafaela Mas Sustentable y el enfoque pedagógico del Desarrollo Territorial como dimensión para poner en juego esa perspectiva en la práctica. Sumando al proceso, también haremos una reflexión sobre el aporte de la Investigación Acción a este tipo de procesos no sólo como metodología, sino como una forma de entender la producción de conocimiento en diálogo con las y los actores del territorio. 
Asimismo, otra de las dimensiones conceptuales claves para el abordaje de esta tesis será la perspectiva de sistematización de experiencias, a la que dedicaremos un apartado en este capítulo. Al igual que la Investigación - Acción encontramos en este sentido un cruce entre la perspectiva teórica y la metodológica en donde la sistematización de experiencias será abordada como un marco para el análisis y el abordaje del caso elegido, produciendo conocimiento desde la experiencia, pero también como una herramienta metodológica, que conjuga y pone en juego una serie de etapas para articular teoría y práctica, para poner en diálogo las perspectivas conceptuales con el campo material y el caso de análisis.

Finalmente, realizaremos una breve reflexión acerca de la importancia de la perspectiva de la Maestría en Planificación y Gestión de procesos comunicacionales (PLANGESCO) como marco para mirar, analizar y producir nuevas lecturas y aprendizajes de las propias prácticas; en este caso una práctica profesional que recupera elementos claves de esta instancia formativa en el posgrado.

\section{Conceptos centrales como marco de la sistematización de la experiencia 1.1 La articulación Comunicación / Educación}

Una dimensión que aparecerá a lo largo de este trabajo de tesis tiene que ver con el propio recorrido en el campo de la comunicación y el modo que se articula con la experiencia de la formación de grado y posgrado. Sin lugar a duda un hito fundante en la propia biografía, tal como mencionábamos en las páginas precedentes, lo constituyen los diecisiete años de docencia universitaria y la pertenencia a la cátedra de Comunicación y Educación en la Facultad de Periodismo y Comunicación Social, de la Universidad Nacional de La Plata.

Ahí se conjuga una mirada de la comunicación como producción social de sentidos en articulación con la formación de sujetos (Huergo, 2002) entendiendo el carácter formativo que tienen las prácticas sociales, más allá de las que transcurren en las instituciones educativas formales. Se traen desde aquí, desde la pertenencia a esta cátedra, dos ideas centrales, que aparecerán en las reflexiones de esta tesis y que claramente tienen que ver con la propia biografía conceptual, en donde hay unos de modos de leer el mundo, en términos de Paulo Freire (1999) que nos van acompañando, en este caso a otras experiencias laborales, académicas, de investigación.

La primera de estas ideas tiene que ver con la mirada sobre la comunicación, que con claridad se aleja de las perspectivas informacionales e instrumentales para volverse relacional, para anclarse en la trama de la cultura. Y ahí un eje principal lo constituye entender la comunicación desde la opacidad, desde la complejidad y el conflicto (Huergo, 2003) fuera de los enfoques en donde la comunicación se transforma en una "solución mágica", en una herramienta que resuelve los conflictos en forma armoniosa y armónica, que transparenta las relaciones sociales. 
La segunda idea, se vincula con los marcos conceptuales y metodológicos de la educación popular, especialmente con la perspectiva de la educación problematizadora de Paulo Freire (1999). Y en ese sentido aparece como central el concepto de diálogo, asociado al de praxis en donde "no hay palabra verdadera que no sea una unión inquebrantable entre acción y reflexión, y por ende que no sea praxis. De ahí que decir la palabra verdadera sea transformar el mundo". Y continúa "el diálogo es este encuentro de los hombres, mediatizados por el mundo, para transformarlo" (Freire, 1999, p. 100).

El diálogo, fruto de un pensamiento crítico, es central en el proceso comunicacional y sin él, afirma Freire, no hay verdadera educación. De allí que la perspectiva comunicacional, sea clave a través del concepto de diálogo, para comprender y para desarrollar procesos transformadores.

Esta confluencia de la perspectiva de Comunicación / Educación marca un modo de entender las prácticas que seguramente aparecerá explícitamente y también entrelíneas en este trabajo de tesis, no solo por ser una forma de abordaje sino y más que nada por ser el lugar desde el cual uno reconoce que mira el mundo.

\subsection{La articulación de la Comunicación con los procesos de Desarrollo Territorial}

La comunicación puede entenderse y abordarse desde diferentes perspectivas, o lo que llamamos "modelos de comunicación" que, por supuesto están asociados a contextos históricos, y que han ido cambiando a través del tiempo. Desde la década del 50 a la actualidad, los paradigmas comunicacionales han estado en estrecha vinculación con los modelos de desarrollo vigentes. Por esta razón existe una multiplicidad de concepciones y propuestas en el campo de la comunicación en procesos de desarrollo.

Inspirada en teorías modernizadoras, la comunicación aplicada al desarrollo económico y social ha sido tradicionalmente incluida desde una visión principalmente instrumental, que la delimita a técnicas y herramientas para apoyar la efectividad del desarrollo. Según Gumucio Dagrón (2012), existe otro punto de partida en el que se encuentran aquellas corrientes comunicacionales inspiradas en las teorías de la dependencia que se vincularon con la inclusión de técnicas participativas y de democratización de medios de comunicación, que apoyaban la idea de que el desarrollo debe construirse por los sujetos de cada experiencia concreta y se recogen en experiencias de comunicación popular, alternativa, endógena, entre otras.

Un aporte en ese sentido lo constituye la comunicación para el cambio social como búsqueda de una propuesta que priorice el proceso comunicacional, frente al producto, en un contexto vinculado con la cultura local. La comunicación para el cambio social, se nutre de la experiencia participativa de la educación popular, de la democratización de la palabra que defienden las corrientes de comunicación alternativa. 
Lo esencial de la comunicación para el cambio social es que cuestiona el concepto de un desarrollo que no cuente con la participación de los sectores directamente afectados y promueve una comunicación que haga efectiva, la participación comunitaria, particularmente de los sectores más pobres y aislados (Gumucio Dagrón, 2012).

Premisas básicas de la Comunicación para el Cambio Social (CCS):

La sostenibilidad de los cambios sociales es más duradera y profunda cuando los individuos o comunidades se apropian del proceso y los contenidos.

La CCS, horizontal y fortalecedora del sentir comunitario, debe ampliar las voces de aquellos que no han accedido a la palabra pública, y tener como eje contenidos locales y la noción de apropiación del proceso comunicacional;

Las comunidades deben ser agentes de su propio cambio y gestoras de su propia comunicación; En lugar del énfasis en la persuasión y en la transmisión de informaciones y conocimientos desde afuera, se promueve el diálogo, el debate y la negociación desde el seno de la comunidad; lo cual no implica un aislamiento a otros debates y conocimientos, sino un intercambio complementario y asentado en el contexto local.

Los resultados del proceso de la CCS deben ir más allá de los comportamientos individuales, y tomar en cuenta las normas sociales, las políticas vigentes, la cultura y el contexto del desarrollo; Es diálogo y participación, con el propósito de fortalecer la identidad cultural, la confianza, el compromiso, la apropiación de la palabra y el fortalecimiento comunitario;

Rechaza el modelo lineal de transmisión de la información desde un centro emisor hacia un individuo receptor, y promueve un proceso cíclico de interacciones desde el conocimiento compartido por la comunidad y desde la acción colectiva.

Tal como se mencionaba anteriormente, la comunicación en los procesos de desarrollo comúnmente se ha limitado a la difusión de información y conocimiento, a la promoción de los beneficios o resultados de una iniciativa o al uso de tecnologías sin conexión con la realidad local. En este sentido, se entiende que una comunicación centrada en la difusión de resultados, se limita a una parte del acto comunicativo y minimiza la potencialidad de los espacios de diálogo y encuentro que también tienen una enorme contribución a los procesos de desarrollo.

La comunicación se involucra en el desarrollo territorial, no sólo como un medio para difundir mensajes o los resultados de dichos intercambios, sino como "un modo de relacionarse para activar diálogos transformadores y construir capacidades locales junto con las y los actores" (Muñoz y Spinelli, 2015).

Se entiende a la comunicación como una relación de diálogo e interlocución entre personas, entre ellas y sus instituciones. Bajo esta premisa, la comunicación es una apuesta por la vinculación entre los actores y un compromiso por la construcción de sentido del "nosotros". Se enfoca en posibilitar espacios democráticos, construir capacidades para ejercerlos y fomentar la emergencia de una visión compartida que dote de sentido al proceso de desarrollo en el contexto de la cultura local (Muñoz y Spinelli, 2015). 
Para lograrlo, claramente se utilizarán medios de comunicación, tecnologías y materiales informativos, se apoyará en facilitadores y profesionales de la comunicación; sin embargo, se distinguirá de estrategias de comunicación más instrumentales al asumir que:

- La estrategia comunicacional tiene como fin último apoyar en la facilitación del proceso de desarrollo.

- Informar resultados, es una parte del proceso comunicativo, no lo es todo.

- La comunicación, además de facilitar información, promueve espacios de intercambio.

- El ejercicio del diálogo entre los actores territoriales es fundamental para la construcción de conocimiento colectivo y capacidades locales.

- Las acciones comunicativas son definidas en y de acuerdo al contexto territorial, con el propósito de reafirmar la identidad local, lenguaje común y visión de futuro.

Se retoma en este marco la perspectiva de Mario Kaplún (2002) en donde la comunicación no está dada por un emisor que habla y un receptor que escucha, sino por dos o más seres o comunidades humanas que intercambian y comparten experiencias, conocimientos, sentimientos. Es a través de ese proceso de intercambio como los seres humanos establecen relaciones entre sí, y pasan de la existencia individual aislada a la existencia social comunitaria. En este modelo las y los actores del territorio son protagonistas activos, completan el sentido de la comunicación desde su propia lectura (a partir de los condicionamientos de la historia, el poder y la cultura). Este nuevo lugar que se le da a las y los sujetos no debe dejar de lado el papel que el poder juega en los procesos socioculturales, tampoco puede obviar que existan las condiciones para que los actores territoriales construyan.

Desde un horizonte político, la comunicación en procesos de desarrollo entonces debería tener como premisa el diálogo, entendido como acción y reflexión sobre el mundo (Freire, 1999) y contribuir a habilitar nuevas y otras voces que tradicionalmente han sido excluidas o han sido habladas por otros (varones).

Como anticipábamos, para emprender un proceso de comunicación dialógico es central la categoría que plantea Paulo Freire (1999) del reconocimiento del universo vocabular. Y aquí se señala la importancia de que no es lo mismo conocer que reconocer al otro y a la otra, reconocer implica tener en cuenta que quienes participan de las acciones son poseedores de saberes, haceres, prácticas y representaciones que son absolutamente valiosas e importantes para la acción colectiva.

Retomando las palabras de Juan Díaz Bordenave (2008), la comunicación en desarrollo territorial es "aquélla que facilita los procesos de diálogo a través de los cuales las personas definen quiénes son, qué desean, qué necesitan y cómo pueden actuar colectivamente para satisfacer sus necesidades y mejorar sus vidas. Apoya a los procesos de toma de decisiones y acción colectiva en las bases de la sociedad y construye ambientes de comunicación favorables al crecimiento del poder de la sociedad". 
Complementariamente a lo planteado, podríamos proponer entonces tres formas de abordar el diálogo en un proceso de desarrollo (Obregón y Botero, 2011):

1. Como modelo de comunicación: se construye por oposición a las propuestas comunicativas que enfatizan el poder de los medios masivos de comunicación para generar procesos de cambio. Se asume la comunicación como un proceso horizontal y de construcción de sentidos y significados. Pone el énfasis en las interacciones interpersonales y en las iniciativas comunitarias. Posición ética al entenderlo como herramienta que contribuye a que las personas sean críticas y conscientes acerca de la información que reciben y el contexto en el que viven.

2. Como comunicación interpersonal y reconocimiento del otro: la comunicación no es un acumulado de información intercambiado por los individuos, sino un evento entre dos seres humanos, en el cual el otro no es no es un receptor de información, sino un ser humano complejo. El otro y la otra ya no son vistos como "subdesarrollados" e "ignorantes" sino que se convierte en actores con el mismo estatus del diseñador / diseñadora de políticas o proyectos. Se enfatiza en el respeto por el otro/otra y por sus formas de ver el mundo. El diálogo no es un intercambio de ideas ni de palabras, sino una red de significados.

3. Como proceso de deliberación pública: medio para resolver problemas, negociar, tomar decisiones y reflexionar acerca de un determinado problema. Permite identificar obstáculos y desarrollar procesos para lograr los objetivos definidos. La noción de dialogo se asocia con el concepto de acción colectiva en el cual las y los miembros de una comunidad emprenden acciones grupales para resolver un problema común. Es un elemento central de la comunicación participativa que implica democratizar los procesos comunicativos para que las y los miembros de la comunidad puedan involucrarse en actividades de producción de mensajes y significados, diseño de proyectos, entre otras acciones.

En relación a estas tres perspectivas del diálogo que aparecen además vinculadas y se cruzan como dimensiones de la propia práctica de los procesos de desarrollo territorial, es necesario advertir y tener en cuenta que una "aproximación romántica o ingenua al diálogo nos hace olvidar que éste emerge en contextos políticos y, por ende, está sujeto a relaciones de poder. Dicha despolitización del diálogo lo reduce a un mero fenómeno discursivo, aislado de las condiciones políticas y económicas en las que surge" (Obregón y Botero, 2011, p.125).

En este sentido nos referimos a la importancia de recuperar la complejidad de la comunicación en donde generar un proceso de diálogo verdadero implica asumir la emergencia de conflictos, de tensiones en donde se encuentran diferentes perspectivas y formas de leer el mundo. Esto implica tomar distancia de aquellas visiones que abordan estos procesos entendiendo a la comunicación como una herramienta que transparenta las relaciones sociales y las armoniza, 
más vinculada a los acuerdos y a los consensos (racionales), que al orden de las opacidades y las complejidades y de los encuentros (y por qué no los desencuentros) que es el sentido que aquí recuperamos.

En este marco, se reafirma un sentido ético y político en la comunicación, en donde el horizonte de sus acciones se basa en implicar a las y los sujetos, comprometerlos e integrarlos desde sus propias lecturas y visiones del mundo, facilitando un proceso que acompañe la conformación de un sentir más colectivo, representativo de las diversidades de voces.

Desde este lugar, pensar la comunicación como producción social de sentidos permite ampliar la mirada hacia el terreno de la cultura. Es decir que, reconocemos que en los procesos culturales y sobre todo en las instancias de encuentro con otros y otras aparecen también los conflictos y el poder como casi constitutivos de las relaciones sociales. Ahí es cuando afirmamos que se producen "luchas por el sentido", donde las y los sujetos (individuales o colectivos) interpelan y se ven interpelados en una puja constante por la significación (Spinelli, 2004).

Comenzamos a ver entonces una nueva dimensión, en la que los procesos comunicacionales ya no pueden pensarse a partir de roles de emisión y recepción prefijados y alternados, sino más bien como un interjuego constante aún en la diferencia y la asimetría. Por lo cual la comunicación no significa necesariamente un momento de armonía, de consenso, sino que a veces sucede todo lo contrario, ponerse en diálogo con otros y otras, expresar las opiniones, producir mensajes propios supone poner en relación una visión del mundo que a veces es contrapuesta o diferente a la de otros y otras.

Entonces esta mirada de la comunicación, que desarrollamos en este apartado, contribuye al modo en que pensamos y abordamos la sistematización de esta experiencia poniendo el énfasis en los procesos por sobre los productos, en los sentidos colectivos que se han generado y transformado, en los espacios de diálogo que han gestado iniciativas de acción conjunta, en los momentos de tensiones, dificultades y conflictos que también constituyen aspectos que desata un proceso de comunicación para nosotras y nosotros realmente verdadero.

\subsection{El enfoque del Desarrollo Territorial}

La fundamentación conceptual y la perspectiva del modelo de gestión de la experiencia elegida como campo material de esta tesis (la política ambiental territorial, Rafaela Más Sustentable) puede vincularse claramente con el enfoque del desarrollo territorial que se viene gestando en la ciudad de Rafaela desde la década del 90' a partir del diálogo entre las experiencias concretas de las y los actores del territorio (el sector público, el privado, el sistema científico tecnológico, las gremiales empresarias, el sector educativo, las organizaciones de la sociedad civil, entre otros) y las posiciones teóricas que entienden que la idea del desarrollo territorial (en adelante DT) trasciende al crecimiento económico y contempla múltiples dimensiones; lo que lo hace un concepto multidimensional cada vez rico y complejo (Costamagna, 2015). 
En este sentido es interesante retomar una perspectiva del DT que permita abordar y profundizar los aprendizajes de la experiencia de Rafaela Más Sustentable, para considerar en qué medida se pone en acción esta perspectiva, que procesos alienta, que visiones o lenguajes compartidos se desarrollan en la práctica, que nuevos elementos suman a la construcción de este enfoque a partir de temáticas innovadoras como lo son las ambientales.

La perspectiva a la que se hace referencia considera al desarrollo territorial como "un proceso de acumulación de capacidades cuya finalidad es mejorar de manera colectiva y continuada el bienestar de una comunidad" (Alburquerque, Ferraro y Costamagna, 2008). En esta definición aparece claramente una mirada sobre el territorio, que no lo entiende solamente como un espacio geográfico en el que tienen lugar las actividades económicas y sociales, sino que la apuesta se basa en concebirlo a partir del conjunto de las y los actores y los y las agentes que lo habitan, con su organización social y política, su cultura e instituciones (Alburquerque, 2015).

Según Mabel Manzanal (2017) territorio y desarrollo son construcciones sociales. Porque son producto de nosotros, de nuestro accionar, del accionar de hombres y mujeres, verdaderos, primeros y últimos actores y actoras en la conformación de los procesos sociales. Pero además allí circula el poder ya que nos estamos refiriendo a productos resultantes de relaciones sociales. Y es a través de esta circulación de poder que opera en red, que se conforma y se instituye una definición, un concepto, enmarcado en determinadas posturas, historias y condiciones político ideológicas.

Tal como señala Alburquerque (2015), el punto de partida de cualquier estrategia de desarrollo territorial radica en el esfuerzo de movilización y participación de las y los actores locales que hay que lograr impulsar en un determinado territorio, a fin de fortalecer el capital social en el mismo, lo cual requiere actividades de fortalecimiento de los gobiernos locales, el impulso de la cooperación público-privada y la coordinación de las diferentes instituciones públicas de los niveles central, provincial y municipal, así como entre los distintos departamentos sectoriales (Economía, Industria, Agricultura, Trabajo, Turismo, Interior, etc.), y el fomento de la cultura emprendedora local, con el fin de sentar bases para los procesos de innovación social y cultural que se plantean de forma integrada en la estrategia que se busca.

En este sentido se reconoce que la perspectiva del DT debe asumir una mirada compleja, en la que se combinan y relacionan diferentes dimensiones que trascienden el eje sobre lo económico, tal como se aclara en el siguiente cuadro: 


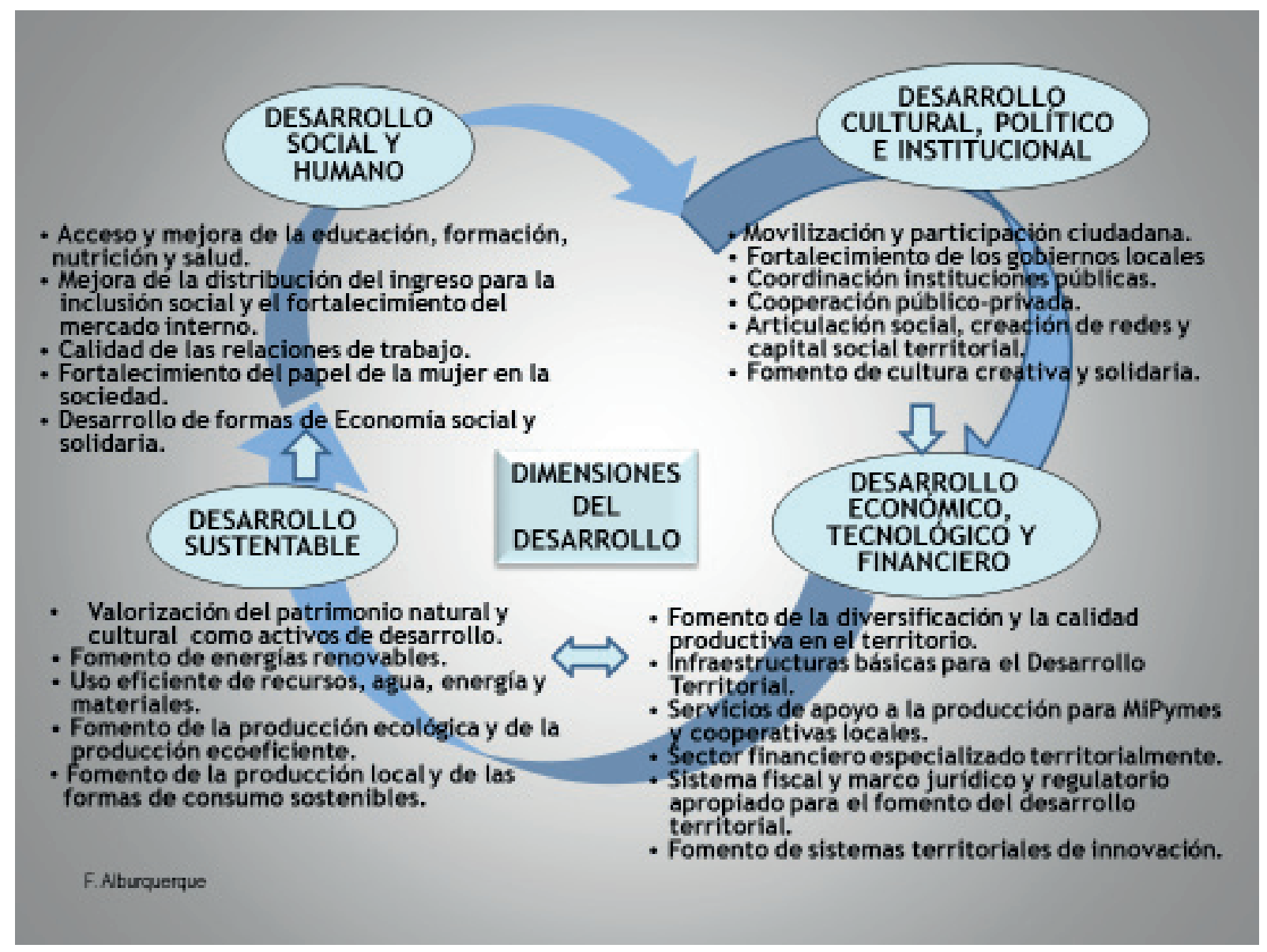

\section{Dimensiones del Desarrollo Territorial}

Fuente: Alburquerque (2015)

Asimismo, una de las dimensiones que cobra valor y se relaciona directamente con la experiencia que estamos sistematizando, tiene que ver con la sustentabilidad ambiental. Ello requiere la valorización del patrimonio natural y cultural local como activos importantes del desarrollo territorial, el fomento de las energías renovables, el uso eficiente de los recursos naturales, entre ellos el agua y la utilización de los materiales, el fomento de la producción ecológica y de la eco-eficiencia productiva (ecología industrial, producción limpia, etc.), así como el impulso de la producción local, las distintas formas de consumo sostenible, la gestión de los residuos urbanos y rurales, y el fomento de la educación sobre la sustentabilidad entre la ciudadanía, las empresas y los hogares en dicho territorio (Alburquerque, 2015).

Como se señaló anteriormente, para todo ello será necesario que las diferentes políticas de desarrollo emprendan acciones de mejora en el acceso a la educación, la formación, la nutrición y la salud, tratando de incidir igualmente en la mejora de la distribución del ingreso para la inclusión social y el fortalecimiento del mercado interno, y mejorar la calidad de las relaciones de trabajo, fortaleciendo el papel de las mujeres y los colectivos de las diversidades sexuales en la sociedad, así como atender a colectivos vulnerables, tratando de fomentar las formas de economía social como parte de las estrategias de desarrollo. 
Retomando la propuesta de Pablo Costamagna (2015), cobra una centralidad muy importante la idea de que el DT es un proceso de construcción social y política con características multidimensionales. Desarrollo Económico, Desarrollo Social, Urbano Ambiental y Desarrollo Institucional y una gobernanza compleja con un rol activo del Estado. Además, suma otros elementos como:

- Este enfoque discute la mirada que se centra sólo en lo macro y lo sectorial y también la idea de que crecimiento equivale a desarrollo.

- La clave está en la gente y se debe trabajar el tema de capacidades. Se pone énfasis en las potencialidades endógenas.

- Es un enfoque para la acción donde importa la manera de hacer las cosas.

- Plantea sistemas productivos locales, empleo decente, distribución y cambio en el modelo productivo y de consumo, pero también temas educativos, de salud, de infraestructura, entre otros.

- Impulsa la incorporación de innovaciones productivas, instituciones sociales y la importancia de las infraestructuras tangibles, pero también las intangibles para facilitar la difusión de conocimientos.

-Valoriza el medio natural y el patrimonio cultural local como un elemento fundamental de diferenciación del territorio.

- Estudia la relación con los procesos externos para aprovechar oportunidades desde una mirada de sistema abierto.

En esta perspectiva entonces aparecen y se suman elementos que no habían estado tan claramente señalados en los enfoques tradicionales y que ponen énfasis en los diálogos entre actores y sectores, las modalidades de gestión y participación, la formación de capacidades, la cogeneración de conocimientos, entre otros, que van generando un enfoque complejo y dinámico y que forman parte del enfoque pedagógico del desarrollo territorial. Más adelante recuperaremos esta dimensión.

También es importante destacar y sumar una mirada política del desarrollo tal como plantea Oscar Madoery (2005) en donde "lo local representa su punto de encuentro, el ámbito donde los agentes territoriales adquieren capacidad de fijar el rumbo, de "construir desarrollo". El desarrollo local es, por tanto, un proceso territorializado de maduración social (aprendizaje colectivo para el cambio cultural) y construcción política que se despliega en múltiples dimensiones". También cuestiona que el desarrollo esté pensado en el que debería ser su punto de llegada (sustentable, humano) y no desde su punto de partida: el sujeto y la praxis humana, las relaciones sociales, las representaciones, los acuerdos y las disputas. Entiende que revertir esta perspectiva sólo es posible desde la política, por ser la instancia que se preocupa por el tipo de vinculación entre campos sociales y ser la praxis que interroga al poder (Madoery, 2005). 
Vinculado a la dimensión política aparece aquí otro elemento relevante que tiene que ver con el rol de las instituciones en los procesos de desarrollo, en especial el rol del Estado, en nuestro caso del Estado local, como promotor y facilitador de este tipo de procesos. El desarrollo territorial depende esencialmente de un esfuerzo de articulación y coordinación interinstitucional, y de cooperación entre los diferentes actores territoriales e institucionales, con el fin de compartir un enfoque de desarrollo integrado y en este aspecto, tal como veremos en el transcurso de la experiencia, el papel del sector público es clave.

En relación a la temática específica que Rafaela Más Sustentable aborda, es interesante dar cuenta de cómo se vincula claramente al enfoque DT, retomando nuevamente a Francisco Alburquerque (2012) quién plantea que, frente a este nuevo contexto, y el cambio de paradigma tecnológico y productivo, se vuelve esencial trabajar en la sostenibilidad del desarrollo. Ello implica replantear las formas de producción y consumo, así como muchas de las formas de trabajo, es decir, estilos de vida de nuestra sociedad. Por lo tanto, la innovación económica y social que se demandan como parte de las estrategias de desarrollo, deben guiarse por la sostenibilidad ambiental, con el desarrollo de nuevas industrias de bienes y servicios ambientales y empleos verdes, sobre la base de dotación de recursos con conocimientos adaptados a estas demandas.

Finalmente, esta perspectiva nos ayuda a repensar una mirada acerca de las políticas ambientales como parte de la estrategia de desarrollo de las comunidades locales en donde la mirada no se reduce a una dimensión sectorial, sino a una construcción social del territorio en donde intervienen una multiplicidad de aspectos. En esa construcción cobra valor la creación de redes, la participación de las instituciones y de las y los actores de diversos sectores en la elaboración de la agenda y la gestión de las políticas locales, poniendo especial énfasis en el aprovechamiento de los recursos y potencialidades endógenas. Para ello se requieren algunos cambios en las modalidades más tradicionales de planificar y gestionar el territorio, de abordar las políticas públicas, los procesos de comunicación y participación, la formación de capacidades de los recursos locales, entre otros aspectos, que es lo que intentaremos abordar en la sistematización del caso de Rafaela Más Sustentable.

\subsection{Enfoque pedagógico en el Desarrollo Territorial y su aporte a la sistematización de experiencias.}

Tal como se anticipaba en los apartados anteriores, tanto en DT como en la relación Comunicación, Educación y DT, este trabajo partirá de entender el desarrollo territorial como un proceso de construcción de capacidades en donde será clave una mirada vinculada a lo que hemos denominado, en algunas reflexiones, el enfoque pedagógico en el Desarrollo Territorial (Costamagna, Pérez y Spinelli, 2015).

En esta perspectiva el enfoque pedagógico es una forma de entender y actuar en la construcción de procesos de formación para el cambio en el territorio coherentes con una construcción 
social y política, que active la participación de las y los actores territoriales. Supone un modo de comprender el conocimiento, la vinculación teoría - práctica, el reconocimiento del otro y la otra (saberes locales, prácticas y experiencias), la vinculación basada en el diálogo y la resolución de conflictos promoviendo instancias democráticas.

Desde este marco, es que se pretende construir la sistematización de la experiencia mencionada como campo material en este trabajo de tesis y mirar los aprendizajes con la intencionalidad de volver a discutir estas reflexiones en la academia y con las y los actores, proponiendo también otros modos de construcción de conocimiento y de investigación que vienen estando en los márgenes, como es el caso de la sistematización de experiencias y la investigación acción.

El enfoque pedagógico nace más vinculado con los procesos formativos, pero con el correr de nuestras prácticas se fue planteado como una parte de la estrategia del desarrollo territorial brindando marcos de acción para trabajar procesos de diálogo y formación de capacidades en el territorio, trascendiendo los espacios tradicionales del acompañamiento desarrollados hasta el momento; más unidireccionales, de transferencia de saberes, de ausencia de diálogo y/o de negación del conflicto y donde la formación de capacidades se centraba en el aula.

Su génesis estuvo vinculado en principio en la formación en Desarrollo Territorial pero luego rompe barreras conectando la formación con el territorio, ampliándose en términos de un proceso construcción de capacidades más integral y que no funciona en forma aislada. Es claramente un planteo crítico a las propias prácticas donde la formación era casi un bien en sí mismo que se daba en el aula o en talleres repitiendo muchas veces conceptos y recetas, donde tampoco generábamos la reflexión necesaria sobre el cómo y las capacidades para el cambio. Según Costamagna y Larrea (2015) algunos de los principales elementos que sintetizan el Enfoque Pedagógico, que además continúa en permanente discusión y reelaboración, son:

\section{De la formación tradicional al territorio y al concepto de praxis.}

La formación sale del aula, del taller, del seminario exclusivamente, y se da también en el territorio en forma simultánea con las acciones propias de la búsqueda de un camino mejor. Esto nos obliga a pensar más allá de las situaciones de enseñanza - aprendizajes tradicionales y entender cómo aprenden las y los actores en los espacios cotidianos, en sus diálogos, en sus vinculaciones, en sus modalidades de comunicación y como eso se retroalimenta.

Además, tal como se desarrolla en la perspectiva de comunicación, recupera el concepto de praxis, donde se retroalimentan teoría y práctica, y donde los procesos de formación no son sólo aquellos que transcurren en espacios cerrados; sino que consideramos formativas también aquellas acciones que se dan en el proceso de las experiencias que permiten una dinámica de reflexión-acción como una relación indisoluble (Freire, 1992).

Desde esta perspectiva entonces, el conocimiento no es exclusivo de los ámbitos académicos, sino que hay un reconocimiento de las experiencias y saberes producidos 
desde las prácticas que adquieren jerarquía y valor, frente a tradiciones que los negaban, desestimaban o ignoraban.

Asimismo, trasciende las miradas didactistas, que ponen la centralidad y el énfasis en las metodologías, las herramientas y las técnicas, tradición que ha operado fuertemente en las formaciones en DT, para atender al espesor y la complejidad de los procesos donde ésta dimensión es una más entre otras que atraviesan la práctica.

\section{La construcción de capacidades en DT y la no neutralidad.}

La formación implica la acción y la transformación. La formación en DT implica involucrarse en la construcción de las estrategias donde existen distintos caminos a tomar y esto genera complejidades y tensiones. Estos procesos producen interpelaciones de diferente índole: en los conocimientos, en las prácticas, en las modalidades de gestión, en la participación, en las tomas de decisiones.

En este marco es necesario explicitar los pensamientos y las posiciones con que se definen los procesos formativos. Hay que destacar que estos procesos comienzan antes del diseño mismo de una propuesta de construcción de capacidades y que, el mismo, no siempre es armonioso, tampoco es neutro; los temas planteados en el aula y en el resto de los espacios, definen acciones de futuro y tipologías del desarrollo que se pretende. Es fundamental que los espacios sean democráticos, ahí se toman decisiones sobre los enfoques, las metodologías, sentamos posiciones políticas e ideológicas.

\section{El proceso de cogeneración.}

Como se viene señalando, dependiendo de cómo se diseñan y se ponen en práctica los procesos de formación, se condiciona los resultados del fortalecimiento de capacidades en el territorio. Infinidad de veces reproducimos acciones que no originan cambios, que son transferencias lineales y en otros casos generamos fuertes procesos de autonomía, de criticidad e innovación.

Desde este punto de vista, la formación en DT debería plantearse como un ejercicio de construcción colectiva, participativa, horizontal y flexible donde el formador y la formadora trabajan junto a las personas que participan.

El planteo es que el compromiso "debería concentrarse en construir con actores, contextos, situaciones y resultados practicables, con una visión que se amplíe incorporando experiencias y saberes producidos en espacios reales, buscando su democratización y enriquecimiento y siendo coherente con su desafío transformador" (Costamagna y Pérez, 2013).

En este sentido es necesario también reflexionar sobre "a quien va dirigida la formación". Parece de sentido común pero la cantidad de recetas aplicadas a uno u otro grupo sin ninguna diferenciación nos obliga a tenerlo bien presente a lo hora de pensar colectivamente el proceso. 


\section{La comunicación y la sistematización en el DT.}

Si bien venimos abordando el enfoque de la comunicación y profundizaremos más adelante la perspectiva de la sistematización de experiencias, ambos conceptos resultan centrales como elementos del Enfoque Pedagógico.

Nos interesa, en relación a los planteos teóricos realizados, profundizar en la comunicación como este espacio de producción de sentidos sociales y de negociación, orientados a generar procesos más amplios de participación y cambio social que, desde la perspectiva del desarrollo territorial, aportarían a la construcción de capacidades locales para la gestión del desarrollo. Por su parte, la sistematización de experiencias se convierte en una herramienta sumamente importante para reconstruir y compartir (comunicar) los procesos realizados en el territorio. El enfoque de la sistematización que proponemos, se vincula directamente con el concepto de praxis, al que viene haciendo referencia, es decir, realizar una mirada reflexiva y crítica de los proyectos y experiencias para tomar los aprendizajes (aquellos que han resultado, y también, las dificultades y complejidades); pero además para transformar las prácticas a futuro, con vistas siempre a mejorar nuestros territorios y la calidad de vida de las y los actores que lo habitan.

\section{La revalorización del contexto.}

Un punto de partida que también venimos mencionando, es que el DT es fuertemente contextual. Cada territorio es una realidad distinta y compleja debido a su historia, la identidad, la cultura, la institucionalidad y la gente que lo habita.

Esta idea nos lleva a tener cuidado con generalizaciones teóricas, y también, con los casos de éxito que generan recetas; esto ha sido, y es, una práctica habitual en la Región tanto de gobiernos, como de organizaciones no gubernamentales o de la Cooperación Internacional. En este sentido es importante insistir que cuando entendemos a los territorios como diferentes y heterogéneos, lo planteamos también por la diversidad en la manera de generar aprendizajes y capacidades.

En el marco de la experiencia que estamos sistematizando sobre Rafaela Más Sustentable, esta perspectiva del enfoque pedagógico (vinculado al desarrollo territorial) nos aporta una mirada sobre la práctica a partir de su dimensión formativa. Que contribuye a pensar cómo este tipo de políticas suponen un aporte a generar nuevas miradas, nuevas modalidades de gestión de proyectos, otras lógicas de construcción de alianzas y articulaciones entre actores. Instalan en la agenda pública temas innovadores que requieren para su abordaje la participación de una multiplicidad de sectores, entre otras dimensiones. En tal sentido es que el análisis de la experiencia apuntará a recuperar los aprendizajes desde la perspectiva del enfoque pedagógico, para contribuir también a aportar nuevas reflexiones en torno al modo en que se construyen capacidades en el territorio a partir de este tipo de procesos.

\subsection{Los aportes de la Investigación Acción en la sistematización de experiencias en Desarrollo Territorial}

Si bien la perspectiva de la Investigación Acción pareciera ser una dimensión más de tipo metodológica que de abordaje conceptual, en relación a las herramientas teóricas para este 
trabajo de tesis nos resulta relevante retomar la importancia que asume este enfoque en tanto nos brinda algunas pistas que consideramos estratégicas en relación a la forma en que entiende y propone un modo de producción de conocimiento, la posicionalidad de las y los investigadores sociales y la mirada sobre los cambios y las transformaciones que se van generando en la práctica, en diálogo con nuevos conocimientos y aprendizajes surgidos del "hacer" con otros y otras.

En este sentido, significa un aporte muy importante para el objeto de este trabajo en tanto no sólo establece puntos de encuentro con el enfoque pedagógico que desarrollábamos en el apartado anterior, sino que ambos marcos de análisis e intervención abonan y orientan los procesos de sistematización de experiencias en el sentido en que lo estamos proponiendo para el caso de Rafaela Más Sustentable.

Vinculado mayormente a los procesos educativos críticos en el contexto de América Latina, podemos retomar el pensamiento sobre la Investigación Acción Participativa (en adelante IAP) del sociólogo colombiano Orlando Fals Borda, fundador de la Facultad de Sociología de la Universidad Nacional junto al sacerdote y sociólogo Camilo Torres, comienza a desarrollar durante los años 50 la idea de darle un sentido diferente a la investigación social. Luego de trabajar con campesinos en la región andina de su país, Fals Borda cuestiona el canon dominante en la producción del conocimiento científico y da lugar a las preguntas sobre quiénes y desde dónde se produce el conocimiento.

Si bien la IAP surgió como una metodología inspirada en la sociología, se convirtió de inmediato en acción educativa, en cuanto recuperó la vinculación entre la teoría (hasta ese momento alejada de las y los actores sociales) y la praxis, cuyo desarrollo demostró procesos de aprendizaje significativo, haciendo de la investigación una constante acción creadora tanto para los investigadores e investigadoras como para las y los actores sociales. Diría Orlando Fals Borda que: "Una de las características propias de este método, que lo diferencia de todos los demás, es la forma colectiva en que se produce el conocimiento, y la colectivización de ese conocimiento." (Fals Borda y Brandao, 1987, p.18)

Esta nueva forma de investigar es una vivencia que transforma las relaciones entre investigador e investigado, entre estudiante y maestro, superando por completo tales dicotomías, poniendo como prioridad la producción de conocimiento a partir del diálogo con quienes construyen la realidad, que se entiende como propia de las y los sujetos que participan de la construcción de conocimiento social. En ese sentido, tanto la labor investigativa como la labor pedagógica de construcción de conocimiento, reconocen a las y los sujetos que hacen los procesos sociales y los reúne en la búsqueda y consolidación de propuestas transformadoras de su realidad. En ese orden de ideas, la IAP transforma a las personas y al tiempo transforma su propia realidad, de tal manera que es una pedagogía de la transformación (Calderón y López Cardona, 2016). La IAP entiende a todos los que participan como sujetos de conocimiento y a su vez como sujetos en proceso de formación: "Los investigadores entran así en un proceso en que la objetivación de símismos, en una suerte de inagotable sociología del conocimiento, se convierte en testigo de la calidad emancipatoria de su actuación" (Fals Borda, 1991, p. 34) 
Según Amaya Sierra (2017) la IAP se convierte en un proceso educativo en el que se articula la experticia del investigador social, con las comunidades en las que él está trabajando. Esta relación busca romper la verticalidad propia de la investigación de corte positivista, en la que el saber recae exclusivamente en el investigador y la investigadora. Así, podemos señalar que la IAP rompe con la relación dicotómica entre sujeto - objeto, reconociendo las mediaciones que existen entre ambas, problematizando lo dado.

Los procesos de sistematización empleados en la IAP y también en la educación popular se convirtieron en instrumentos de primer orden para formular derroteros de acción tanto política como académica. A nivel político, posibilitó el replanteamiento de las demandas y las estrategias de las y los actores y organizaciones sociales en la búsqueda de alternativas a sus situaciones. Estos replanteamientos, puede decirse, fueron posibles por el diálogo permanente entre teoría y práctica impulsada por la IAP. Para la educación, además, representa la posibilidad de pensar las prácticas pedagógicas, y con ello, nuevas formas de plantear procesos educativos abiertos al disenso, al diálogo de saberes y al replanteamiento permanente de las relaciones que a diario se entretejen en los espacios formativos (Amaya Sierra, 2017).

La investigación acción participativa -como propuesta epistemológica- critica la relación que desde el funcionalismo se hacía entre ciencia y realidad, sobre todo cuestionando los dualismos instituidos desde la ciencia entre sujeto-objeto, teoría-práctica, razón y conocimiento. Rechaza tanto el traslado de nociones de las ciencias naturales a las ciencias sociales sin ninguna mediación, como la constitución de la figura de un observador u observadora externa imaginado como poseedor o poseedora innata de una serie de virtudes, tales como la neutralidad valorativa y la objetividad científica (Lois, 2017).

Frente a esto, Fals Borda propone la inserción en el proceso social, que exige al investigador y a la investigadora una identificación con los grupos con quienes se desarrolla la investigación "no sólo para obtener información fidedigna, sino para contribuir al logro de las metas de cambio de esos grupos" (Fals Borda, 1989, p. 19).

Por su parte, la pedagoga argentina María Teresa Sirvent (2018) define a la IAP como un modo de hacer ciencia de lo social que procura la participación de las y los sujetos involucrados en la misma, con el objetivo de generar de modo colectivo un conocimiento crítico sobre la realidad, fortalecer la capacidad de participación y la organización social de los sectores populares, y promover la modificación de las condiciones que afectan su vida cotidiana.

En otra línea de análisis y vinculando directamente la Investigación Acción en el enfoque del desarrollo territorial, retomamos la perspectiva de Karlsen y Larrea (2015) quienes afirman que la Investigación Acción en Desarrollo Territorial (en adelante IADT) busca mejorar en los territorios la aportación desde la investigación social: 
“La primera reivindicación en este sentido es que, así como se ha visto de forma relativamente natural que los investigadores de las ramas científico tecnológicas colaboren directamente con las empresas u otras organizaciones en la búsqueda de soluciones a problemas concretos, al investigador social se le ha visto normalmente como alguien que observa el desarrollo territorial desde fuera, haciendo diagnósticos y dando recomendaciones a los actores. Pocas veces se visualiza al investigador social como un actor más que genera el cambio. La Investigación Acción en el Desarrollo Territorial plantea un papel para los investigadores sociales como actores en los procesos de innovación social, es decir, en la búsqueda y construcción de nuevos modos de interacción entre los actores del territorio". (Karlsen y Larrea, 2015, p 42).

Según Greenwood y Levin (2007) la Investigación Acción es una estrategia para el cambio en tiempo real donde los elementos de investigación, acción y participación se combinan en un único proceso. Ello implica que el proceso de generación del conocimiento, que ayuda a actores a solucionar un problema y al investigador e investigadora a realizar su contribución a la academia, es un proceso co-generativo entre actores e investigadores. Para esto es necesario construir espacios de diálogo con las y los actores.

El concepto central en este proceso de construcción, es el de conocimiento colectivo en la acción que es una capacidad colectiva, un patrón aprendido para la acción colectiva por el que las y los actores del territorio sistemáticamente modifican sus acciones a lo largo del tiempo a través de procesos de aprendizaje. En este proceso resulta imposible separar reflexión de la acción, la teoría de la práctica. Se trata pues de una capacidad basada en el concepto de praxis (Costamagna y Larrea, 2015) tal como venimos desarrollando a lo largo de este capítulo. Frecuentemente los espacios universitarios y los institutos de investigación están diseñados pensando que hay un proceso lineal en dos fases por el que en primer lugar se crea el conocimiento y después se transfiere. La aproximación a la praxis, la inseparabilidad de la reflexión y la acción requieren superar esta visión lineal, para entender que son necesarios nuevos espacios de encuentro de las y los investigadores con las y los actores territoriales.

Una de las reflexiones más potentes dentro del proceso de aprendizaje de la IADT es la imposibilidad de interpretar que ni los investigadores e investigadoras a título personal, ni las organizaciones de investigación, son actores neutrales en el territorio. El hecho de integrarse en los procesos como una y un actor más, la y el actor investigador, que también tiene sus intereses en el proceso y busca el cambio en direcciones concretas cambia la forma de trabajar de estas organizaciones.

Una de las contribuciones críticas a la IADT, que permite entender cómo se desarrollan estos procesos, es la de Gustavsen (1992) que plantea el diálogo democrático como el camino para ir generando el cambio. Se trata de un concepto que, lejos de significar tan sólo que las y los actores y las y los investigadores hablan entre ellos, conlleva una interpretación profunda de cómo los procesos de cambio se pueden construir de forma colectiva. En la aproximación dialógica a la IA es donde se encuentran Gustavsen y Freire. De este último la IADT incorpora 
la relevancia de los procesos de concientización. Muchos de los procesos del desarrollo territorial se abordan como problemas técnicos, en los que frecuentemente falta una reflexión profunda sobre las causas que las provocan, o modos alternativos de hacer las cosas. Muchos de los marcos que encuadran la reflexión sobre problemas concretos, se sobreentienden y no se consideran parte del debate para solucionar el problema.

La aproximación de Freire propone iniciar el proceso por la toma de conciencia de estos factores que, en gran medida se sobreentienden, y, sin embargo, son la base de cómo se organizan nuestras sociedades. Inspirada por estas contribuciones, la IADT propone la creación de espacios de diálogo no solo para la coordinación y diseño de políticas o para la intervención, sino que propone espacios de diálogo para la concientización. En estos espacios se parte de la imposibilidad de neutralidad por parte tanto de las y los actores como las y los investigadores que participan en el proceso. Se subraya por lo tanto el carácter político de los procesos de cambio compartidos. Ello supone una posición no siempre libre de conflicto para las y los investigadores.

Finalmente es relevante señalar que tanto el enfoque pedagógico como la investigación acción y sus puntos de encuentro respecto al diálogo como dimensión central, la vinculación entre la teoría y la práctica, la recuperación de los saberes de las y los actores del territorio, los modos de producción de conocimiento y la posicionalidad (no neutral) de las y los investigadores, son para nosotros y nosotras los marcos que nos han permitido revisar, reconstruir y abordar un proceso de sistematización de experiencias como el que emprendimos en este trabajo de tesis. Asimismo, también nos ha permitido construir nuevas y propias interpretaciones acerca de los conceptos mismos y su vinculación.

\subsection{La sistematización de experiencias en procesos de Desarrollo Territorial:}

Nuevamente es importante mencionar que, la sistematización puede ser también una dimensión más de tipo metodológica que de abordaje conceptual, pero en esta tesis y en el entrelazamiento de comunicación/territorio/construcción de conocimiento juega en ambas perspectivas, la teórica y la metodológica. En este sentido, varios son los enfoques que podemos encontrar referidas a la sistematización de experiencias, especialmente en América Latina. El trabajo de sistematización se ha desarrollado fundamentalmente a partir de las experiencias de educación popular.

Graciela Messina (2005), indica que la sistematización es una manera particular de investigar, generada desde la educación popular en América Latina, y que comparte sus compromisos en torno de la transformación social.

Un punto clave es que la sistematización nace en los años 80 , en un período de grandes movilizaciones políticas. $Y$ nace después de la investigación participativa y, en parte, como una continuidad y como una réplica a ella. El cuestionamiento de las formas tradicionales de 
evaluación e investigación sostenía que éstos no daban cuenta de los procesos y aprendizajes potenciales que en muchas ocasiones aparecían como apreciaciones injustas e imparciales. (Cerro y Rearte, 2007)

En este contexto la sistematización surge como una propuesta de recuperar y aprender de las experiencias acumuladas, junto con las nuevas formas de investigación y evaluación que promueven la participación de la población con quien se ejecuta las acciones. En esta lógica el acceso a la información sobre las prácticas y su procesamiento toma dimensiones distintas a la del trabajo meramente intelectual. Es así que uno de los desafíos siempre presentes es el de definir metodologías de producción de conocimiento adecuadas a la forma de pensar y actuar de aquellos y aquellas que parten de la práctica de la acción. (Centro de Estudios para la Educación Popular CEPEP, 2010)

Este tipo de enfoques han sido (y siguen siendo) en algunos ámbitos de producción científica mirados con cierta desconfianza, sostenida bajo argumentos que separan a la sistematización de la investigación, dado que la entienden como prácticas opuestas. La investigación social, en las corrientes dominantes de la formación, y en buena parte de su ejercicio, se ha desarrollado siguiendo las orientaciones y los principios del positivismo, que impone las siguientes condiciones a la hora de hacer investigación (Palma, 1992)

- Diferenciación entre el investigador y el objeto investigado.

- Neutralidad valórica de la investigación

- La verdad se identifica con los rasgos generales.

- Las experiencias particulares no tienen importancia en sí mismas, sino en cuanto se eligen como muestras de afirmaciones más generales.

- La aplicación del método científico, una estrategia de conocimiento ordenada en torno a la experiencia significativa y al test de hipótesis, es la que permite pasar de la observación particular a la generalización.

La educación popular, la sistematización de experiencias, la investigación acción participativa y otras prácticas afines, son actividades que se comprometen e interactúan constantemente con los grupos y organizaciones a los que se refieren, coincidiendo con ellos en una intención política y que buscan conocer y actuar en lo singular.

De allí que algunas reflexiones propongan la sistematización como una práctica alternativa de la investigación tradicional. Se trata de una necesidad que se evidencia cuando los marcos teóricos se hacen inoperantes para sustentar acciones. Sistematizar es organizar una práctica para volver a intervenir con mayores y mejores elementos en una situación dada. En este punto se diferencia del interés del conocimiento de la investigación social tradicional, que busca sobre todo una mayor compresión teórica de esa misma situación (Palma, 1992). 
En este sentido también se constituye como desafío para este trabajo propiciar y alentar la construcción de otros modos de producir conocimientos, otras metodologías para poner en diálogo las experiencias con los marcos conceptuales como es el caso de la sistematización, generando también disputas al interior de la propia academia, proponiendo otros enfoques para revisar nuestras propias prácticas como docentes e investigadores.

Siguiendo este propósito nos interesa especialmente aquí construir y debatir una mirada de la sistematización vinculada al enfoque del desarrollo territorial, y especialmente; al enfoque pedagógico del DT tal como se anticipaba en el apartado anterior y que desarrollaremos en profundidad en el capítulo siguiente.

\subsection{La perspectiva de la Maestría en Planificación y Gestión de procesos comunicacionales (PLANGESCO)}

La perspectiva PLANGESCO se va pregnando en el modo de entender y abordar la planificación y la gestión de procesos comunicacionales y en este sentido este trabajo de tesis pretende dar cuenta del modo en que se van articulando estos trayectos con las prácticas profesionales, intentando, tal como los objetivos de la maestría lo persiguen: "sistematizar los conocimientos en materia de planificación y gestión de la comunicación a través de la investigación e intervención para el desarrollo. La comunicación como dimensión estratégica para la ideación de procesos de cambio social, supera la instancia de la lectura para convertirse en perspectiva orientativa de personas y organizaciones que en base a objetivos político-culturales pueden diseñar, planificar y gestionar procesos de comunicación que favorecen transformaciones sociales en contextos micro y macro sociales".

Planificar y gestionar procesos comunicacionales es la forma en que desde la Maestría se denominan modalidades de intervención sociocultural desde la mirada de la comunicación. Esto supone una lectura de los procesos sociales, la identificación de problemáticas, de interpelaciones en los territorios en donde intervienen sujetos que construyen prácticas de producción de sentidos de diversa índole.

Se trata de identificar los sentidos producidos por actores en un proceso histórico susceptible de ser explicado, entendido, de modo tal que las prácticas expresen la memoria acumulada tanto en términos micro como macro. Lo que se planifica son procesos sociales con objetivos políticos - culturales donde la comunicación acontece y es una dimensión de gestión y análisis. Por ello la comunicación es una clave de lectura y una mirada estratégica de la intervención.

En términos generales y tratándose de una experiencia como la que aquí se aborda, pueden mirarse desde esta perspectiva PLANGESCO, distintos aspectos vinculados a la dimensión misma de la comunicación, pero también las dimensiones institucionales, políticas, las prácticas formativas y el campo mismo del desarrollo territorial entre otras variables. 


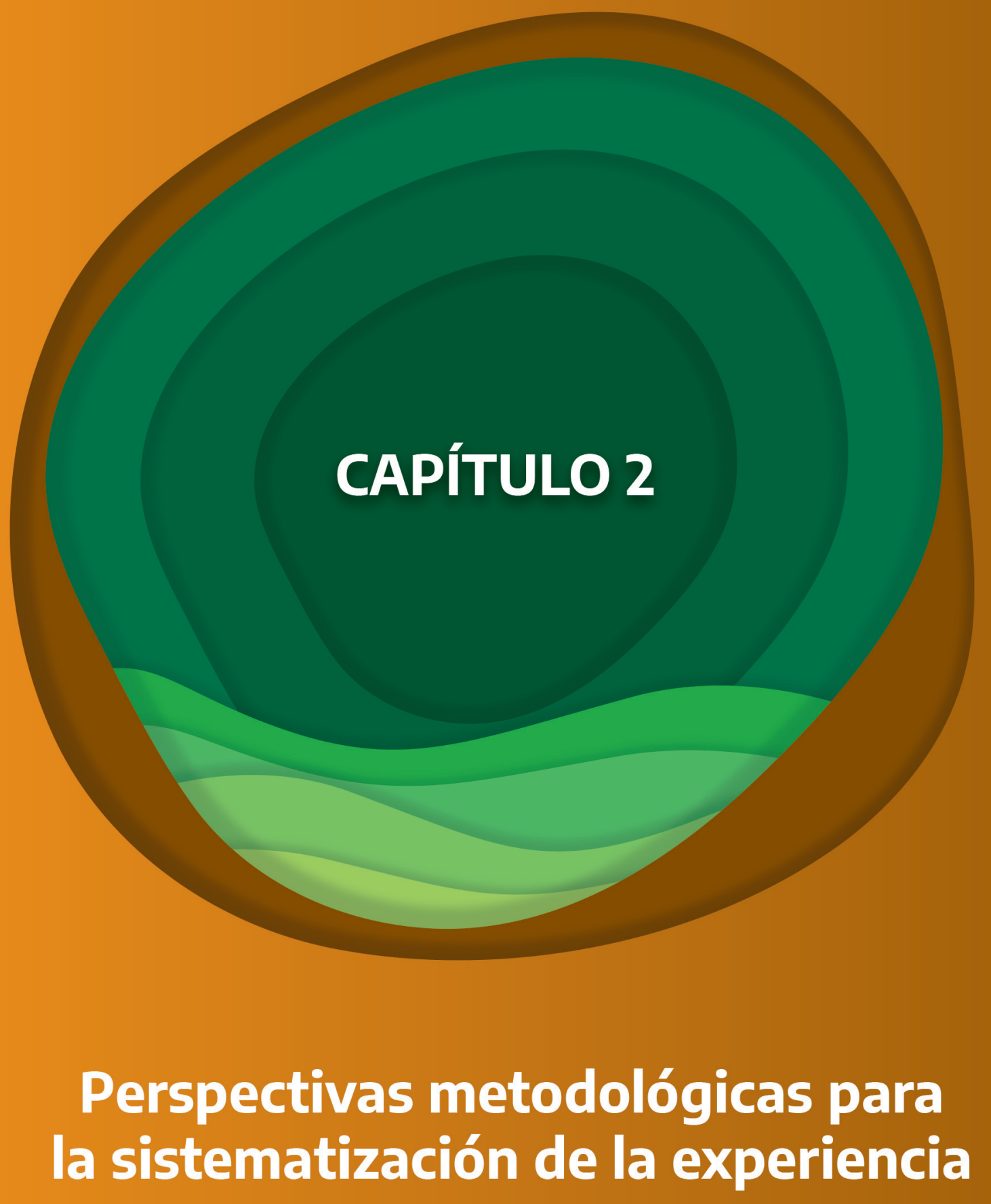




\section{CAPÍTULO 2.}

\section{Perspectivas metodológicas para la sistematización de la experiencia}

\section{Consideraciones generales sobre el enfoque metodológico}

En este apartado nos proponemos dar cuenta y desarrollar la perspectiva metodológica puesta en acción en este trabajo de tesis que apunta a construir aprendizajes en torno a procesos y prácticas de planificación y gestión en políticas territoriales y tiene, en los objetivos específicos, un planteo vinculado a trabajar la historización y reflexionar a partir de los relatos de las y los propios actores participantes, generando un proceso de construcción de conocimientos de manera colectiva.

Con este marco, una investigación social de estas características, se constituye en algún punto como un proceso artesanal, "un artefacto hecho pieza por pieza" (Ortiz, 2004, p. 12), que implica hilvanar técnicas y recursos con miradas conceptuales de manera estratégica y situada. "Es una verdadera aventura metodológica, donde hay necesidad de exploración, de creatividad y de rigor" (Vasallo de López, 2012, p. 22).

La construcción de la metodología no se restringe al trazado de métodos y técnicas ni se circunscribeal momento inicial del proceso investigativo, sino que pone en juego ineludiblemente una dimensión epistemológica y teórica que orienta la toma constante de decisiones y de opciones. Se trata de "una concepción no- tecnicista y no-dogmática de la metodología como trabajo que prohíbe la comodidad de una aplicación automática de procedimientos aprobados y exige que toda operación dentro de la investigación deba cuestionar a la misma" (Vasallo de López, 2012, p. 25). Cada investigación, debe configurar una estrategia metodológica acorde a sus particularidades.

Se parte de un método cualitativo, de un modo de hacer cualitativo clarificando nuestros objetivos de investigación vinculados a la interpretación de experiencias subjetivas; "al glose de los puntos de vista de los actores y su construcción de la realidad" (Sautu, 2005; p.10). Pero también a la propia reflexión sobre los procesos de acercamiento al campo y las interacciones que se establecen con "las y los actores", constituyen en sí mismas un objeto para el análisis. El trabajo de campo que se realiza se identifica con un modelo etnográfico, en tanto se observa y describe el contexto de intervención intentando dar cuenta de sus principales problemáticas. Este modelo supone una presencia sostenida en el territorio, ya que se requiere "un modo de participación que permita crear relaciones cercanas favorables a la recogida de datos fiables que de otro modo serían difíciles de obtener, pero, sobre todo, de comprender" (Álvarez - Álvarez, 2008; p.4).

Asimismo, el proceso lleva la imposibilidad de pensar una perspectiva metodológica de trabajo totalmente definida "a priori", sino más bien una que funcione de manera reflexiva y en diálogo 
permanente con el proceso de investigación. En esta lógica existen una serie de actividades a continuación, que dan lugar a los lineamientos generales del proceso metodológico:

a. Recuperación y análisis de los documentos producidos antes, durante y en el desarrollo de la sistematización de Rafaela Más Sustentable: principalmente se rescataron los textos escritos inicialmente para fundamentar y conceptualizar el Programa y el Instituto, aquellos provenientes de las argumentaciones construidas para formalizar su creación como órgano de gobierno, los documentos de trabajo y las publicaciones generadas para el desarrollo de actividades especiales, las distintas presentaciones realizadas en relación a premios y eventos, producciones realizadas para la comunicación institucional y los medios de comunicación locales, ordenanzas, notas periodísticas, videos y recursos multimedia, así como también informes y materiales internos y producciones audiovisuales.

b. Historización del proceso: se reconstruye el surgimiento, antecedentes y el proceso del Programa Rafaela Más Sustentable desde sus inicios hasta la consolidación en la creación del Instituto. Para realizar la historización se ha recurrido tanto al análisis de documentos como a entrevistas con informantes claves partícipes desde su creación.

c. Entrevistas en profundidad: a las y los actores significativos de la experiencia representativos de la multiplicidad de sectores vinculados a esta política ambiental (cuál es el sentido que ellos y ellas le encuentran al proceso). Se tuvo en cuenta la diversidad de perfiles y ámbitos de pertenencia (empresas, organizaciones de gestión pública, actores de la política, del sector educativo, del sistema científico tecnológico, de las organizaciones sociales, entre otros). Se enfatizó asimismo en las y los integrantes del Consejo Ambiental que se conforma a través de la creación del Instituto para el Desarrollo Sustentable.

En este aspecto retomamos el planteo de Rosana Guber (2001) quien afirma que "la entrevista es una estrategia para que la gente hable de lo que piensa, sabe y cree, una situación en la cual (el investigador-entrevistador) obtiene información sobre algo interrogando a otra persona (entrevistado, respondente, informante). Esta información suele referirse a la biografía, al sentido de los hechos, a sentimientos, opiniones y emociones, a las normas o estándares de acción, y a los valores o conductas ideales".

Existen variantes de esta técnica: hay entrevistas dirigidas que se aplican con un cuestionario preestablecido, semiestructuradas, grupos focalizados en una temática, y clínicas (Bernard, 1988; Taylor \& Bogdan, 1996). En este caso, las entrevistas fueron realizadas bajo un formato de semiestructuradas.

El panel de actores, para dichas entrevistas, estuvo seleccionado bajo la metodología de informantes claves, consideradas personas que han estado en el "corazón" del proceso sistematizado, que lo han experimentado y que le permite al investigador y a la investigadora establecer relaciones desde la experiencia. Según Taylor y Bogdan (1986) "informantes claves son personas que permiten a los investigadores cualitativos acercarse y comprender en profundidad la "realidad" social a estudiar". 
d. Análisis y construcción del corpus: a partir del análisis de documentos, la historización de la experiencia, la construcción de la Memoria y la realización de las entrevistas a informantes clave, se establecieron una serie de ejes de análisis para profundizar en los principales aprendizajes surgidos de la experiencia y elaborar un primer documento analítico para poner en diálogo con las y los actores partícipes de la experiencia. Para profundizar en las reflexiones se volvieron a realizar una serie de entrevistas a nuevos y nuevas integrantes del Consejo Ambiental e incluso a algunos de las y los entrevistados para obtener su perspectiva acerca de la identificación de los ejes de análisis y los aprendizajes identificados.

e. Taller de reflexión del proceso con el Consejo Ambiental de Rafaela Más Sustentable: una vez generada una primera etapa analítica a partir de las entrevistas y teniendo como base un documento borrador que fue enviado a cada uno y cada una de las y los entrevistados, se realizó un taller con las y los integrantes del Consejo Ambiental en donde se trabajó a partir de los siguientes aspectos: la utilidad del documento, su comunicabilidad, la ampliación o no de la cantidad de representantes en el Consejo como parte de una de las reflexiones surgidas del proceso de análisis de las entrevistas, la modalidad de participación en el espacio del Consejo, la discusión sobre los temas hacia delante de la agenda ambiental de la ciudad y la región y los temas pendientes de ejecución.

f. Taller de reflexión del proceso con estudiantes de la Maestría en Desarrollo Territorial: para retomar los aprendizajes y el vínculo con la academia (lo que hemos denominado "la vuelta a la academia") trabajamos la discusión del documento preliminar de sistematización de Rafaela Más Sustentable con estudiantes de la cohorte 2017-2018 de la Maestría en Desarrollo Territorial en el marco del Taller de Reflexión sobre la Praxis, en donde nos dedicamos también a realizar procesos de sistematización de experiencias desde el enfoque del Desarrollo Territorial propuestos y realizados por las y los cursantes.

En ese marco es que realizamos el espacio de análisis y reflexión a partir de un trabajo grupal en donde se discutió a partir de los siguientes tópicos: cuáles eran los elementos más innovadores de la política ambiental territorial de Rafaela Más Sustentable, que problemáticas, abordajes y discusiones resultaba importante profundizar, qué evaluación podía realizarse de la red de actores del territorio que involucra el Programa / Instituto R+S y que nuevos participantes sería importante convocar. Sobre los resultados de este taller profundizaremos más adelante.

g. Aprendizajes para la realización de sistematización de experiencias desde el enfoque del desarrollo territorial: a partir del camino recorrido, de transitar la experiencia de sistematizar este proceso, nos proponemos compartir en el apartado de conclusiones por un lado nuestros aprendizajes respecto a la metodología de sistematización y por otro, algunas propuestas vinculadas a transformar estas perspectivas a futuro, enfatizando en las dificultades, complejidades propias del proceso de la práctica que 
nos han hecho pensar en la metodología como un camino que se modifica en el hacer, transformando incluso la propia construcción teórica.

\section{h. Aprendizajes vinculados a la planificación y gestión de políticas públicas socio} ambientales: finalizando el recorrido también en el apartado de las conclusiones finales, nos animaremos, a partir de la recuperación analítica, a enfatizar sobre algunas dimensiones referidas a la planificación y gestión de políticas públicas socio ambientales, especialmente vinculadas a la comunicación, retomando la perspectiva PLANGESCO que tanto tiene para contribuir a este tipo de experiencias en el territorio.

\section{La metodología como un camino en construcción}

Con respecto a los aprendizajes nos parece importante aclarar la relevancia de retomar el enfoque pedagógico donde la metodología tiene que tratar de entender cómo se activa la participación de las y los actores territoriales, cómo se reconocen los saberes locales, prácticas y experiencias y cómo se construyen cambios.

El hilo es el de conocimiento colectivo en la acción ya mencionado, y como modifican sus acciones a lo largo del tiempo a través de procesos de aprendizaje con el diálogo como eje central donde intentaremos reconstruir nuevas y propias interpretaciones acerca de los conceptos mismos y su vinculación.

Para esto, sistematizar los procesos y proyectos desarrollados en el territorio supone partir de la idea de praxis, en el sentido de Paulo Freire (1997) como "reflexión y acción de los hombres sobre el mundo para transformarlo", es decir, basado en la importancia de generar procesos críticos y reflexivos acerca de lo acontecido, pero también que estos aprendizajes se traduzcan en acción y transformación de los territorios para mejorar la calidad de vida de las personas y fortalecer sus capacidades.

En este sentido, la perspectiva que asumimos en este trabajo se vincula con la propia biografía y trayectoria personal, partiendo de lecturas colectivas, de experiencias concretas de trabajo sistematizando experiencias y de diferentes espacios de intercambio. Uno de ellos, quizás el más importante, tiene que ver con la Maestría en Desarrollo Territorial de la Universidad Tecnológica Nacional - Facultad Regional Rafaela, en donde en el año 2015 se inicia con la tercera cohorte un espacio de "Sistematización de experiencias en Desarrollo Territorial", donde los y las estudiantes debían llevar adelante esta actividad con el propósito de profundizar los aprendizajes desde la práctica misma, dialogando con las y los actores del territorio, planteando propuestas transformadoras.

Las principales reflexiones de este proceso han sido reflejadas en el documento "Aprendizajes de un proceso de Sistematización de Experiencias de DT con alumnos y alumnas de la Maestría en DT - Año 2015". A partir de allí, generamos un espacio desde donde repensar nuestra propia 
práctica y revisar el enfoque respecto a lo que entendemos por sistematizar una experiencia en DT, desarrollando algunos conceptos y proponiendo momentos que creemos necesarios a la hora de iniciar este camino.

Parte de esas reflexiones entonces, son las que se desarrollan como perspectiva conceptual y metodológica en este trabajo de tesis y han sido los marcos de abordaje, interpretación y análisis del proceso que se ha sistematizado y que se recorrerá durante todo el documento y sobre todo en las conclusiones.

Para complementar el planteo volvemos a nuestra perspectiva de la sistematización de experiencias como una metodología y un proceso que supone un aprendizaje desde las prácticas y que según Peiretti (2017) "debe entenderse como dinámico y flexible, que sea capaz de adaptarse a las necesidades de los actores y contextos. En tal sentido, no debe considerarse acabado, por el contrario, debemos dejar abierta la posibilidad de regresar a él, atendiendo a las necesidades que surjan durante su desarrollo".

En este camino, uno de los puntos claves, es la interacción del investigador y la investigadora y la y los diferentes actores ya que la sistematización no busca solamente evaluar resultados, sino que, a partir del diálogo, intenta detectar los aprendizajes del proceso de desarrollo de la experiencia y compartirlos, vinculando esos nuevos conocimientos a procesos de cambio (Spinelli, 2015, p 10).

\section{El enfoque de la sistematización de experiencias}

Generalmente se asocia sistematizar con "ordenar información", no obstante, el concepto hace referencia a un proceso más complejo donde ordenar información es sólo una parte. Así para Oscar Jara (1994), sociólogo y educador popular, quien ha sido y es una de las principales referencias en la metodología y la praxis del enfoque de Sistematización de Experiencias en Latinoamérica, la sistematización puede tomarse desde dos lugares donde el segundo es más importante que el primero:

Como sistematización de información: se refiere al ordenamiento y clasificación de datos. Esta modalidad nosotros solemos llamarla también "Memoria de la experiencia".

Como sistematización de experiencias: se intenta ir más allá del ordenamiento de la información, se trata de mirar las experiencias como procesos históricos complejos en los que intervienen diferentes actores, en un contexto económico-social determinado y en un momento institucional del cual formamos parte para reflexionarla, comprenderla, significarla y producir aprendizajes desde ellas.

En tal sentido, Jara manifiesta que sistematizar experiencias significa "entender por qué determinado proceso se desarrolló de una manera y no de otra, interpretar lo acontecido, a partir 
de un ordenamiento y reconstrucción del proceso. Se parte de una reconstrucción de lo sucedido y un ordenamiento de los distintos elementos objetivos y subjetivos que han intervenido, para comprenderlo, interpretarlo y así aprender de las propias prácticas" (Jara, 1994, p. 55)

La sistematización, mediante una metodología, no busca solamente evaluar resultados, sino que, a partir del diálogo con actores, intenta detectar los aprendizajes del proceso de desarrollo de la experiencia. Trata de relevar las "pequeñas" acciones que hicieron posible y exitosa una experiencia, o bien, que dificultaron la obtención de los resultados planificados.

Entonces, esta idea de contar lo que se hace no se basa solamente en la difusión de los resultados (que también es importante) sino en aquello que hemos aprendido y que puede ser "embrión" a futuro de nuevos procesos, que puedan ser utilizados como aporte en el territorio. Y aquí nuevamente la vinculación directa con la investigación acción y el enfoque pedagógico dado que como resultado final, lo que nos interesa es profundizar en la formación de capacidades en el territorio, y en ese sentido recuperar una mirada crítica de las experiencias nos permiten "intervenir" hacia adelante, tomando mejores decisiones en relación a las dinámicas de los proyectos, a la modificación de diseños, al establecimiento de redes y alianzas, entre otros aspectos, y fundamentalmente compartiendo los conocimientos con otros y otras.

\subsection{Las definiciones para el abordaje metodológico.}

Según Jara (1994), se ha entendido que la palabra "sistematización" en determinadas disciplinas se refiere, principalmente, a clasificar, catalogar, ordenar datos e informaciones, a "ponerlos en sistema".

Este es el sentido más común, más utilizado y totalmente válido de la noción o del concepto "sistematización": sistematizar datos o informaciones. Pero desde la educación popular, o bien desde los proyectos sociales, utilizamos el mismo término, pero lo vinculamos no sólo a datos e informaciones, sino a experiencias; por eso no hablamos sólo de "sistematización", a secas, sino de "sistematización de experiencias". (Centro de Estudios para la Educación Popular CEPEP, 2010)

La sistematización de experiencias es una estrategia multisectorial para evaluar las intervenciones de desarrollo con énfasis en las lecciones aprendidas. La reflexión crítica sobre nuestra intervención y el aprendizaje desde nuestra experiencia llevan a la creación de nuevas ideas y conocimiento para mejorar la práctica futura. El conocimiento generado a través de este proceso contribuye a comprender mejor nuestro trabajo y la manera en que suceden los cambios (Tapella y Rodríguez, 2013). Quienes participamos en este tipo de tareas, entendemos que la fase de generación de nuevos conocimientos se realiza a partir del diálogo con las y los mismos actores protagonistas de la experiencia, generando ámbitos de co - construcción y de reflexión conjunta y participativa. 
La sistematización prevé instancias de reflexión compartidas, donde se trata de conceptualizar el aprendizaje de las y los actores del territorio, y donde se genere aprendizaje tanto para estos actores como para la academia. (Peiretti, 2017)

Siguiendo la lectura del Centro de Estudios para la Educación Popular (2010), coincidimos en la definición que indica que la sistematización de experiencias es un proceso político, dinámico, creador, interactivo, sistémico, reflexivo, flexible y participativo, orientado a la construcción de aprendizajes, conocimientos y propuestas transformadoras, por parte de las y los actores sociales o protagonistas de una experiencia en particular, mediante el análisis e interpretación crítica de esa experiencia a través de un proceso de problematización.

Este tipo de prácticas en el mundo del desarrollo suelen tener instancias de reflexión sobre los aprendizajes logrados, aunque se caracterizan por dos circunstancias comunes: suelen ser informales y fortuitas, con dificultades para superar el plano de lo meramente anecdótico, y, por otro lado, se circunscriben a los equipos internos de los proyectos y programas, sin que dicha reflexión sea más ampliamente conocida, documentada y valorada. (Tapella y Rodríguez, 2013).

Estos aprendizajes deben ser compartidos entre actores del desarrollo, que pueden generar conocimientos e intentar vincular estos conocimientos a sus procesos. La comunicación vinculada a procesos de desarrollo comúnmente se ha limitado a la difusión de información y conocimiento, a la promoción de los beneficios o resultados de una iniciativa o al uso de tecnológicas sin conexión con la realidad local. Bajo este enfoque entendemos central a la comunicación que pone énfasis en los procesos, y no tanto en los resultados.

Para abordar la sistematización es importante en un principio tener en cuenta algunos elementos (Spinelli, 2015):

1. Las y los actores que forman parte de las experiencias son quienes principalmente llevan adelante la mirada reflexiva sobre sus acciones, las analizan en ese contexto y producen aprendizajes propios y para otros y otras. A estos se suman, en determinadas ocasiones, actores externos que ayudan a construir esa mirada a través del relato colectivo.

2. Es importante qué se sistematiza, pero también cómo se sistematiza. Es importante que el proceso sea lo más participativo y pluralista posible, capturando, incorporando y aprovechando los conocimientos y opiniones que sobre la experiencia tengan diversos actores vinculados a la misma.

3. Gran parte del sentido de la sistematización se encuentra en aprender críticamente de las experiencias con el fin de: - Mejorar nuestras propias prácticas (la experiencia como instancia de aprendizaje). - Compartir nuestros aprendizajes con los de otras experiencias similares (socializar las experiencias). - Contribuir a la producción de nuevos conocimientos. 
Bajo el marco anterior, podemos decir que existen algunos elementos o coordenadas significativas para pensar en la sistematización (Ocampo y Berdegué, s.f):

- Se trata de un proceso de reflexión y autocrítica: permite darse el tiempo para pensar que hicimos, por qué, cuáles fueron los resultados, y para qué y a quién sirvieron los mismos. En muchos casos, también involucra la mirada de "las y los externos" (consultores, asesores, docentes, formadores, entre otros) que si bien no son quienes han "gestado" el proceso $\mathrm{y}$ han participado de acciones puntuales poseen una mirada valiosa (y con apreciaciones muy importantes por una perspectiva más desde afuera del día a día).

- Su propósito es provocar procesos de aprendizaje colectivo. Por supuesto que interesan los resultados, y describirlos, pero también (y a veces es lo que más interesa) extraer, "descubrir" aprendizajes que nos permitan mejorar las prácticas en experiencias futuras.

- Se basa en la idea de "organizar" o de "ordenar": es un proceso metodológico que tiene como propósito poder ordenar un conjunto de elementos (prácticas, conocimientos, ideas, datos) que hasta ese momento están dispersos y desordenados.

- Se propone mejorar las prácticas: aspectos como las decisiones que se tomaron para hacer las cosas y las razones que se tuvieron para hacerlas así y no de otra manera, son preguntas claves sobre las que es necesario reflexionar. Una aprendizaje o lección aprendida es una proposición generalizada sobre qué tendría que pasar o suceder para que un determinado resultado se alcance, o ciertos inconvenientes se eviten.

Desde esta perspectiva, entonces la sistematización debe ser vista como un nuevo conocimiento que se caracteriza por ser situacional y estar orientado a la acción. Para que además sea relevante, es imprescindible que existan instancias multiactorales de análisis e interpretación de lo sucedido, e instancias de revisión y crítica. El paso final de un proceso de sistematización no es el simple hecho de producir conocimiento a partir de la práctica y comunicar las lecciones aprendidas. El nuevo conocimiento debe ser institucionalizado e integrado. Sin el compromiso de las y los diferentes actores involucrados en la intervención de un determinado proyecto o programa, no habrá metodología capaz de generar un nuevo conocimiento para transformar esa intervención (Tapella y Rodríguez, 2013).

Podemos pensar, además, que existen capacidades personales e institucionales que necesariamente debemos tener en cuenta a la hora de iniciar una actividad de este tipo. Respecto a las capacidades personales: las personas que decidan emprender el ejercicio de sistematizar deberán mostrar interés en aprender de la experiencia, sensibilidad para dejarla hablar por sí misma, habilidad para hacer análisis y síntesis. (Jara, 1994).

El interés refiere a que es muy común que se piense que solo se puede aprender de los libros o clases y no se considera a la propia experiencia como una fuente fundamental de aprendizaje. 
Por ello, desarrollar esta condición supone una ruptura con un esquema de pensamiento y es por ello que debe hacerse de manera consciente, motivándonos a aprender de lo que hacemos (Peiretti, 2017). La mejor motivación será descubrir que, efectivamente, lo que hacemos todos los días está lleno de enseñanzas, y que hace falta que nos propongamos a aprender de ellas, haciéndoles preguntas a nuestras propias prácticas. Hemos sido formados en un esquema educativo donde la vida y el estudio se ven como dos cosas separadas, por lo tanto, debemos romper con esto y entender la importancia de estudiar nuestras prácticas.

Respecto a la sensibilidad para dejar hablar a la experiencia, refiere a desarrollar nuestra capacidad de observación y de percepción. Supone liberarse de prejuicios y de esquemas rígidos de pensamiento y mirar la experiencia a partir de lo que efectivamente ha ocurrido y no como quisiéramos que hubiese sido. Desarrollar esa sensibilidad supone darles valor a los factores cotidianos: no guiarse solo por el impacto de los grandes acontecimientos, sino poner atención en los matices y sutilezas de los procesos en los que vivimos durante la mayor parte del tiempo.

Según Peiretti (2017) adicionalmente a estas dos condiciones, cualquier persona que aspire a sistematizar experiencias deberá desarrollar una habilidad suficiente que le permita el manejo de dos operaciones lógicas básicas: el análisis y la síntesis. No es posible extraer las enseñanzas de una experiencia sino logramos ir más allá de la mera descripción de lo sucedido, analizando la complejidad de los hechos en sus diferentes aspectos. Puesto que estas habilidades no nos fueron enseñadas en nuestros sistemas educativos, comenzar a sistematizar es quizás la mejor oportunidad que nos podemos dar para hacerlo.

Estas tres condiciones personales se complementan entre sí y no deben ser entendidas como "condiciones previas" que el investigador o la investigadora debe "tener" antes de empezar el proceso, sino como condiciones que vamos forjando en nosotros y nosotras mismas en un proceso de formación del que la sistematización debería ser un componente importante. En todo caso, estas habilidades significan una afirmación vital del desarrollo de la creatividad, la imaginación, la reflexión crítica, la curiosidad y la inquietud intelectual.

Las condiciones institucionales son tan importantes como las anteriores para que la sistematización sea posible y viable. La condición básica en este nivel es que la sistematización sea una prioridad para la política de la institución o instituciones que estén involucradas, asignando dedicación en cuanto a tiempos y recursos, atendiendo a las necesidades del proceso. La sistematización no debe ser un "reclamo" o un esfuerzo solitario de alguna o algunas personas, sino que debe estar articulada al conjunto de la estrategia institucional.

Por último, es importante distinguir entre evaluación y sistematización. En la mayoría de los enfoques de evaluación, generalmente se pone énfasis en la medición de los resultados o impactos del proyecto. Así, lo esencial de una evaluación es la valorización de las acciones emprendidas en una práctica y comprende, por ejemplo, la valorización del cumplimiento de metas y objetivos, o la relación costo beneficio en el uso de los fondos. 
Si bien la sistematización puede incluir estos elementos y muchas veces se vale de estos análisis, lo esencial en ella es concentrarse en la comprensión de los procesos que se desarrollan en un determinado proyecto, mejorar su implementación y rescatar los aprendizajes. En la sistematización se intenta conocer y descubrir cómo funciona una propuesta de intervención en un contexto determinado, qué factores obstaculizan y favorecen el logro de objetivos, cuáles son las posibilidades de sostenibilidad y replicabilidad del proyecto en el mismo y otros escenarios, y qué lecciones se aprendieron de la experiencia. (Tapella y Rodríguez, 2013).

Sistematizar experiencias no es solamente reconstruir o narrar hechos, actividades o acciones. Tampoco es ordenar datos e información por simplemente ordenarlos, sino que esta actividad se propone llevar adelante una reflexión crítica con propósitos transformadores, que favorece un proceso de aprendizaje y construcción social de conocimientos por parte de las personas que han protagonizado la experiencia, así como también favorece la concepción de acciones para la transformación social. La sistematización de experiencias debe garantizar la participación activa y protagónica de las y los actores sociales claves de las experiencias a sistematizar, con miras hacia su empoderamiento y a elevar su contribución con el proceso. (Centro de Estudios para la Educación Popular CEPEP, 2010)

Siguiendo la propuesta del Centro de Estudios para la Educación Popular (2010) podemos identificar y resaltar al menos cuatro propósitos fundamentales de la sistematización de experiencias, que representan una expresión clara y concreta de la presencia de los principios de la educación popular, que se propone a partir de la práctica o experiencia: aprender, producir conocimientos, construir propuestas transformadoras y socializar los resultados.

1. Aprender de la experiencia: desde la sistematización de experiencias, la práctica se convierte en una fuente inagotable de aprendizajes que deben ser construidos socialmente, a través de la participación protagónica del equipo de sistematización que se haya conformado. Esto implica un proceso de estudio e investigación por parte de ese equipo durante todos los momentos del proceso de sistematización que desarrollaremos, especialmente durante la interpretación crítica, que promueva abordaje e integración de saberes, transformándose de esta forma la experiencia en conocimiento, actitudes, valores, habilidades y destrezas.

2. Producir conocimiento desde la experiencia: la reflexión crítica sobre la experiencia debe ser la base para contribuir con la generación de nuevos conocimientos mediante la problematización y consecuente interpretación crítica de la experiencia sobre la base de los ejes centrales de la sistematización que fueron definidos. La sistematización de experiencias es en sí, un método de investigación que rescata la interpretación crítica como una vía para construir conocimiento. Es muy importante aclarar que estos aprendizajes identificados están sesgados por el perfil profesional de quien los busca. Esto nos lleva a pensar que no podemos hablar sobre "el o los aprendizajes" de tal experiencia, sino que debemos exponer el o los aprendizajes identificados por 
el investigador e investigadora o equipo investigador. Quien investiga se encuentra influenciado por su propia formación, su trayectoria personal y académica, su posicionamiento ideológico frente a determinadas situaciones. Todo esto influye a la hora de identificar aprendizajes. Esto nos poner a reflexionar que ciertos investigadores e investigadoras pueden rescatar aprendizajes que no se hacen invisibles frente a otros y otras, atendiendo a estas situaciones planteadas.

3. Construir propuestas transformadoras desde la experiencia: en un proceso de sistematización, los nuevos aprendizajes y conocimientos deben ser puestos al servicio de la transformación de la realidad y los contextos políticos, sociales, económicos de las y los sujetos protagonistas. Estas propuestas transformadoras deben construirse en ámbitos participativos, junto con las y los actores de la experiencia.

4. Socializar los resultados: todo proceso de sistematización trae consigo productos o resultados concretos que se traducen en: aprendizajes, conocimientos (teoría) y propuestas transformadoras. La sistematización debe contemplar estrategias claras para la apropiación social de estos resultados, no sólo por parte de equipo de sistematización de dicha experiencia, sino también por otras y otros actores territoriales. En este contexto, socializar como propósito es impulsar el desarrollo del conocimiento libre, a través de un proceso de divulgación o comunicación de estos resultados, mediante diversas estrategias, a fin de contribuir con el empoderamiento de estos aprendizajes y propuestas por parte de actores que participan en procesos de desarrollo territorial.

Finalmente y para concluir, a partir de la perspectiva expuesta, en este trabajo de tesis entonces nos propondremos asumir la sistematización de experiencias desde una doble dimensión: por un lado como un enfoque conceptual para generar nuevos conocimientos sobre nuestras propias prácticas y encontrar otros modos de producir comunicativamente relatos sobre estas experiencias de desarrollo en los territorios y, por otro, avanzar hacia reflexiones y aprendizajes sobre el concepto y la metodología misma de sistematización de experiencias en procesos de DT que nos permita enriquecer y poner en juego esta herramienta en la práctica.

\section{La sistematización de experiencias como método de trabajo}

Para avanzar en el proceso, fue necesario encontrar un marco desde el cual posicionar una mirada que permitiera reconstruir lo acontecido, yendo más allá de la realización de una mera evaluación, que por más profundidad que pudiera cobrar siempre se quedaría en lo sucedido. $Y$ como la intención de este trabajo también tiene que ver con el aporte al campo de comunicación y educación y a la planificación y gestión de procesos comunicacionales vinculada a las políticas públicas socioambientales, se requería de una perspectiva que dialogue desde y con la teoría en la construcción de conocimiento. 
Es en este marco que la metodología de la sistematización de experiencias desde el enfoque del desarrollo territorial, tal como profundizamos en el apartado anterior, se convirtió al mismo tiempo en coordenada conceptual y en "caja de herramientas" generando un meta aprendizaje en el proceso de escritura de esta tesis. Aportando nuevas dimensiones que nos permitieron revisar nuestros propios modos de abordar la sistematización, produciendo otros y nuevos conocimientos que aún hoy nos desafían en el ámbito de la docencia y la investigación.

La sistematización de experiencias como metodología nos permitió concretamente poder reflexionar sobre lo realizado, para generar teoría desde la praxis y producir nuevos saberes sobre la práctica que llevamos adelante, desde una mirada reflexiva que trascendiera las perspectivas de evaluación tradicional. Perspectiva desde la cual se ha mirado en forma hegemónica la práctica, los programas y proyectos en los territorios que son "medidos" en tanto resultados tangibles, pero que poco nos dicen de las transformaciones vinculadas a aquello que no se puede valorar en términos cuantificables.

En tal sentido, nos centraremos aquí en trabajar sobre las etapas y las metodologías propias de este enfoque que es el que hemos puesto en práctica sobre el caso que estamos abordando, Rafaela Más Sustentable.

La experiencia está preñada de conocimientos, pero las demandas de la acción muchas veces impiden a las y los actores percibir claramente la manera en que los cambios en la práctica son consecuencia de los saberes que van adquiriendo. Al responder a problemas que exigen enfrentamiento rápido e inmediato, estos procesos no siempre son conscientes $y$, por tanto, no dan lugar a un conocimiento ordenado, fundamentado y transmisible. La sistematización de experiencias, justamente, pretende explicitar, organizar y, por tanto, hacer comunicables, los saberes adquiridos en la experiencia, convirtiéndolos, por consiguiente, en conocimientos producto de una reflexión crítica sobre la práctica (Barnechea \& Morgan, 2007).

\subsection{Las “etapas” de la Sistematización de Experiencias}

En este punto vamos a hacer referencia entonces a algunos elementos concretos y dimensiones acerca de cómo realizamos un proceso de sistematización desde el enfoque del Desarrollo Territorial, en este caso de la experiencia que estamos tomando para este trabajo de tesis.

El proceso de sistematización implica una serie de etapas o momentos. En tal sentido, hemos propuesto y desarrollado estos momentos a los fines de "orientar" el proceso, sabiendo que pueden existir otras aproximaciones o que estas mismas pueden tener zonas grises entre ellas ya que deben ser flexibles frente a la realidad. Lejos de querer ofrecer una "receta" para llevar adelante este proceso, planteamos la sistematización como una actividad contextual, donde ciertos elementos del entorno marcan su influencia en el proceso y por lo tanto en el "producto final", tal como ocurre con el caso que estamos abordando. Dicho esto, es imposible pensar en metodologías únicas que nos marquen de manera estricta los pasos a seguir, pero sí podemos plantear algunas etapas que podrían tenerse en cuenta a la hora de iniciar una sistematización. 
Cuando hablamos de elementos del entorno, nos referimos al modelo de gobernanza establecido en el territorio donde se lleva adelante la experiencia, a la capacidad de sus actores de propiciar ámbitos de diálogo, de reflexión y planificación.

Otro elemento clave en este proceso es abordar la sistematización como experiencia de aprendizaje, en donde los procesos de aprendizajes no se llevan adelante solamente en el aula, sino que se construyen junto a las y los actores del territorio.

Como se ha planteado, existen elementos intangibles del entorno que favorecen o perjudican la puesta en marcha de un proceso de sistematización, en este caso, en el marco de una actividad académica. La cultura del diálogo, los liderazgos, la confianza entre actores del territorio, las relaciones de poder, la estrategia de desarrollo del territorio, terminan siendo factores influyentes y que se deben tener en cuenta a la hora de iniciar el camino de la sistematización basada en el diálogo.

Si bien este apartado no pretende ofrecer recetas o fórmulas absolutas sobre sistematización de experiencias, sí podría establecer algunas pautas para llevar adelante el proceso, a través de la identificación y descripción de algunas fases o momentos importantes que son las que hemos llevado adelante y de las cuales hemos aprendido. Cada uno de estos momentos guarda relación entre sí y forman parte de un sistema o de un todo. Esto significa que no podemos concebir un momento sin el anterior o el posterior, y mucho menos abordar cada una de estas fases sin tener en cuenta los propósitos y objetivos planteados previos al inicio de la sistematización. (Centro de Estudios para la Educación Popular CEPEP, 2010)

El proceso de sistematización debe entenderse como algo dinámico y flexible, que sea capaz de adaptarse a las necesidades de las y los actores y contextos. En tal sentido, un momento nunca debe considerarse acabado, por el contrario, debemos dejar abierta la posibilidad de regresar a él, atendiendo a las necesidades que surjan durante el desarrollo del mismo proceso.

\section{2 ¿Cuáles son esos momentos del proceso de sistematización de experiencias que propusimos en este trabajo de tesis?}

Existen diferentes enfoques para desarrollar un proceso de sistematización de experiencias en DT. Intentamos abordar uno que nos permita llevar adelante un análisis que cumpla con los objetivos que se propone la actividad de sistematizar. Para ello, nos apoyamos en lecturas de diferentes autores e institutos de investigaciones, pero principalmente en la estructura que propone CEPEP (Cooperativa Centro de Estudios de la Educación Popular), y generamos nuestra propia herramienta, que es la que desarrollamos a continuación. 


\section{Conformar el equipo de sistematización:}

El primer aspecto a tener en cuenta es conformar el equipo de sistematización. Si bien suele haber un facilitador o facilitadora que coordina el proceso es importante desde el inicio contar y prever la participación de las y los actores que participan del proyecto. Se sugiere que quien coordina haya formado parte de la experiencia, ya que siempre se es parte de un proceso anterior. Este rol de coordinador o coordinadora puede rotar entre las y los distintos miembros del equipo, y hasta es saludable que esto ocurra, de manera tal que todos y todas asuman la tarea de coordinación y seguimiento del proceso en algún momento.

En algunos casos y dependiendo de la experiencia a sistematizar, esta mirada de las y los actores involucrados en la experiencia puede combinarse con el aporte de una o un actor externo (por ejemplo, por su conocimiento de la temática específica del proyecto).

El punto de partida de la sistematización no necesariamente ocurre -cronológicamente hablando- una vez finalizada la experiencia que va a ser el objeto de la sistematización. Es decir que el registro puede ser ex ante (si se define la sistematización como parte de un proyecto desde el inicio), durante o ex post y es recomendable que sea una dimensión presente desde el diseño de una experiencia (ya sea un proyecto o proceso de formación). Es importante remarcar que sistematizar es un proceso participativo, que se espera que lo realicen las y los mismos actores directos de la experiencia.

Es probable que una sistematización llevada adelante por una o un profesional "externo" con mucha experiencia e idoneidad, dé como resultado un documento excelente desde el punto de vista técnico y metodológico. Pero aquel que pueda ser llevado a cabo por las y los mismos actores permitirá dotar de nuevas capacidades a las y los involucrados, y de esta manera es probable que la sistematización se pueda ir transformando en un hábito, que genere nuevos conocimientos a partir nuestras propias prácticas. Si esto se logra, la sistematización de experiencias puede llegar a ser la base de un verdadero sistema de gestión del conocimiento acumulado por diversos actores del territorio.

Es importante destacar que esta posición no pretende instalar que el conocimiento necesario para desarrollar un territorio está contenido en el seno de las y los actores locales, y que por lo tanto el conocimiento externo, incluyendo el conocimiento técnico y científico, carece de relevancia. Por el contrario, pensamos que buena parte de la capacidad de una comunidad local para tomar decisiones y sostener procesos de aprendizaje, tiene que ver precisamente con su habilidad para interactuar, comunicarse y establecer relaciones con agentes externos de todo tipo. El desarrollo de las capacidades de aprender y de tomar decisiones, incluye por cierto el diálogo entre sistemas de conocimientos distintos. (Jara, 1994) 


\section{Proyecto de sistematización de la experiencia (plan de trabajo).}

El equipo de sistematización deberá llevar adelante un plan de trabajo, donde se definan las actividades a ejecutar en cada uno de los momentos. Además, todas y todos los integrantes del equipo deberán ser conscientes del camino a recorrer y comprometerse con el mismo. De nada servirá abordar esta metodología si no contamos desde el momento cero, con el compromiso de aportar tiempos y recursos por parte de las y los actores intervinientes. De aquí la importancia de establecer buenos espacios de diálogo para generar los acuerdos necesarios previo a la puesta en marcha de las actividades. Todas y todos los actores deberán conocer el camino a transitar.

Los componentes básicos de un plan o proyecto de sistematización podrían ser: título del proyecto, introducción, objetivos, justificación del proyecto de sistematización, ejes centrales de la sistematización. En este momento, se define para qué queremos sistematizar, qué aspectos centrales de esa experiencia nos interesa recuperar. Los ejes funcionarán como hilos conductores y atraviesan la experiencia en todo el proceso. Abarcan los propósitos, son más amplios, y pueden vincularse, por ejemplo, a nuevas capacidades territoriales, novedosos procesos de organización y gestión, nivel de participación ciudadana, modelos de comunicación o gestión de conflictos, nuevas prácticas e innovaciones en procesos productivos y/o sociales, modelos de gestión colaborativos, etc.).

\section{Reconstrucción de la experiencia (Memoria):}

En este momento se recupera de forma ordenada (cronológicamente, por etapas, por temáticas según el equipo lo defina) lo que sucedió y como sucedió, se clasifica la información disponible y se identifican las etapas del proceso. Para esto es fundamental organizar la información en forma clara y sencilla, basándose en todos los registros posibles. Se pueden utilizar registros que se hicieron durante la experiencia, o generar nueva información.

Es importante aquí señalar la relevancia de generar herramientas que permitan recuperar las voces de las y los participantes, tomando notas durante la experiencia, pero también cotejando con una mirada retrospectiva de la misma. Las fuentes de información en esta etapa pueden ser: informes escritos, reportajes, artículos periodísticos, revistas, minutas de reuniones, declaraciones, documentales audiovisuales, programas de radio y televisión, testimoniales, informantes claves, fotografías, etc. Todas las fuentes deben ser debidamente referenciadas en la redacción de la memoria.

En este momento es importante (aunque difícil) no hacer valoraciones de lo sucedido ni fijar posiciones críticas. En todo caso, se recomienda en esta etapa tomar nota de estos puntos de vista, y retomarlos cuando iniciemos la fase de análisis e interpretación crítica. 
Elementos a tener en cuenta a la hora de redactar la memoria:

- Título de la experiencia.

- Localización geográfica

- Antecedentes

- Identificación de actores intervinientes

- Fundamentación desde el enfoque del Desarrollo Territorial

- Objetivos generales y específicos de la experiencia: ¿Qué problema intentaba resolver? ¿A quién/es estaban dirigidas las acciones?

- Proceso de intervención: descripción de las actividades desarrolladas - líneas de acción.

- Principales resultados de la experiencia: cuantitativos y cualitativos.

Adicionalmente, se plantean algunos interrogantes que pueden ayudarnos a reconstruir la experiencia:

- ¿Cómo surgió el proyecto? (especialmente dar cuenta de las alianzas interinstitucionales o intersectoriales que pueden haberlo originado, las necesidades del territorio, las tradiciones y dinámicas de la región en que se inscribe, las dimensiones identitarias y culturales, económicas, políticas y sociales en donde se enmarca, otros)

- ¿Cuál ha sido la situación que le dio origen? (identificación de un problema que se quiso resolver, una oportunidad para mejorar algún aspecto del territorio, la finalización de un proyecto desde donde surge una temática nueva a abordar, la propuesta de un organismo de financiación a través de una línea específica, otros)

- ¿Quiénes son las y los actores que participan? (Identificar las y los actores más relevantes y sus perspectivas en relación al proyecto, recuperando las distintas miradas de los destinatarios de las acciones y de las y los facilitadores de los procesos).

- ¿Cuáles son los objetivos generales y específicos?

- ¿Cuál es la fundamentación del proyecto? (tanto vinculada al enfoque DT como de los principales conceptos clave que el proyecto aborda)

• ¿Cuáles son las principales líneas de acción implementadas y cómo han surgido?

- ¿Qué metodologías se emplean o han empleado para el desarrollo del proyecto? (talleres, grupos focales, encuestas, entrevistas, mesas de discusión, reuniones, visitas, etc.)

- ¿Cuáles han sido los principales resultados alcanzados a partir de la puesta en marcha del proyecto?

- ¿Cuáles han sido los medios y recursos (humanos, materiales y financieros) empleados y cómo se han gestionado?

• ¿Cuáles han sido los factores del contexto que facilitaron o dificultaron el proceso? 


\section{Análisis e interpretación de lo sucedido: procesos de diálogo en la sistematización}

Como lo hemos anticipado en el apartado sobre las categorías conceptuales, teniendo en cuenta que se ponen en permanente relación con las dimensiones metodológicas en el proceso de sistematización de experiencias, esta etapa corresponde al momento más importante, desde nuestra perspectiva, que tiene que ver con una instancia reflexiva y analítica de la experiencia objeto de análisis.

Para ello, recuperamos nuevamente la perspectiva de la Investigación - Acción Participativa (IAP) que enfatiza en la relevancia de que este tipo de procesos de aprendizaje no lo hacemos las y los investigadores solamente, obteniendo conclusiones a partir de nuestras observaciones, sino que el conocimiento es una construcción colectiva, un proceso de co construcción (Costamagna y Larrea, 2015).

Desde este marco entonces, para trabajar sobre el análisis, la interpretación y los aprendizajes generados en la experiencia de Rafaela Más Sustentable, es fundamental la construcción de espacios de diálogo con las y los actores, en donde resulta imposible separar la reflexión de la acción, que es praxis (Freire, 1997). El diálogo entonces se constituye como dimensión central, trabajando en clave de reconocimiento (Huergo, 2003) de los saberes de las y los actores del territorio y es hacia ese lugar que apunta a orientarse nuestro trabajo.

Metodológicamente, en este momento lo que intentamos es comprender por qué sucedió lo que sucedió que implica la reflexión crítica del proceso mirando también las relaciones, las tensiones y las contradicciones y se comienzan a identificar más claramente los aprendizajes del proceso. Un punto importante aquí es no reducir los aprendizajes a los resultados (si bien es importante detallar cómo éstos se han alcanzado) ni tampoco considerar que los aprendizajes son sólo aquellos aspectos que han sido exitosos, sino que también necesitamos problematizar los conflictos.

Otro aspecto a desarrollar en este apartado es la mirada a futuro, es decir a partir de los aprendizajes que nuevos proyectos, ideas e iniciativas pueden realizarse en ese territorio (que "semillas" se han sembrado hacia adelante que pueden traducirse en nuevas acciones y continuidades del proyecto realizado o en realización). El análisis crítico de la experiencia supone un ejercicio dialéctico de leer críticamente la teoría con base en la práctica e interpretar críticamente la práctica con base en la teoría. Este ejercicio de reflexión y de contraste entre la práctica y la teoría, generará aprendizajes significativos para el equipo de sistematización, se servirán de base para la elaboración de propuestas transformadoras, en el siguiente paso de la metodología sugerida.

Esta fase se entiende como un proceso de reflexión crítica, de interacción dialógica entre los y las protagonistas de la experiencia objeto de estudio. Estos puntos deben promover el desarrollo de respuestas argumentadas desde el diálogo crítico entre la teoría y la experiencia previamente reconstruida (memoria). 


\section{Desarrollo de propuestas transformadoras: etapa de co construcción.}

Una teoría sin práctica es solo un tema interesante del cual hablar y una práctica sin teoría es una acción ciega que no sabemos hacia dónde se dirige. La unidad dialéctica entre teoría y práctica, el saber y el hacer, se concreta en la sistematización de experiencias a través del desarrollo de propuestas transformadoras (Centro de Estudios para la Educación Popular CEPEP, 2010).

Una propuesta transformadora formulada en el contexto de un proceso de sistematización de experiencias es mucho más que una frase o idea que expresa una intencionalidad. Debe ser un cuerpo estructurado de ideas con una clara orientación transformadora y con una base de sustentación sólida, elaboradas por el equipo de sistematización en diálogo con las y los actores principales de la experiencia objeto de análisis.

En este sentido, una vez generado el proceso de diálogo con actores e identificados los aprendizajes y conocimientos producidos durante el proceso de análisis e interpretación crítica de la experiencia surgen las propuestas transformadoras.

\section{Aprendiendo desde la experiencia: construcción de nuevos conocimientos y la "vuelta a la academia".}

Durante el proceso de reflexión crítica de la experiencia se irán generando nuevos conocimientos y aprendizajes. Es importante que una vez identificados, podamos documentarlos para dejar plasmado lo que hemos aprendido durante todo el proceso, identificando y describiendo aspectos tales como teorías, conceptos, enfoques, paradigmas, actitudes, valores, etc.

Como ya lo hemos mencionado, recuperando la perspectiva de la IAP es interesante compartir estos procesos de acción, reflexión, acción en el marco del aula, en nuestro caso en el proceso mismo de la Maestría en Desarrollo Territorial. Poniendo el énfasis en que la academia es un actor más del proceso de construcción colectiva en donde se enriquecen los aprendizajes generados en el territorio.

\section{La comunicación de la experiencia:}

Esta etapa es de gran importancia porque de nada sirve sistematizar un proceso sino comunicamos los aprendizajes a quienes han formado parte del mismo y a otros y otras que se encuentren en procesos de similares características. Para ello hay que trabajar fuertemente en "hacerlos comunicables" y en la elaboración de diversos productos de comunicación que faciliten la gestión de conocimiento; para lo cual es necesario recurrir a formas diversas, creativas y adecuadas pensando en los interlocutores. 
Al llegar a esta última etapa, cada una de las personas que ha participado de los distintos momentos de la sistematización que anteceden a la sociabilización de los resultados, están apropiadas de los aprendizajes y conocimientos obtenidos por ser parte de todo el proceso. El desafío consiste en definir un conjunto de actividades que favorezcan la apropiación social de dichos resultados por parte de otros y otras actores sociales que no participaron en la construcción de estos, con el interés de que contribuyan a impulsar procesos transformadores de sus realidades, espacios o contextos (sabiendo que estos espacios o contextos son distintos y que las propuestas transformadoras no son transferibles de un territorio a otro)

Tanto los procesos de comunicación como la sistematización desde el DT, poseen un importante diferencial si ambos procesos se vinculan directamente con las y los actores, que las y los sujetos sean partícipes como protagonistas y no espectadores. Requiere de un ejercicio permanente y de abrir espacios en dónde abordar esta perspectiva, estamos acostumbrados y acostumbradas a ser receptores antes que productores de nuevos sentidos y aprendizajes. Por lo cual se requiere ir asumiendo colectivamente los desafíos que estas herramientas nos proponen, formándonos y liderando procesos.

\section{Algunas consideraciones finales sobre la dimensión metodológica:}

Como consideraciones finales podemos mencionar que la sistematización de experiencias como enfoque y metodología nos resulta central para este trabajo de tesis, ya que funciona también como perspectiva política que recubre o da sentido al trabajo académico.

La sistematización de experiencias abona a una construcción de conocimiento con los otros y otras, donde nuestros mundos culturales, o mejor dicho para este momento de la tesis, nuestras reflexividades, como investigadores e investigadores, y la de aquellos y aquellas con quienes trabajamos, puedan estar puestas en tensión y ser recuperadas consolidando unas perspectivas teóricas que se nutran de mundos y prácticas que nos son propias.

Si en el trabajo de campo etnográfico la propuesta es el pasaje de la reflexividad del investigador a la del investigado (Guber, 2001), a partir de comprender sus propias formas de ser y hacer, aquí, la sistematización pretende el pasaje de la reflexividad de las y los sujetos que participaron en el proyecto a la conceptualización de modelos de trabajo y de análisis posteriores, que se basen en ella y por lo tanto en las formas de ser, hacer y sentir de quienes participaron.

Es por ello, que, a cada paso de este trabajo, el universo vocabular en términos de Paulo Freire (1997), el mundo cultural o la reflexividad como categorías equivalentes, se tornan fundamentales y su reconocimiento y recuperación, una decisión político epistemológica que debe intentar atravesar todo el relato. La sistematización de experiencias no llevará a formular directamente una teoría, pero podrá dar riquísimos insumos a otros esfuerzos de reflexión y conceptualización que apunten a ese resultado (Guber, 2001). 
Del mismo modo, se pretende aportar al campo comunicacional en general o más particularmente al de la planificación y gestión de procesos comunicacionales. Para ello también se debe tener en cuenta que un indicador de una buena sistematización podría ser el haber descubierto algo que no se sabía y tenerlo claramente identificado, así como sentir una satisfacción desafiante respecto a la práctica que realizamos, sabiendo que este ejercicio de sistematizar nos ha abierto la mente, el corazón y la sensibilidad hacia lo que hacemos y que, por lo tanto, es una gran alegría, como decía Freire, no sólo saber, "sino saber que sabemos; saber que no sabemos; saber que podemos saber más... lo cual es mucho más importante y placentero que sólo saber" (Guber, 2001).

La sistematización en el marco de la Educación Popular transformadora para mujeres y hombres, es un ejercicio de reflexividad que puede desarrollar habilidades cognitivas complejas, que permiten captar la mayor cantidad de variables, inundadas de subjetividad, ayudar a contextualizar sin determinaciones fijas, relacionar saberes con sentires y posibilitar la comprensión de problemas que cada día se van haciendo más y más globales y transformarlos para contribuir a mejorar la calidad de vida de las personas. 


\section{CAPÍtULO 3}

El inicio y la puesta enmarcha de la sistematización

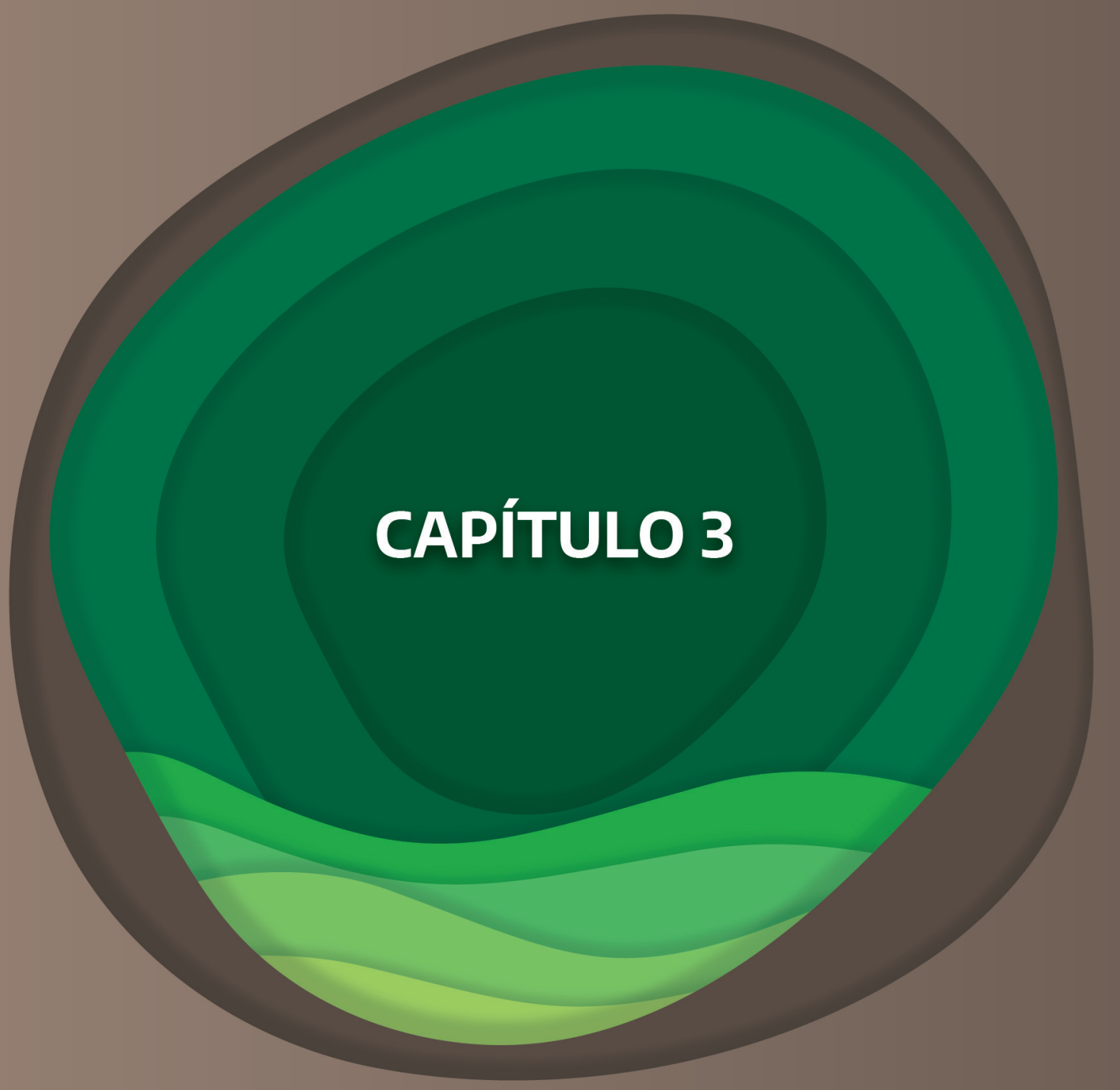




\section{CAPÍTULO 3.}

\section{El inicio y la puesta en marcha de la sistematización.}

En este capítulo nos proponemos desarrollar los primeros pasos para la realización de la sistematización de "Rafaela Más Sustentable". En tal sentido es que abordaremos, tal como se ha expresado en el apartado de la metodología, las etapas iniciales referidas a la definición del equipo de sistematización, el diseño del plan de trabajo y el proyecto de sistematización.

Es importante destacar que esta etapa y las siguientes, no han sido lineales y que existe en el desarrollo del proceso una distancia entre el enfoque y la puesta en práctica del mismo. En este sentido, iremos haciendo referencia y reflexionando acerca de las diversas estrategias que hemos asumido como desafíos y aprendizajes en el desarrollo de sistematizar esta práctica. Un aspecto inicial que vale la pena desarrollar lo constituye el punto de partida para la realización de la sistematización, es decir, ¿cómo surge la iniciativa? Es interesante recuperar este aspecto porque en nuestro caso la necesidad no aparece vinculada a la realización de un documento de sistematización de las características que estamos desarrollando, sino que más bien ha sido parte de un proceso de negociación.

El equipo de coordinación y de liderazgo del Instituto para el Desarrollo Sustentable, plantea la necesidad de contar con un documento que dé cuenta de la importancia de dicho organismo en el impulso de políticas públicas socioambientales en la ciudad de Rafaela y en la región, entendiendo que en el proceso de consolidación de un programa hacia un ente autárquico como es un Instituto, era relevante contar con un material comunicacional que acompañe este proceso. A partir de esa necesidad, y producto de la articulación interinstitucional que los organismos locales tienen como tradición en la ciudad de Rafaela, se traslada esta inquietud a la Maestría en Desarrollo Territorial y al Instituto de Investigaciones Praxis, ambos dependientes de la Universidad Tecnológica Nacional - Facultad Regional Rafaela.

Un primer desafío en este sentido, los constituyen las negociaciones previas al inicio de la sistematización que no aparecen explícitas (o demasiado explícitas) en la literatura que hemos referido tanto en el enfoque teórico como metodológico, pero que significan un aspecto absolutamente relevante. Diríamos aquí que es como un "punto cero" al inicio del proceso que se constituye como un momento clave y que tiene que ver con la decisión política e institucional para generar este tipo de experiencias.

Cuando hablamos de negociaciones previas nos referimos a que el requerimiento no era necesariamente de una sistematización, sino más bien un documento que muestre los logros alcanzados en los años de implementación, atendiendo a un formato comunicativo más orientado a la difusión de resultados y logros de gestión, que a una instancia de reflexión colectiva tal como el enfoque de sistematización de experiencias supone. 
En ese marco, se trabajó previamente al inicio que la importancia (política) de este trabajo no sólo radicaba en "mostrar" los logros y las "buenas prácticas" sino también, y con mayor énfasis, los aprendizajes, los conflictos, las tensiones y las contradicciones que son casi inherentes a la implementación de las políticas públicas, tal cual lo entendemos desde el marco conceptual de la comunicación en procesos de desarrollo territorial.

Paralelamente, y atendiendo al enfoque, se abordó en distintas reuniones de trabajo que la decisión política de avanzar hacia un proceso de sistematización de experiencias implicaba asumir otros compromisos. No era solo la tarea de brindar la información necesaria a quien realiza la sistematización o garantizar la llegada a las y los entrevistados, sino involucrarse en el proceso, entendiendo que cuando sistematizamos desde el enfoque del desarrollo territorial que abordamos, también estamos formando capacidades de manera colectiva (Costamagna, 2016), bajo la apuesta de adquirir una práctica que nos permita implementar hacia adelante y en futuras oportunidades este ejercicio de reflexión - acción.

A partir de estas negociaciones es que se avanza y se decide realizar la sistematización de "Rafaela Más Sustentable" que a continuación se desarrolla. Luego en las conclusiones retomaremos, tal como se mencionaba al inicio de este capítulo, las contradicciones y tensiones entre el enfoque y su puesta en práctica, enfatizando en nuestros propios aprendizajes como facilitadores de estos procesos.

\section{La conformación el equipo de sistematización:}

El primer aspecto a tener en cuenta, tal como se explicita en el apartado de la metodología, es la conformación del equipo de sistematización.

Si bien desde el enfoque que retomamos de Oscar Jara (1994) y del Centro de Estudios para la Educación Popular (2010) el equipo de sistematización está formado casi exclusivamente por las y los propios actores de la experiencia al igual que la coordinación del mismo, en este caso la facilitación del proceso estuvo a cargo de una persona "externa", quien es la autora de esta tesis, proveniente del equipo de la Maestría en Desarrollo Territorial y del Instituto Praxis y además, docente de los Talleres de Reflexión sobre la Praxis I y II en donde se trabaja sobre la sistematización de experiencias desde el enfoque del desarrollo territorial.

Esta decisión no fue azarosa y tuvo que ver con la importancia de que paralelamente al desarrollo del proceso, el equipo del Instituto para el Desarrollo Sustentable se fuera formando en la práctica de la sistematización, tanto teórica como metodológicamente. La idea entonces fue conformar un equipo que incluyera personas del ámbito de la universidad (Maestría en DT e Instituto Praxis) y personas que lideran el Instituto para el Desarrollo Sustentable dependiente de la Municipalidad de Rafaela. En ese marco el equipo de sistematización queda conformado de la siguiente manera y con los siguientes roles: 


\begin{tabular}{|l|l|l|}
\hline \multicolumn{3}{|c|}{ EQUIPO DE SISTEMATIZACIÓN } \\
\hline Participante & \multicolumn{1}{|c|}{ Institución de procedencia } & \multicolumn{1}{c|}{ Rol } \\
\hline $\begin{array}{l}\text { Pablo } \\
\text { Costamagna }\end{array}$ & $\begin{array}{l}\text { Director de la Maestría en DT y del Instituto } \\
\text { Praxis (UTN Facultad Regional Rafaela) }\end{array}$ & $\begin{array}{l}\text { Facilitador / Responsable } \\
\text { institucional }\end{array}$ \\
\hline $\begin{array}{l}\text { Eleonora } \\
\text { Spinelli }\end{array}$ & $\begin{array}{l}\text { Maestría en DT y del Instituto Praxis } \\
\text { (UTN Facultad Regional Rafaela) }\end{array}$ & $\begin{array}{l}\text { Coordinadora / Facilitadora / } \\
\text { Responsable del proyecto }\end{array}$ \\
\hline $\begin{array}{l}\text { María Paz } \\
\text { Caruso }\end{array}$ & $\begin{array}{l}\text { Directora del Instituto para el Desarrollo } \\
\text { Sustentable (Municipalidad de Rafaela) }\end{array}$ & $\begin{array}{l}\text { Facilitadora / Responsable } \\
\text { institucional }\end{array}$ \\
\hline $\begin{array}{l}\text { Alejandro } \\
\text { Jurado }\end{array}$ & $\begin{array}{l}\text { Asesor y creador del Instituto para el } \\
\text { Desarrollo Sustentable }\end{array}$ & $\begin{array}{l}\text { Facilitador / Responsable } \\
\text { institucional }\end{array}$ \\
\hline
\end{tabular}

De esta forma, luego de varias reuniones de trabajo, queda conformado formalmente el equipo de sistematización que asume la responsabilidad de llevar adelante el proceso.

\section{El diseño del proyecto de sistematización de la experiencia (plan de trabajo).}

Una vez definido el equipo de sistematización y luego de acordar algunas cuestiones generales y relevantes acerca del sentido del proceso, desde la coordinación se trabajó en la elaboración de un plan de trabajo y un proyecto de sistematización que recogiera y diera cuenta de todos los aspectos relevantes que pretendíamos llevar a cabo y, en donde, además, queden claros los compromisos asumidos para iniciar el proceso.

Si bien existen propuestas varias para realizar el proyecto / plan de trabajo para la sistematización, tal como se especifica en el apartado metodológico de este trabajo de tesis, como equipo optamos por la propuesta que desarrollamos a continuación y que surgió del acuerdo del conjunto de participantes de la sistematización.

\section{PROYECTO DE SISTEMATIZACIÓN - RAFAELA MÁS SUSTENTABLE}

\section{Introducción}

Para iniciar una sistematización en primer lugar nos planteamos tres preguntas claves como ejes ordenadores para abordar la experiencia:

1.) ¿Para qué queremos sistematizar? Con esta pregunta nos referimos al sentido, la utilidad, el proceso y resultado que esperamos obtener. En este caso particular el foco se encuentra puesto especialmente en dar cuenta no sólo de las acciones y las líneas de trabajo implementadas y el modo en que éstas se fueron gestando y articulando; sino también a dar cuenta de un marco conceptual y una modalidad de gestión en la que se visualicen las y los actores y las y los facilitadores de los procesos generados. Por tal motivo es interesante mencionar que la perspectiva desde la cual se realizará la sistematización de esta experiencia parte del enfoque pedagógico y la investigación acción (EPIA) para el desarrollo territorial como modo de producir nuevos conocimientos vinculados a las prácticas y orientados a la acción, recuperando centralmente la mirada de las y los actores involucrados. 
2) ¿Qué experiencias queremos sistematizar? En este punto se seleccionan experiencias concretas, delimitando el lugar, el tiempo y su desarrollo. Los criterios de selección pueden ser muy variados y dependen de los objetivos, del contexto, del tipo de experiencia, entre otros. Para este caso se tomará el caso del Programa Rafaela más Sustentable, desde sus orígenes en el marco del Programa de Competitividad Territorial (BID -FOMIN) en el año 2009 en el ámbito de la Agencia de Innovación y Desarrollo de Rafaela (ACDICAR); hasta su reciente transformación en Instituto para el Desarrollo Sustentable como ente autárquico, dependiente de la Municipalidad de Rafaela.

3) ¿Qué aspectos centrales de esas experiencias nos interesa sistematizar? Aquí lo que se pretende es fijar el eje de la sistematización. En el caso que nos ocupa el eje estará puesto en la reconstrucción del proceso, poniendo especial énfasis en las articulaciones con los actores, los diálogos, la perspectiva de trabajo y las modalidades de gestión en el territorio, así como también las temáticas innovadoras en relación a las problemáticas del medio ambiente desde el enfoque del desarrollo territorial.

\section{Etapas de trabajo propuestas:}

\section{Primera etapa: Reconstrucción de la experiencia y del proceso realizado (Memoria)}

En esta primera etapa se recuperará de forma ordenada (cronológicamente, por etapas, por temáticas según se defina) lo que sucedió y como sucedió, se clasifica la información disponible y se identifican los momentos del proceso. Para esto es fundamental organizar la información en forma clara y sencilla, basándose en todos los registros posibles. Consiste en recoger una visión global de los principales acontecimientos. Ya que los hechos "fueron vividos" será importante dejar constancia de todas aquellas interpretaciones que se presenten en su reconstrucción. Para ello podremos incluir todos aquellos acontecimientos que por el contexto (local, político, etc.) se puedan asociar a ellos.

A fin de organizar la reconstrucción de la experiencia y la escritura se han definido los siguientes ejes a tener en cuenta:

\section{Antecedentes para la creación, origen y surgimiento de Rafaela Más Sustentable:}

En este apartado se relatan las experiencias previas o antecedentes en las temáticas ambientales que dan lugar y propician la creación de este Programa en el contexto particular de la localidad de Rafaela por sus propias tradiciones vinculadas a la temática del desarrollo territorial. Un hito lo constituye en este sentido el Programa de Competitividad Territorial de la Región Central de Santa Fe (BID - FOMIN).

\section{Alianzas e instituciones involucradas para su creación y realización:}

Se describe brevemente el marco institucional en el que se inscribe el Programa / Instituto (instituciones participantes públicas y privadas, alianzas y vinculaciones que hicieron posible el surgimiento de la iniciativa)

\section{Localización geográfica:}

Se describe el territorio concreto en donde se inscribe el proceso, sus características principales teniendo en cuenta un destinatario amplio que cuente con información para conocer cuáles 
han sido las condiciones de posibilidad para que este experiencia se de en este territorio en particular.

\section{Objetivos generales y específicos:}

Consignar los objetivos generales y específicos que fueran definidos en la conformación y creación del Programa y del Instituto.

\section{Fundamentos y enfoque general:}

Aquí se explicitan los puntos de partida y las problemáticas que dan origen a Rafaela Más Sustentable (un diagnóstico de la situación que por la temática que aborda no sólo debe contemplar la realidad local, sino vincularse a una escala más amplia).

Se desarrolla también el enfoque conceptual sobre el que se enmarca y como entiende y aborda la temática del ambiente y las políticas socioambientales en el marco del enfoque del desarrollo territorial. También es importante aquí hacer alguna referencia en relación a prácticas innovadoras respecto al perfil de gestión y las estrategias de articulación tanto inter institucionales como público - privadas a partir de las cuales se implementa.

\section{Beneficiarios y beneficiarias directos e indirectos:}

Describir y caracterizar brevemente los perfiles de las y los beneficiarios (directos e indirectos) y el impacto que poseen sus acciones en términos del alcance a la población.

\section{Mapa de actores:}

Realizar un mapa de las y los principales actores intervinientes y sus modalidades de participación, enfatizando las procedencias (sistema científico tecnológico, organismos del estado en sus diferentes niveles, empresarios, gremiales empresarias, sistema educativo, organizaciones sociales y de la sociedad civil, entre otros)

\section{Líneas de acción planteadas}

Describir las acciones y líneas de trabajo planteadas y ejecutadas en el marco de Rafaela Más Sustentable, su surgimiento y definición. En este caso: - Gestión integral de residuos, Educación y comunicación ambiental, -Eficiencia y promoción del uso de energías alternativas, - Verde urbano y biodiversidad, - Cuidado del agua y producción local, - Movilidad sustentable.

\section{Estrategias de intervención}

En este caso se desarrollarán los modos y las metodologías empleadas para la realización de las acciones, prestando especial atención a las propuestas innovadoras y participativas.

\section{Principales resultados alcanzados}

Sedesarrollaránlosprincipalesresultadosalcanzadosoenprocesoysuimpactoenelcontextolocal

\section{Segunda etapa: Trabajo de campo a partir de entrevistas y diálogos con actores}

En función del análisis y el diagnóstico de la primera etapa de trabajo, y a partir de un primer proceso de diálogo con actores clave, se da paso al segundo momento en el que se realiza una 
tarea de encuentro con diferentes referentes del territorio identificados como representativos del proceso acontecido. Sobre la base de los ejes centrales relevados, se estructura una entrevista en profundidad en la que se recuperan los principales temas en primera persona, promoviendo la incorporación de la voz de las y los protagonistas del proceso.

También en este momento no sólo se recupera la perspectiva de las y los actores sino también se da búsqueda a aquella información faltante que sea necesario para completar la etapa de la memoria.

En este momento se indaga sobre: la situación inicial y su contexto, el proceso vivido por las y los actores, la situación actual, los hallazgos, las conclusiones y recomendaciones que surgen del análisis de la experiencia, los aprendizajes.

En este punto también es importante aclarar que en la etapa de diálogo y entrevistas con actores claves no sólo se buscará su perspectiva sobre los procesos realizados; sino que también se indagará en los puntos de tensión, los conflictos que puedan haber surgido, las negociaciones propias de este tipo de procesos y las soluciones conjuntas que se han generado para la resolución de los problemas que hayan podido surgir en el camino. La intencionalidad con este ítem tiene que ver con recuperar que las iniciativas de estas características también atraviesan situaciones conflictivas que generalmente se traducen en nuevos aprendizajes para compartir con otros.

\section{Tercera etapa: Análisis de la experiencia}

Esta es la etapa reflexiva de la experiencia para comprender por qué sucedió lo que sucedió. Implica la reflexión crítica del proceso mirando también las relaciones, las tensiones y las contradicciones y principalmente porque se identifican claramente los principales aprendizajes. Un punto importante aquí es no reducir únicamente los aprendizajes a los resultados (si bien es importante detallar cómo éstos se han alcanzado) ni tampoco considerar que los aprendizajes son sólo aquellos aspectos que han sido exitosos, sino que también necesitamos problematizar los conflictos y cómo se han elaborado, superado o no.

A partir de identificar estos elementos en términos de aprendizajes se puede trabajar a partir de ejes o preguntas críticas que nos ayuden a identificarlos. Estos aprendizajes surgen del proceso de la memoria, pero principalmente del diálogo con los actores.

\section{Cuarta Etapa: Redacción final de la experiencia}

Si bien se va trabajando con documentos parciales que se van elaborando durante el proceso, luego se destina un tiempo para la redacción final de la experiencia teniendo en cuenta que no sea de una extensión excesiva, que se presente en forma ordenada y comprensible y en un formato de diseño amigable que permita destacar la información y los aprendizajes más importantes. 
CRONOGRAMA PRELIMINAR PROPUESTO

\begin{tabular}{|c|c|c|c|c|c|c|c|}
\hline ETAPAS & $\begin{array}{l}\text { Mes } \\
1\end{array}$ & $\begin{array}{l}\text { Mes } \\
2\end{array}$ & $\begin{array}{l}\text { Mes } \\
3\end{array}$ & $\begin{array}{l}\text { Mes } \\
4\end{array}$ & $\begin{array}{l}\text { Mes } \\
5\end{array}$ & $\begin{array}{l}\text { Mes } \\
6\end{array}$ & Mes 7 \\
\hline $\begin{array}{l}\text { Recopilación de materiales y } \\
\text { antecedentes }\end{array}$ & & & & & & & \\
\hline Elaboración de la Memoria & & & & & & & \\
\hline $\begin{array}{l}\text { Elaboración de guiones y real- } \\
\text { ización de trabajo de campo }\end{array}$ & & & & & & & \\
\hline $\begin{array}{l}\text { Análisis de la experiencia } \\
\text { (desgravación y documento } \\
\text { de aprendizajes) }\end{array}$ & & & & & & & \\
\hline $\begin{array}{l}\text { Redacción de primera versión } \\
\text { del documento }\end{array}$ & & & & & & & \\
\hline Socialización y ajustes & & & & & & & \\
\hline Redacción final & & & & & & & \\
\hline
\end{tabular}

Luego de trabajar sobre el proyecto de sistematización e intercambiar con el equipo sus alcances, metodología y objetivos comenzamos a avanzar en el desarrollo del primer documento de reconstrucción histórica de la experiencia (la Memoria) que presentamos en el siguiente capítulo. 


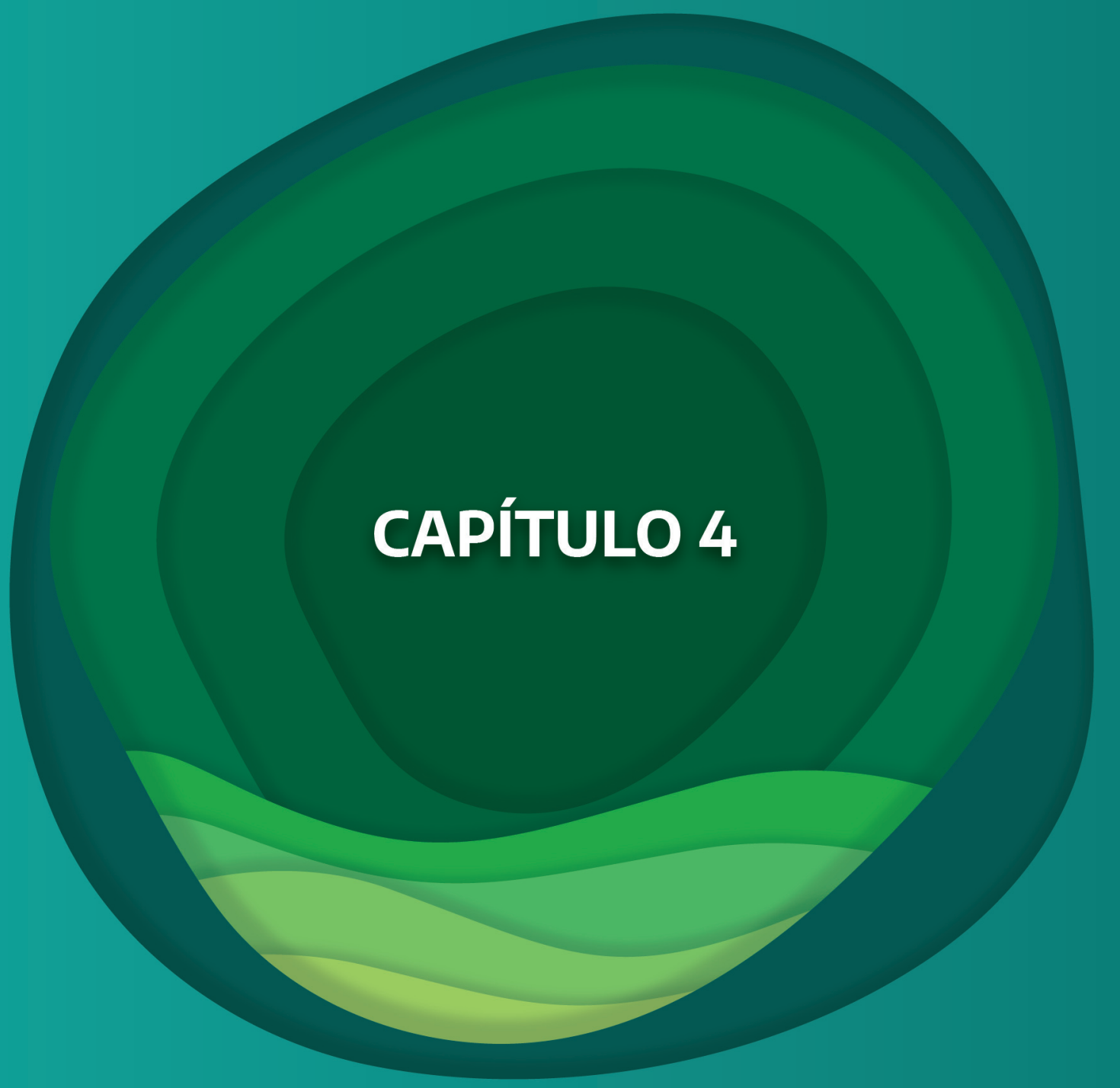

Memoria de la experiencia "Rafaela más Sustentable" 


\section{CAPÍTULO 4.}

\section{Memoria de la experiencia "Rafaela más Sustentable".}

Uno de los primeros aspectos como punto de partida de esta sistematización tiene que ver con el desarrollo de lo que hemos denominado en el apartado metodológico "Memoria de la experiencia". El objetivo de esta etapa apunta a recuperar el proceso e historizar el modo en que se ha ido desarrollando Rafaela Más Sustentable en el territorio, marcando los principales hitos y una visión global de los principales acontecimientos.

También se trata de contextualizar y situar la experiencia, para lo cual desde el punto de vista metodológico en esta instancia se toman como fuentes de análisis toda la documentación y los materiales previos disponibles sobre el Programa/Instituto (libro, videos del canal de You Tube, página web, documentos de presentación a premios, entrevistas, notas periodísticas y bibliografía de referencia) e información adicional que se ha requerido a través de informantes claves y medios de comunicación.

Esta fase da paso y es insumo hacia otra de profundización de procesos de diálogo a partir de entrevistas y talleres con diversas y diversos actores del territorio, en donde se establecen reflexiones a modo de tomar aprendizajes y nuevos desafíos hacia adelante, objetivo central de la sistematización.

A fin de organizar la reconstrucción de la experiencia y la escritura se han definido ejes temáticos de la memoria que permitan dar cuenta de los procesos y el modo en que éstos han acontecido y que desarrollamos a continuación.

\section{Antecedentes para la creación, origen y surgimiento del Programa Rafaela Más Sustentable.}

Para comenzar a situar la experiencia es importante dar cuenta de los antecedentes y trayectorias previas vinculadas a las temáticas ambientales que dan lugar y propician la creación de este Programa en el contexto particular de la localidad de Rafaela.

Un hito lo constituye en este sentido el Programa de Competitividad Territorial de la Región Central de Santa Fe (BID - FOMIN) ejecutado por la Agencia de Innovación y Desarrollo de Rafaela (ACDICAR), asociación civil sin fines de lucro de constitución público- privada, e impulsado a partir de la iniciativa del Centro Comercial e Industrial de Rafaela y Región (CCIRR) y la Municipalidad de Rafaela. Desde el diseño y la puesta en práctica de este Programa en el año 2007 el ambiente y la energía se presentan como ejes relevantes en el marco de los comités (en tanto líneas de actuación) de producción primaria y metalmecánico que trabajan la mejora de las distintas cadenas de valor. 
Luego con el devenir de las acciones del Programa y a partir de diagnósticos compartidos de la importancia de estos temas vinculados al desarrollo territorial de la región, estos ejes se vuelven transversales, y se institucionalizan con entidad propia como una nueva línea de actuación denominada Energía, Ambiente y Economía Verde.

En el desarrollo de esta línea fue clave la contratación de un consultor externo, Alejandro Jurado, quien coordinó el Programa Rafaela Más Sustentable y continúa asesorando permanentemente las actividades y políticas referidas al tema. Este perfil rompe con la dinámica del consultor tradicional basado en un abordaje específico y sectorial del tema o enfocado sólo hacia la normativa, para situarse desde un modelo de trabajo basado en los diálogos, los procesos y con una mirada que puso el énfasis en el nexo entre la innovación, la investigación y la vinculación de procesos externos con el entramado local.

Desde este ámbito se promueve la participación activa de las y los actores locales logrando instalar en las agendas públicas y privadas temas importantes relacionados con la eficiencia energética, la gestión de los residuos y la incorporación de la sustentabilidad ambiental como una apuesta por la calidad y la competitividad territorial y empresarial (Alburquerque, 2011).

A partir de la ejecución de estas líneas de trabajo en el año 2009, y aún en el marco del Programa de Competitividad, se crea el Programa Rafaela + Sustentable desde donde se impulsan no sólo acciones específicas sino políticas a mediano y largo plazo. De esta etapa se destacan actividades y proyectos que comienzan a instalarse fuertemente en la agenda pública local, tales como: energías Renovables y el uso de energía solar con unidades demostrativas para el alumbrado público; el diseño del sistema de gestión de residuos industriales; el establecimiento de un carril de bicicletas; un plan de formación en empleos verdes, la ampliación de la Estación de Residuos Clasificados y preparación de un Punto Verde Móvil, proyecto de refuncionalización del relleno sanitario de Rafaela, diseño y construcción de una terraza verde en el Palacio Municipal, verde urbano y biodiversidad, educación ambiental, entre otros que luego se ampliarán en el transcurso del documento.

En el año 2010 la Municipalidad de Rafaela asume el desafío y el compromiso de liderar estas políticas e incorpora al Programa Rafaela + Sustentable $(R+S)$ a su estructura, específicamente en el ámbito de la Secretaría de Servicios, Espacios Públicos y Ambiente bajo el liderazgo de Marta Engler quien en ese entonces era la Secretaria de la mencionada área. Uno de los aspectos que es interesante señalar en este sentido es que permanece la impronta del Programa $R+S$ basado en el trabajo colaborativo, interinstitucional y transversal, impronta propia también del Programa de Competitividad Territorial. Se suma a este enfoque la importancia de la sostenibilidad de las acciones a través del liderazgo de las y los actores locales, en este caso de la Municipalidad de Rafaela, que asume esta línea como política pública.

A las acciones generadas a partir del impulso del estado local se le suman dimensiones importantes en términos de política pública como los son los nuevos marcos regulatorios 
traducidos en ordenanzas municipales como elementos estratégicos para la gestión. Tales como: la Ordenanza de Gestión Integral de Residuos Sólidos Urbanos de la ciudad de Rafaela (Ord. 4404 del año 2010), la de Gestión de Aceites Usados (Ord. 4439 del año 2011), la de creación de un Parque Tecnológico del reciclado de residuos (Ord. 4452 del año 2011), y la de Promoción e incorporación de sistemas de captación y utilización de energía solar (Ord. 4826/16), que van marcando un horizonte de política pública integral en materia de ambiente y desarrollo sustentable bajo las lógicas de la articulación interinstitucional y público - privada, dimensiones propias de un modelo de gestión innovador que Rafaela viene impulsando desde hace por lo menos dos décadas.

Más allá del impulso del Programa de Competitividad Territorial como antecedente más importante, podemos identificar la base generada desde la Municipalidad de Rafaela marcando un hecho muy importante en el año 2003: la compra del terreno y construcción del relleno sanitario en donde se comienza a desplegar una política de manejo de residuos (asegurando la disposición adecuada de los mismos y el cierre del basural a cielo abierto) y la planta de recupero en 2005 , formalizando a los recicladores urbanos en cooperativas de trabajo (Caruso, 2008).

Si bien es recién en el año 2010 que se diseña e implementa la Política de Gestión Integral y Transformación de Residuos, cristalizada en la Ordenanza GIRSU y en la Ordenanza de creación del Parque Tecnológico del Reciclado, tal como mencionamos con anterioridad. Estos antecedentes traducidos en acciones y políticas concretas comienzan a hacer evidente un nuevo paradigma de gestión de residuos que pone el foco en la reducción, su separación en origen, recolección diferenciada, tratamiento y valorización, evitando su inadecuada disposición final.

En líneas generales puede interpretarse que la temática de los residuos ha sido el eje transversal más fuerte que le ha dado impulso a las políticas vinculadas a los temas ambientales, pero que luego se han ido complejizando en nuevas oportunidades y alternativas abordadas de manera más integral e incorporando dimensiones que generan valor para un territorio competitivo e innovador. Ahora bien, es interesante también en este punto preguntarse por qué esta experiencia se da con determinadas características en este territorio en particular y no en otro. En este marco aparece otra dimensión entonces que vale la pena mencionar que tiene que ver con la tradición propia de una modalidad de gestión y de intervención en donde, según Costamagna (2016) "el diferencial de la ciudad (así como sucede en otras) es que se han construido capacidades para poder trabajar nuevos desafíos, eso es lo que se denomina el desarrollo territorial".

Entonces, retomando el planteo de Pablo Costamagna (2016), pueden identificarse algunos elementos que hacen posible construir políticas diferenciales en las temáticas ambientales y en el enfoque del desarrollo territorial; tales como: la decisión política de las y los dirigentes del sector público y privado por asumir que el ambiente sería un tema central en la agenda, la dinámica del sector empresarial, cuya base es el diálogo entre lo público y lo privado, 
atravesado por supuesto por discusiones y conflicto y, por último, la formación de capacidades de las y los actores del territorio, ya sea del sector privado, la universidad y el sector público.

Este crecimiento e impulso, a partir de estas modalidades de gestión y de acción en el territorio sumado a la decisión política de un nuevo Intendente, hizo posible que a fines de 2015 el Programa Rafaela Más Sustentable se transforme en el Instituto para el Desarrollo Sustentable (Ord. 4785 del 28 de diciembre de 2015) como resultado de los diálogos, debates y acciones conjuntas y bajo la necesidad de conformar un ente autárquico, dependiente de la Municipalidad de Rafaela, con mayores posibilidades de actuar y "con el objetivo de promover un modelo de desarrollo sustentable para la ciudad de Rafaela a partir de la preservación y mejora de la calidad ambiental desde y en la utilización de los recursos naturales y la participación de la ciudadanía de los procesos de toma de decisiones, en condiciones equitativas". (Ord. 4785).

\section{Alianzas e instituciones involucradas para la creación y realización de Rafaela Más Sustentable}

Si bien en el apartado anterior se han mencionado los vínculos interinstitucionales que dan cuenta del surgimiento y las redes de Rafaela Más Sustentable, es interesante mencionar los modos en que estas relaciones han promovido la creación del Programa y la posterior conformación del Instituto.

Desde lo conceptual, la idea de la articulación y una nueva gobernanza guía las acciones del territorio. Es claro que la modalidad de gestión de las actividades vinculadas a las políticas ambientales, incrementadas por el impulso del Programa de Competitividad Territorial, ya venían siendo un ejercicio de articulación público - privada y de diálogos inter e intrainstitucionales. $Y$ es en este marco que el sector público asume el liderazgo del Programa y lo anuda a sus propias políticas públicas que venían de una tradición mayormente asociada a la problemática de los residuos. Si bien se localiza claramente una dependencia formal del organigrama (como lo es la Secretaría de Servicios, Espacios Públicos y Ambiente) se intenta darle continuidad a un enfoque transversal en el cual se involucran secretarías y áreas del municipio bajo la perspectiva de la interdisciplinaria que un Programa de estas características supone.

A esta articulación se suma el propio entramado institucional de Rafaela como es el caso del Centro Comercial e Industrial de Rafaela y la Región y sus cámaras empresariales, la Sociedad Rural de Rafaela, el sector científico y tecnológico a través del INTI Rafaela e INTI Lácteos y el INTA, la Asociación civil para el Desarrollo y la Innovación Competitiva Agencia Rafaela (ACDICAR), que ya venían trabajando en conjunto en esta y otras líneas.

También comienzan a vincularse a las actividades sectores claves como la comunidad educativa en todos sus niveles y la participación de la Universidad Tecnológica Nacional Facultad Regional Rafaela a través de la Maestría en Desarrollo Territorial y posteriormente 
con el Instituto Praxis, las organizaciones de la sociedad civil, los medios de comunicación, los Colegios Profesionales, las empresas de servicios públicos provincial EPE (energía) y ASSA (agua). Una participación clave la constituye por supuesto el sector privado- industrias, comercios, servicios a nivel individual que se van sumando a las campañas y, especialmente, a las propuestas de padrinazgos y compromiso.

Una novedad en relación a las alianzas y a las modalidades de articulación entre instituciones se genera a partir de la reciente transformación del Programa Rafaela Más Sustentable en el Instituto para el Desarrollo Sustentable, en donde se formaliza un nuevo organigrama en relación al funcionamiento del Instituto como ente autárquico municipal. Esta nueva figura otorga mayores libertades de acción y gestión vinculadas a las posibilidades de celebrar convenios y contratos y el manejo de un presupuesto propio.

Además, el Instituto también cobra relevancia como un espacio que promueva la innovación y la participación a partir de un nuevo modelo de gobernanza. Un elemento innovador en este sentido lo constituye la creación de un Consejo Ambiental como organismo de asistencia y asesoramiento cuyos miembros son: un representante por bloque del Consejo Municipal de Rafaela, uno por el Centro Comercial e Industrial de Rafaela y la Región, uno por la Sociedad Rural de Rafaela, uno por el Consejo de Pastores, uno por el Obispado de Rafaela, uno por la Federación de Entidades Vecinales y uno por Organizaciones no gubernamentales de la Sociedad Civil y la Confederación General del Trabajo (CGT). Si bien las decisiones de este Consejo son no vinculantes, supone un modo de gobernanza en donde los temas estratégicos, las decisiones y las políticas se someten al diálogo entre sectores.

\section{Localización y contexto}

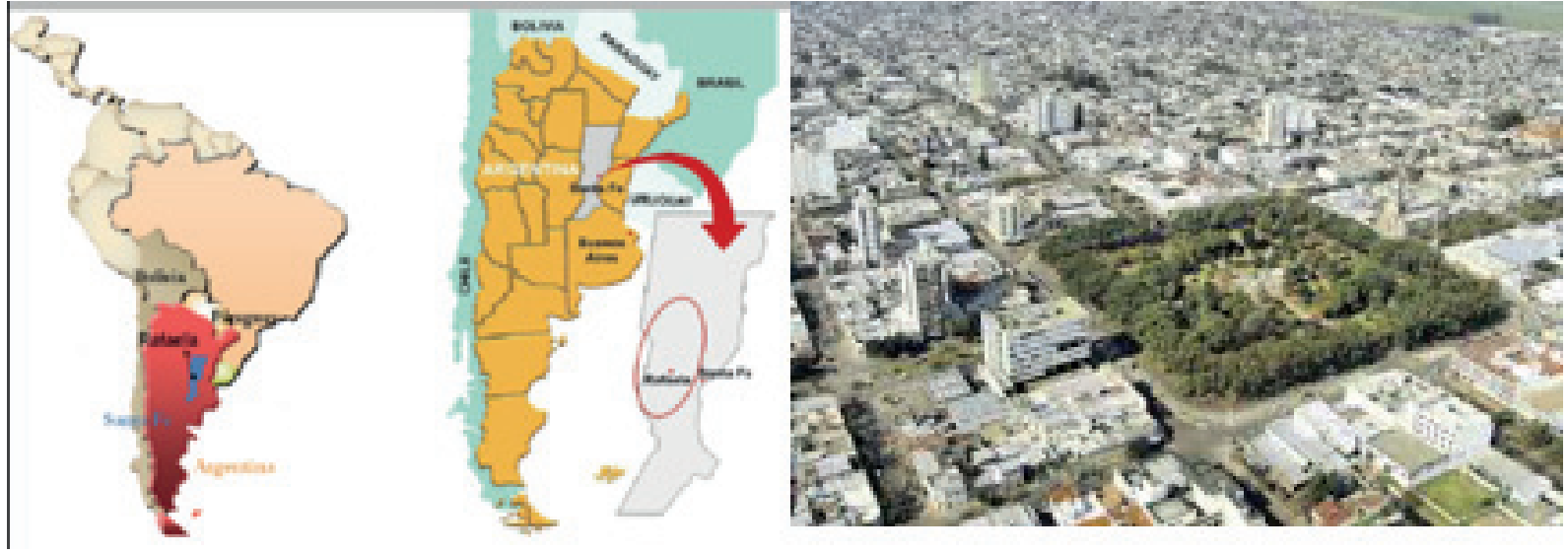

Para dar cuenta de porqué este tipo de iniciativas y políticas innovadoras son posibles de llevar adelante en un contexto particular, es interesante recuperar brevemente las características del entorno territorial y sus dimensiones económicas, políticas e institucionales; más aun teniendo en cuenta lo que representa Rafaela como caso emblemático y modelo en temas de desarrollo local (Alburquerque, 2010). 
La ciudad de Rafaela es cabecera del Departamento Castellanos y se ubica en el centro oeste de la provincia de Santa Fe, unos $90 \mathrm{Km}$. de la capital provincial y unos $540 \mathrm{Km}$ de la Capital Federal. Está emplazada en una Ilanura extensa, llamada Pampa Húmeda, formando parte de la Cuenca Lechera más importante de Sudamérica. Según el último Censo de Población Nacional, realizado en el 2010, la ciudad cuenta actualmente con 92.945 habitantes.

Rafaela fue una colonia agrícola surgida en el contexto del auge colonizador y económico de la década de 1880, caracterizado por una fuerte entrada de inmigrantes de origen europeofundamentalmente italianos del norte. En 1913 logró declararse ciudad, perfilándose como una localidad vinculada fuertemente con la cultura del trabajo, esfuerzo, crecimiento, producción e industrialización.

Constituye un polo de desarrollo industrial regional y es centro de una de las cuencas lecheras más importantes de Argentina y Sudamérica. En la región se encuentran 5 de las 6 empresas lácteas más importantes del país y dos de ellas están radicadas en la ciudad. Conjuntamente con este sector, se fueron desarrollando otros, tales como el frigorífico y el metalmecánico el cual, desde 1960 experimenta una notable expansión y donde es significativa la producción de maquinaria y equipamientos agrícolas, la fabricación de bienes de capital para la industria alimenticia y el sector autopartista. Esta multiplicidad de actividades productivas refleja el espíritu emprendedor de la región que se destaca, además de otros aspectos de sus ventajas competitivas.

Más allá de las dimensiones económicas y productivas que hacen al desarrollo del territorio, uno de los aspectos claves para entender las particularidades de Rafaela tiene que ver con el rol asumido por el Estado local a partir de la década del 90' donde comienza a generarse un nuevo modelo de gestión; basado en: la potenciación del trabajo conjunto entre los distintos sectores para definición y ejecución de políticas de desarrollo; el acercamiento del sector público - privado - educativo, la formación de las capacidades locales como eje estratégico; liderado por nuevo grupo de jóvenes dirigentes que entendía que la agenda del desarrollo no era una competencia exclusiva de la administración pública y que era determinante abrir espacios de participación (Costamagna y Ferraro, 2000). Otro aspecto en el proceso es el sector empresarial en su conjunto quién con dinámica propia además comenzará a compartir una mirada distinta de la administración pública, a la que ya no solo veía como un recaudador sino como un actor con el cual construir sinergias.

Una dimensión de importancia a señalar relacionada con los procesos de desarrollo de la ciudad, tiene que ver con la formación de las capacidades locales que se visualiza en la presencia y el rol protagónico de las instituciones educativas de diversos niveles, claramente vinculadas en relación al perfil económico y productivo de la región. La historia del territorio está vinculada a la formación donde las instituciones del sector educativo, en todos sus niveles, constituyen un factor relevante. 
A este sector se agregan también otros actores claves como son las instituciones científico - tecnológicas tales como el INTI, como Centro Tecnológico referente del sector industrial a partir de los servicios especializados que presta al entramado productivo de Rafaela y la región, y el INTA que cada vez se hacen más presentes en los distintos proyectos e iniciativas y participan activamente en las políticas locales.

En este conjunto de dimensiones tales como las relaciones de cooperación público- privadas, la planificación a mediano y largo plazo, las medidas innovadoras, la mirada de cadena, la internacionalización, el desarrollo institucional, la gestión del conocimiento y la formación de las capacidades locales, entre otras, es que se hace posible la innovación territorial. En donde se demuestra que no sólo el cuidado por el ambiente es un eje que claramente la ciudad está priorizando, sino que además las energías alternativas y la economía verde se constituyen también como renovados desafíos en términos de nuevas oportunidades de negocios que contribuyan a una ciudad cada vez más sustentable.

Esto ha podido visualizarse claramente en las últimas discusiones y debates sobre la Agenda Productiva Rafaela 2020 (Plan Estratégico) en donde la línea de Ambiente y Calidad de vida se constituye como uno de los ejes de discusión y definición de política a futuro.

\section{Objetivos generales y específicos de Rafaela Más Sustentable}

Respecto a los objetivos podemos identificar dos etapas diferentes: por un lado, los vinculados al Programa Rafaela Más Sustentable a partir de su creación en el año 2009 e institucionalización en la Municipalidad en el 2010. Y, por otro, los del Instituto para el Desarrollo Sustentable a partir de su creación por Ordenanza municipal a fines de 2015 en donde se amplían los mismos en relación a una escala mayor y una perspectiva de gestión a largo plazo de políticas públicas en materia ambiental.

\section{Programa Rafaela Más Sustentable:}

\section{Objetivo general:}

- Construir una ciudad más sustentable, en donde todas las actividades que se desarrollen sean sustentables tanto en lo ambiental, como en lo económico y en lo social. Esto se alinea a la política del municipio que gira en torno a dos ejes: la construcción de ciudadanía y la inclusión social.

\section{Objetivos específicos:}

- Potenciar la actividad económica y la creación de empresas vinculadas a la conservación o restablecimiento de la calidad ambiental (Economía Verde).

- Progresar en la cultura de la sostenibilidad mediante la educación y la comunicación ambiental. 
- Reducir la producción de residuos y fomentar la cultura de la reutilización y el reciclaje - Promover el ahorro energético, la eficiencia y el uso de energías renovables.

- Liderar los compromisos de mejora del medio ambiente y de lucha contra el cambio climático.

- Fomentar la producción y el consumo de alimentos de base local.

- Promover un espacio público de calidad y ampliar el verde urbano.

- Promover la movilidad sustentable.

\section{Instituto para el Desarrollo Sustentable:}

\section{Objetivo general:}

- Promover un modelo de desarrollo sustentable para la ciudad de Rafaela a partir de la preservación y mejora de la calidad ambiental desde y en la utilización de los recursos naturales y la participación de la ciudadanía de los procesos de toma de decisiones, en condiciones equitativas.

\section{Objetivos específicos:}

- Proponer políticas y diseñar programas, proyectos y planes tendientes a preservar, mejorar y/o restaurar la calidad ambiental y propender al desarrollo sustentable de la ciudad de Rafaela.

- Implementar acciones vinculadas a las diversas problemáticas ambientales que afectan o pueden afectar significativamente el equilibrio de los ecosistemas locales $\mathrm{y} / \mathrm{o}$ la calidad de vida de la población.

- Desarrollar acciones tendientes a diversificar la matriz energética local, promocionando la implementación progresiva de mecanismos de generación de energía por fuentes renovables, alternativas o no fósiles e implementando políticas orientadas al logro de la eficiencia energética en espacios y edificios públicos, así como en empresas, instituciones y hogares de la ciudad.

- Difundir y promover la aplicación de criterios y tecnologías de construcción sustentables. - Incentivar el ahorro y el uso eficiente del agua en espacios y edificios públicos, instituciones, empresas y hogares de la ciudad, promoviendo hábitos de consumo responsable y solidario de la misma, así como la ampliación y mejora del servicio de la red cloacal.

- Recuperar y generar nuevos espacios de verde urbano incrementando la cantidad de árboles en la ciudad, promocionando las especies autóctonas mejor adaptadas a las características del ambiente y fomentando la producción local de las mismas.

- Fomentar una nueva cultura de movilidad urbana, promocionando formas de movilidad sustentables.

- Promover e implementar programas de educación ambiental, como procesos permanentes de carácter interdisciplinario, destinados a la formación de una ciudadanía que reconozca valores, aclare conceptos y desarrolle conductas necesarias para una convivencia armónica con el ambiente circundante. A tales fines se prepondera a la suscripción de convenios con instituciones públicas y/o privadas locales, provinciales o nacionales. 
- Desarrollar un sistema de acceso a la información pública ambiental, que garantice el acceso libre y gratuito de la comunidad y fomente la participación ciudadana en los temas ambientales.

- Desarrollar programas e implementar acciones diversas que tiendan a promover el consumo sustentable.

- Promover políticas de preservación del patrimonio urbano y arquitectónico, del paisaje y de la calidad de los espacios públicos.

- Promover el dictado de normas de regulación y conservación, tendientes a preservar y/o mejorar la calidad ambiental de los habitantes de la ciudad de Rafaela.

- Desarrollar y revisar sistemas de medición e indicadores de desarrollo sostenible y cambio climático.

- Contar con material informativo y realizar campañas de concientización y difusión masiva de los lineamientos de la política ambiental municipal y promover el desarrollo de hábitos y conductas en la población que resulten amigables con el ambiente.

- Implementar una política de investigación y desarrollo en materia ambiental en la ciudad de Rafaela, estimulando la innovación tecnológica y la transferencia de conocimientos.

- Prestar asesoramiento y/o capacitación técnico - ambiental a funcionarios del Departamento Ejecutivo, el Concejo Municipal, empleados municipales y a la población en general, en forma directa o a través de la celebración de acuerdos y/o acuerdos con instituciones intermedias y empresas locales.

- Otorgar préstamos y desarrollar programas de financiamiento para favorecer la incorporación de tecnologías que brinden mayor sustentabilidad ambiental, en instituciones o personas jurídicas públicas o privadas de la ciudad.

A simple vista puede verse cómo se acrecientan las políticas, temáticas y ámbitos de actuación en la transformación del Programa a Instituto en donde la ordenanza formaliza quizás un crecimiento en las líneas de acción que ya pareciera venir sucediendo en la práctica concreta. La jerarquización del Programa R+S a Instituto supone trascender las actividades concretas (en los ejes de trabajo que se habían definido) para generar un espacio que asuma la coordinación y la gestión de una política pública integral en las temáticas ambientales de la ciudad.

Esto se visualiza claramente en la importancia y la legitimidad que se le da (en términos formales dado que seguramente esto se daba en la gestión y el día a día del accionar del Programa) a las vinculaciones con las instituciones del territorio en todos los lineamientos y en la incorporación de nuevos y más amplios objetivos tales como la investigación, la gestión del conocimiento, la formación de las capacidades locales, el acompañamiento de las acciones a través de la generación de nuevos marcos regulatorios y normativas que acompañen los cambios, entre otras. Y por otro lado también se legitima y jerarquiza un espacio que no existía formalmente en la estructura municipal. 


\section{Fundamentos y enfoque general de Rafaela Más Sustentable}

En este apartado nos interesa retomar el enfoque conceptual sobre el que se enmarca este Programa, es decir, como se entiende y aborda la temática del ambiente, las políticas socioambientales y su vinculación con el enfoque del desarrollo territorial. También es importante aquí hacer alguna referencia más actual en relación a marcos contextuales de carácter internacional tales como la "Encíclica Laudato Si, sobre el Cuidado de la casa común" elaborada por el Papa Francisco y el último Acuerdo sobre Cambio Climático en París, ambos sucesos del año 2015 , que de alguna manera van marcando la agenda y las políticas con una mirada hacia el futuro.

Si nos remitimos al año 2009 en donde surge formalmente "Rafaela Más Sustentable" en el marco del Programa de Competitividad Territorial (BID - FOMIN) y la Agencia de Desarrollo ACDICAR, los enfoques y perspectivas que sustentaban en ese entonces esta línea de acción se asociaban a la importancia de que ciudades de escala intermedia como Rafaela, a partir de la impronta de sus propias tradiciones culturales, políticas y territoriales, asumieran el desafío de abordar con mayor énfasis y compromiso las problemáticas ambientales contribuyendo a mejorar la calidad de vida de las personas, generando experiencias innovadoras que pudieran transformarse y replicarse.

En este marco el enfoque y la justificación del Programa R+S parte de considerar en términos macro que según Costamagna y Jurado (2010):

"hace falta cambiar la relación entre economía y naturaleza. Asegurar que la naturaleza siga proporcionando a la sociedad bienes y servicios como alimentos, agua limpia, suelo fértil, captura de carbono, regulación del clima, entre otros, es una prioridad. La sostenibilidad en el tiempo de estos servicios ambientales es básica para permitir para que las próximas generaciones puedan tener un desarrollo económico y sostenible en igualdad de oportunidades También es imprescindible en el mediano plazo transformar nuestro modo de producción y consumo: hacer un uso racional de los recursos conservando su capacidad de regeneración natural, avanzar hacia una producción más limpia y hacia el uso de energías renovables, eficientes y descentralizadas. Se deberán promover las actividades económicas que ayuden a cerrar los ciclos de la materia o que contribuyan a conservar/restablecer la calidad ambiental, por ejemplo, valorizando los residuos como materias primas de otros procesos productivos o diseñando productos que puedan reciclarse".

Desde esta perspectiva, no sólo se considera el desarrollo sustentable de las ciudades como un compromiso ético y político en relación al cuidado y la preservación del ambiente para las generaciones actuales y futuras, sino que también propone una mirada vinculada con la innovación y las nuevas oportunidades productivas que supone, aún en un contexto de crisis global, apostar por una economía verde que genere beneficios económicos (creación de nuevas empresas y emprendimientos productivos) y sociales (creación de nuevos trabajos, 
reducción de la pobreza). Para ello se plantea como pilares a la innovación, la concertación público - privada, el espíritu emprendedor y la combinación de iniciativas acompañados por políticas gubernamentales.

También se enfatiza en "una forma de hacer" fortaleciendo el gobierno relacional y propiciando la coordinación interna entre diferentes organismos, áreas y dependencias del municipio (vinculación intrainstitucional) y haciendo sinergias con instituciones de la ciudad (vinculación interinstitucional). Sus valores se constituyen a partir de: la participación, el trabajo en red, la capacidad para movilizar recursos y la articulación de redes de decisiones mixtas entre el sector público y el sector privado, poniendo el énfasis en buscar respuestas integrales para problemas complejos y capitalizar las oportunidades de un desarrollo sustentable.

Así el Programa Rafaela + Sustentable, desde su fundamentación conceptual (que es importante reconocer porque es desde donde se enmarcan o deberían enmarcarse las acciones) se propone avanzar hacia una economía verde, que promueva la creación de empleo y nuevos eco-emprendimientos que ayuden a restablecer la calidad ambiental. El programa despliega estrategias territoriales que fomentan el uso racional de los recursos (conservando su capacidad de regeneración natural), la producción más limpia y el uso de energías renovables, eficientes y descentralizadas, la minimización, reutilización, reciclado y valorización de residuos, la incorporación de criterios de sustentabilidad en la vivienda y el urbanismo, los modos de desplazamiento más respetuosas con el entorno, la producción local de alimentos, la extensión del verde urbano diverso y autóctono y la promoción de hábitos y rutinas de consumo responsable, asegurando así la sostenibilidad en el tiempo de los bienes y servicios ambientales (Jurado, 2011).

La fundamentación conceptual y la perspectiva del modelo de gestión de Rafaela Más Sustentable puede vincularse claramente con el enfoque del desarrollo territorial que se viene gestando en la ciudad desde la década del 90', a partir del diálogo entre las experiencias concretas de las y los actores del territorio (el sector público, el privado, el sistema científico tecnológico, las gremiales empresarias, el sector educativo, las organizaciones de la sociedad civil, entre otros) y las posiciones teóricas que entienden que la idea del desarrollo territorial (DT) trasciende al crecimiento económico y contempla múltiples dimensiones.

En relación a la temática específica que Rafaela Más Sustentable aborda, es interesante dar cuenta de cómo se vincula claramente al enfoque DT, retomando a Francisco Alburquerque (2012), quién plantea que, frente a este nuevo contexto, y el cambio de paradigma tecnológico y productivo, se vuelve esencial trabajar en la sostenibilidad del desarrollo. Ello implica replantear las formas de producción y consumo, así como muchas de las formas de trabajo, es decir, estilos de vida de nuestra sociedad. Por lo tanto, la innovación económica y social que se demandan como parte de las estrategias de desarrollo económico, deben guiarse por los imperativos de la sostenibilidad ambiental, con el desarrollo de nuevas industrias de bienes y servicios ambientales y empleos verdes, sobre la base de dotación de recursos con conocimientos adaptados a estas demandas. 
En el caso de Rafaela, ya Alburquerque en el año 2011 en la evaluación final del Programa de Competitividad Territorial señalaba que "la incorporación de la nueva línea de actuación sobre Energía, medio Ambiente y Economía Verde abre un antes y un después para el desarrollo en el territorio. Esta línea de actuación, no prevista inicialmente en el Programa, promovió la participación activa de los actores locales logrando instalar en las agendas públicas y privadas temas importantes relacionados con la eficiencia energética, la gestión de los residuos y la incorporación de la sustentabilidad ambiental como una apuesta por la calidad y la competitividad territorial y empresarial. La apuesta por una Rafaela + Sustentable incorpora una dimensión de futuro, con realizaciones concretas, que supone situar a este territorio con claras ventajas competitivas dinámicas frente a la situación promedio en su país y en América Latina en general".

Otro elemento importante a tener en cuenta en relación a la fundamentación de Rafaela Más Sustentable y que también resulta en uno de los impulsos sobre el cual se sostiene la creación del Instituto para el Desarrollo Sustentable, lo constituyen dos hitos en materia internacional referidos a las problemáticas ambientales: uno de ellos es la "Encíclica Laudato Si sobre el cuidado de la casa común" elaborada por el Papa Francisco y el otro, el Acuerdo de la Cumbre de París sobre Cambio Climático, ambos realizados en el año 2015.

La Encíclica Laudato SI pone de manifiesto, con todo el peso simbólico, político y cultural que supone un mensaje de estas características pronunciado por el propio Papa Francisco, la importancia de realizar un llamamiento a toda la humanidad a proteger nuestra casa común en la búsqueda de un desarrollo sostenible e integral, con vistas a cambiar la situación actual para lo cual se plantea "una invitación urgente a un nuevo diálogo sobre el modo como estamos construyendo el futuro del planeta". Específicamente el escrito, en su primera parte, presenta algunos aspectos centrales referidos a la problemática del ambiente:

1. La contaminación y el cambio climático: advirtiendo los efectos de los contaminantes sobre la salud especialmente de los sectores más vulnerables a lo que se suma la contaminación debida al transporte, al humo de la industria, a los depósitos de sustancias, a los fertilizantes, insecticidas, fungicidas, controladores de malezas y agro tóxicos en general. Considera también la contaminación producida por los residuos problema que se encuentra íntimamente ligado a la cultura del descarte en la que todavía no se ha logrado adoptar un modelo circular de producción que asegure recursos para todos y para las generaciones futuras, y que supone limitar al máximo el uso de los recursos no renovables, moderar el consumo, maximizar la eficiencia del aprovechamiento, reutilizar y reciclar. En relación al cambio climático advierte que la humanidad está llamada a tomar conciencia de la necesidad de realizar cambios de estilos de vida, de producción y de consumo, para combatir el calentamiento global.

2. La cuestión del agua: menciona que la situación actual tiene que ver con el agotamiento de los recursos naturales donde se han rebasado ciertos límites máximos de explotación del planeta. El agua potable y limpia representa una cuestión de primera 
importancia y un problema es el de la calidad del agua disponible. Mientras se deteriora constantemente la calidad del agua disponible, en algunos lugares avanza la tendencia a privatizar este recurso escaso, convertido en mercancía que se regula por las leyes del mercado. Siendo el acceso al agua potable y segura un derecho humano básico, fundamental y universal.

3. Pérdida de biodiversidad: alerta sobre los recursos de la tierra que también están siendo depredados a causa de formas inmediatistas de entender la economía y la actividad comercial y productiva. Se advierte que el nivel de intervención humana, frecuentemente al servicio de las finanzas y del consumismo, hace que la tierra cada vez más limitada y gris, mientras al mismo tiempo el desarrollo de la tecnología y de las ofertas de consumo sigue avanzando sin límite. Es necesario invertir mucho más en investigación para entender mejor el comportamiento de los ecosistemas y analizar adecuadamente las diversas variables de impacto de cualquier modificación importante del ambiente.

En otra línea el Acuerdo de París sobre el Cambio Climático, celebrado en diciembre de 2015, plantea que el cambio climático representa una amenaza inminente y con efectos potencialmente irreversibles para las sociedades humanas y el planeta y, por lo tanto, exige la cooperación más amplia posible de todos los países y su participación en una respuesta internacional efectiva y apropiada, con miras a acelerar la reducción de las emisiones mundiales de gases de efecto invernadero. En donde los países se comprometen a adoptar medidas para hacer frente al cambio climático, para respetar, promover y tomar en consideración sus respectivas obligaciones con respecto a los derechos humanos, el derecho a la salud, los derechos de los pueblos indígenas, las comunidades locales, las y los migrantes, las y los niños, las personas con discapacidad y las personas en situaciones de vulnerabilidad y el derecho al desarrollo, así como la igualdad de género, el empoderamiento de la mujer y la equidad intergeneracional. En este contexto los países desarrollados asumen su compromiso en forma de financiación, tecnología y fomento de la capacidad.

Uno de los temas importantes que también se plantea explícitamente es la necesidad de promover el acceso universal a la energía sostenible en los países en desarrollo, mediante un mayor despliegue de energía renovable, observando la importancia de garantizar la integridad de todos los ecosistemas, incluidos los océanos, y la protección de la biodiversidad. Y otro aspecto a destacar es la importancia de la educación, la formación, la sensibilización y participación del público, el acceso público a la información y la cooperación entre actores y sectores.

Estos marcos internacionales van marcando también la agenda a futuro no sólo a nivel global, sino que impactan a nivel nacional. Un antecedente en este sentido, se visualiza en la nueva ley de energías renovables (sancionada en septiembre de 2015) que establece que en 2017 el país deberá contar con el $8 \%$ de su generación eléctrica a partir de electricidad generada por el viento, 
el sol o las pequeñas centrales hidroeléctricas, entre otras fuentes. La norma además impulsa a que en 2020 ese porcentaje suba al 20\%. El desarrollo de este tipo de fuentes generación constituyen las medidas de mitigación de lucha contra el cambio climático más eficientes.

Otro punto central de la normativa lo constituye la obligación con penalidad a los grandes usuarios de energía eléctrica, en especial lo que tienen un consumo igual o superior a $300 \mathrm{~kW}$ (kilovatios) para el cumplimiento individual de las metas de consumo de energías renovables que fija la ley. Es que la norma obliga a esos consumidores a abastecer sus consumos eléctricos con generación que utilice fuentes de energía renovable.

Este escenario legal sumado al impacto de la suba de las tarifas en los servicios de luz, gas y agua, con las complicaciones y contradicciones que trae aparejado, genera un campo de posibilidades en materia de nuevos emprendimientos vinculados a la economía verde.

\section{Mapa de actores}

En este apartado presentamos gráficamente un mapa de las y los actores principales vinculados a Rafaela Más Sustentable a modo de dar cuenta de la densidad de redes de relaciones que se establecen en el marco de las líneas de acción y la gestión de las iniciativas. Es interesante realizar este ejercicio para luego retomar en los aprendizajes la identificación de las y los actores claves que lideran los procesos o quienes aún no están participando activamente.

Un aspecto a tener en cuenta y a considerar es cómo y por qué este mapa se amplía a partir de la creación del Instituto para el Desarrollo Sustentable y se formaliza, tal como hemos mencionado anteriormente, a partir de su Consejo Ambiental en donde aparecen nuevas y nuevos actores como es el caso de las organizaciones religiosas (Obispado de Rafaela y Consejo de Pastores).

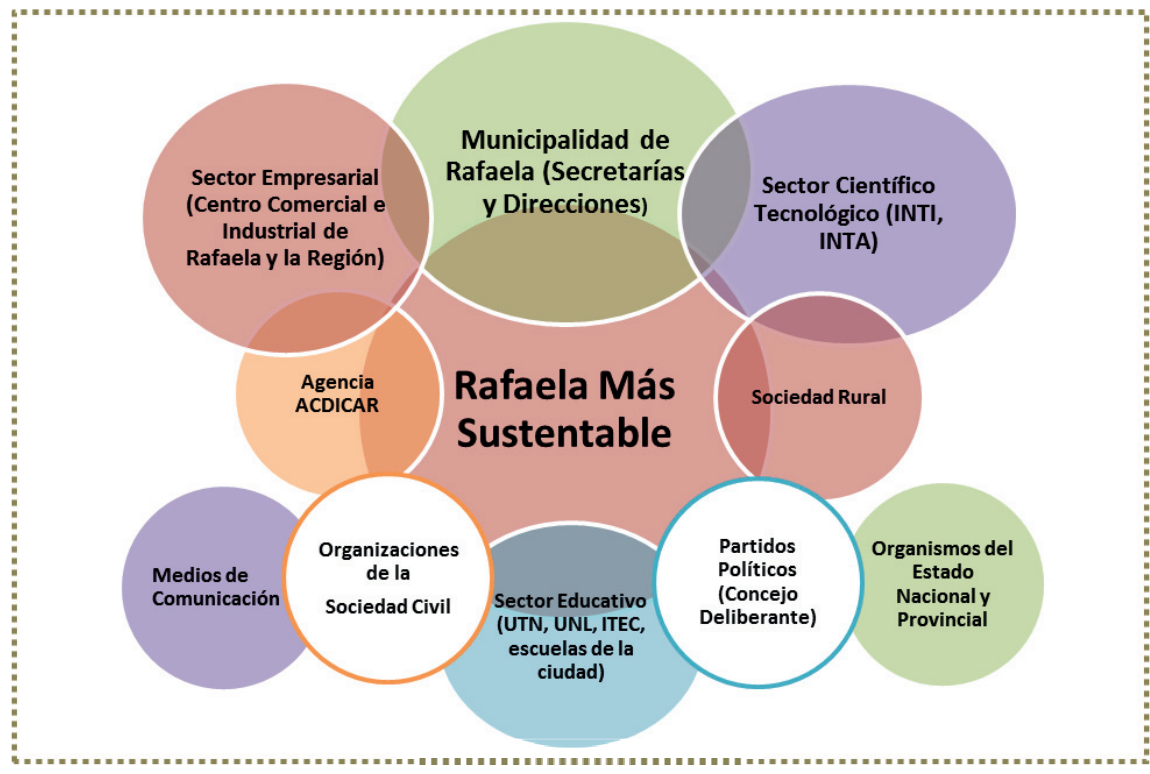




\section{Líneas de acción planteadas}

En este apartado se desarrollan las principales líneas acción abordadas desde Rafaela Más Sustentable desde su inicio como Programa y que mantienen la continuidad y se consolidan también en el marco de la formalización del Instituto para el Desarrollo Sustentable. Donde sólo se visualizan unos pequeños cambios en relación a los ejes que se venían abordando: por ejemplo, se suma el "Cuidado del agua y la producción local" que no estaba inicialmente entre las líneas de acción y también desaparece como espacio específico la línea de Economía verde, si bien se identifica e integra en otras de las acciones como por ejemplo en la gestión de residuos y eficiencia energética.

Desde el inicio en 2009 y su consolidación en 2010 el Programa R+S entonces contemplaba las siguientes líneas de trabajo:

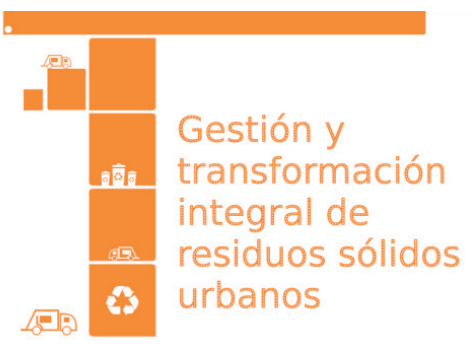

Esta línea, tal como venimos desarrollando, ha sido quizás el eje transversal y fundante de las temáticas ambientales en Rafaela que se va transformando luego con el impulso del Programa en una política de gestión y transformación de residuos. Conceptualmente un Sistema de Gestión Integral de Residuos (GIRSU) implica una perspectiva holística e interdisciplinaria, donde no se conciben ámbitos parciales de actuación (como la recolección) sino que se piensa que a la gestión de los residuos también le incumbe minimizar lo que se genera, clasificar, recolectar, disponer, entre otros. Se trata de un modelo de transversalidad de políticas que permite no perder de vista el carácter integral de la gestión, como un sistema de interrelaciones en el que tanto los aspectos técnicos como los socioeconómicos y políticos son analizados conjuntamente (Schamber, 2011).

Entre los objetivos principales que se definieron en esta temática se encuentran:

- Reducir la generación de residuos, así como la cantidad que se entierran en las celdas del relleno sanitario del Complejo Ambiental.

- Maximizar la separación en origen y la clasificación.

- Disminuir el impacto ambiental que generan los residuos y el costo del manejo de los mismos.

- Tratar y valorizar los residuos de manera que puedan ser reutilizados como materia prima en otros procesos productivos.

- Promocionar la industria del reciclado y el empleo verde.

- Creación de nuevas empresas que transformen los residuos en recursos. 


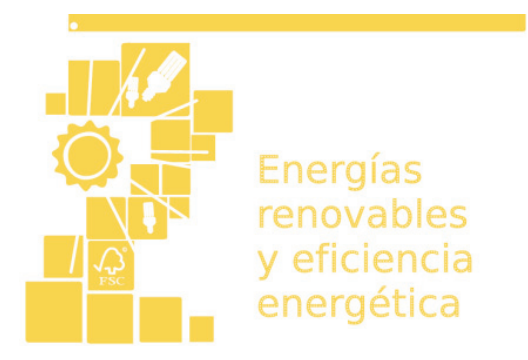

Esta área puede considerarse quizás el aspecto más "visible" del Programa que consiste en la promoción de energías complementarias o alternativas. Rafaela todavía depende de las energías contaminantes, como el gas y el petróleo, que se están agotando y contribuyen al calentamiento global y al cambio climático. Por ello la apuesta es buscar la eficiencia energética y promover el desarrollo de energías limpias. La disponibilidad de energía es un factor fundamental para el desarrollo y el crecimiento económico. El uso eficiente de la energía es la medida más efectiva, a corto y mediano plazo, para lograr una reducción significativa de las emisiones de CO2 y de otros gases de efecto invernadero.

La eficiencia energética es la adecuación de los sistemas de producción, transporte y consumo de energía destinada a lograr el mayor desarrollo sostenible con los medios tecnológicos al alcance, minimizando el impacto sobre el ambiente, optimizando la conservación de la energía y la reducción de costes energéticos (Caminos, 2011).

Los objetivos principales planteados fueron:

- Promocionar las energías complementarias o alternativas y la eficiencia energética, tanto en espacios y edificios públicos como en las empresas, instituciones y hogares de la ciudad.

- Fomentar la producción local y la distribución de energías renovables localmente.

- Disminuir el consumo energético y ahorrar aprovechando las energías más eficientes y sin costo como la energía solar.

- Difundir e implementar criterios de construcciones sustentables para climatizar los ambientes de una manera natural.

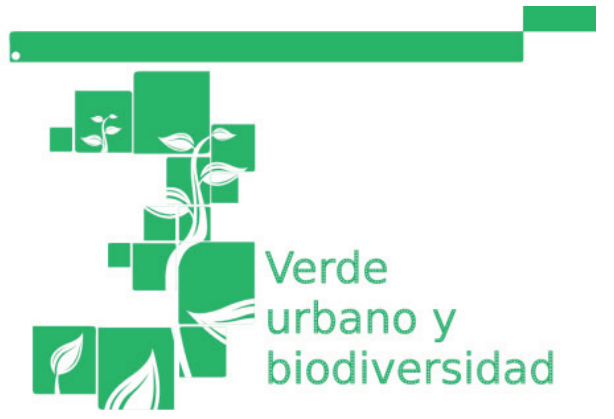

La promoción de la diversidad urbana es otro de los ejes principales de $\mathrm{R}+\mathrm{S}$. Las zonas verdes constituyen un patrimonio colectivo de gran valor social y cultural. Por ello es necesario conocer y dar respuesta a las necesidades y expectativas de los ciudadanos en referencia a la creación y mejora de los espacios verdes.

El verde urbano en este sentido se plantea como un elemento estructurador para un desarrollo urbano sostenible que prioriza la conservación de la biodiversidad y la importancia de mantener el acervo incorporando mayor cantidad de especies nativas (Cerutti, 2011).

Los objetivos de esta línea se definieron como: 
- Promocionar la biodiversidad y del arbolado urbano.

- Conocer la cantidad y las características del arbolado de la ciudad.

- Incrementar la cantidad de árboles de la ciudad, diversos y autóctonos.

- Recuperar o generar espacios verdes de ocio, integración y educación.

- Producción de especies autóctonas

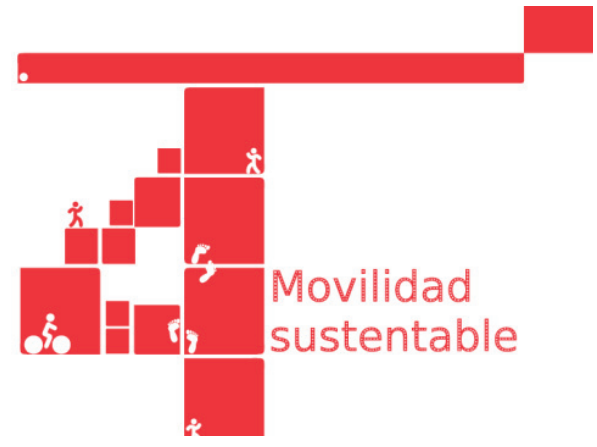

También se plantea entre las acciones fomentar una nueva cultura de movilidad urbana. Esta perspectiva implica abrir la reflexión sobre las pautas de desplazamientos de las ciudades, sobre los comportamientos en relación al uso de la ciudad y al espacio público, sobre el modo de vida y su relación con la velocidad y la proximidad y sobre la equidad. La nueva cultura de la movilidad otorga un papel preponderante a las personas en sus desplazamientos dejando en segundo término los modos de transporte no motorizados. De esta forma más que intentar dar respuesta a las crecientes demandas de circulación y estacionamiento vehicular, lo que hace falta es generar la accesibilidad de todos los ciudadanos a los diferentes espacios de la ciudad (Galak, 2011).

Los objetivos de abordar una movilidad sustentable fueron:

- Fomentar una nueva cultura de movilidad urbana alcanzando la multifuncionalidad de la calle, recuperando los espacios para el peatón y el ciclista.

- Promocionar las formas de movilidad sustentables especialmente la bicicleta y la caminata.

- Dotar a la ciudad de la infraestructura (ciclovías, ciclocarriles, señalización, bicicleteros)

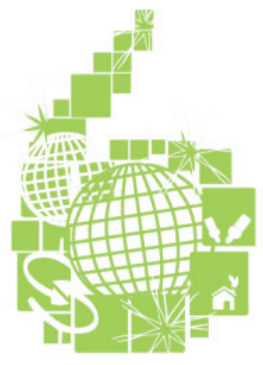

Ante el carácter insostenible del actual modelo de producción y consumo, las y los empresarios innovadores deberán incorporar actitudes previsoras e inteligentes basadas en el conocimiento del grado de sostenibilidad de los procesos productivos y de consumo.

En este sentido la capacidad emprendedora constituye un potencial esencial para generar nuevas oportunidades de negocios en la que colaboren los diferentes actores públicos y privados a través del impulso de prácticas productivas respetuosas con el medio ambiente (Alburquerque, 2011). 
Los objetivos que se plantearon fueron:

- Formación en oficios verdes

- Impulsar proyectos y emprendimientos vinculados a iniciativas de economía verde

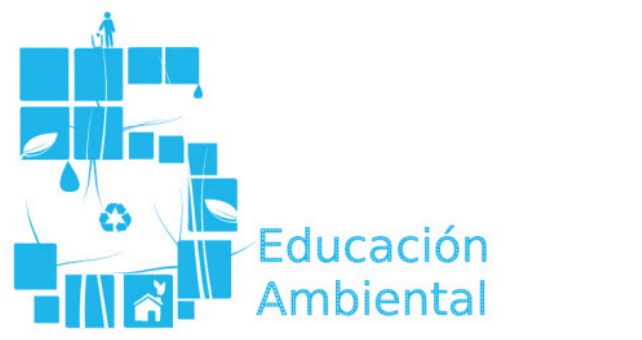

de su entorno (Weissman, 2011).

Los objetivos de esta línea son:

- Transmitir buenas prácticas ambientales a todos los vecinos de la ciudad.

- Educar respecto a cuestiones relacionadas al ambiente.

- Difundir, facilitar la implementación y dar seguimiento a las diferentes campañas del programa.

- Difundir en las escuelas la idea de cuidado del ambiente, aliarlas en nuestras campañas.

- Ambientalizar los establecimientos educativos

Como anticipamos anteriormente cuando el Programa R+S se transforma en el Instituto para el Desarrollo Sustentable se agrega a los ejes de trabajo el Cuidado del agua y producción local, entendiendo que la falta del agua y su distribución más equitativa es un problema que afecta a todos los ciudadanos de Rafaela y que parte de la mejora está en que cada uno de los actores se comprometa con un consumo responsable. El primer paso para avanzar en esta temática fue en indagar los problemas para buscar las posibles soluciones y construir estrategias concretas de intervención. También en relación al eje de educación ambiental se suma la dimensión de la comunicación bajo un enfoque que no sólo supone transmitir la información sino generar conocimientos y acciones colectivas.

El espacio denominado "Economía verde" desaparece como tal, pero pareciera verse integrado transversalmente en otras estrategias de acción especialmente bajo la idea de transformar los residuos en recursos y generar emprendimientos vinculados a energías renovables. 


\section{Resultados alcanzados según las y los responsables de Programa}

Si bien R+S en sus años de vida lleva una innumerable cantidad de acciones y actividades puestas en marcha, a continuación, se ha intentado sintetizar los principales resultados alcanzados teniendo en cuenta el impacto generado en el territorio, no sólo a partir de cambios concretos y tangibles sino también construyendo una política pública integral a mediano y largo plazo:

\section{Gestión Integral de Residuos}

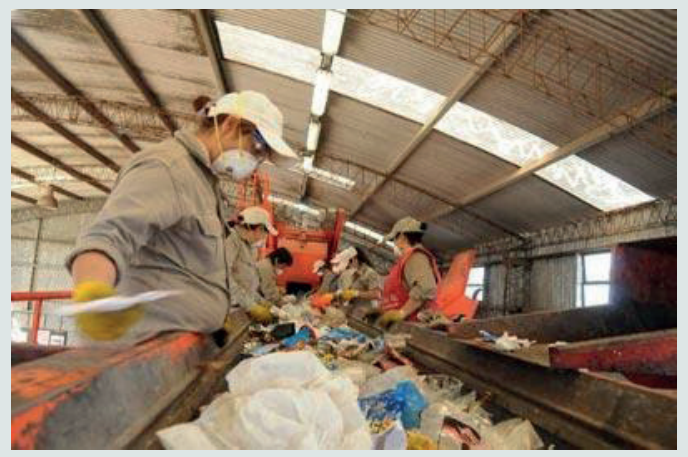

2010 y 2011, se sancionó una ordenanza que regula el sistema de gestión de residuos sólidos urbanos de toda la ciudad (la Ordenanza № 4404, de Gestión Integral de Residuos Sólidos Urbanos), y se repensó todo el sistema, bajo la idea de que los residuos pueden convertirse en materias primas de otros procesos productivos.

Se pusieron en marcha siete sistemas de recolección que van de la mano de la colaboración y participación de los ciudadanos: recolección especial de cartón, recolección de residuos recuperables domiciliarios con un $80 \%$ de hogares que separa residuos, recolección de patios, recolección de residuos especiales, recolección de aceite vegetal usado.

Se construyó un punto verde móvil, que recorre los barrios apoyando la recogida diferenciada de estos residuos.

La planta de recupero y el relleno sanitario han optimizado su funcionamiento, logrando mayor eficiencia y productividad y mejores condiciones de seguridad e higiene.

Se comenzaron a tratar los residuos electrónicos e informáticos que pueden ser peligrosos para el medio ambiente a través de talleres de revalorización de componentes informáticos.

Estación de residuos clasificados: en 2011 se crea el Parque Tecnológico de reciclado único en el país.

6 empresas de carácter público privado transforman residuos en recursos (Planta de fabricación de Biodiesel, Planta de Biodigestión y Biometano, Planta de procesamiento de plásticos, Planta de generación de combustible a partir de Aceite vegetal usado, Planta de procesamiento de neumáticos y procesamiento de chatarra)- La correcta gestión de los residuos en Rafaela representa 250 puestos de trabajo.

Campaña de uso racional de Bolsas Plásticas implementada en conjunto con la Cámara de Supermercados de la ciudad, se logró el objetivo de reducir su generación para minimizar el impacto ambiental, económico y paisajístico que producen. 
Campaña de recolección de papel de oficina 120 empresas e instituciones de la ciudad separan este material. Los registros indican que 11 toneladas de papel se reciclan por mes.

\section{Educación Ambiental}

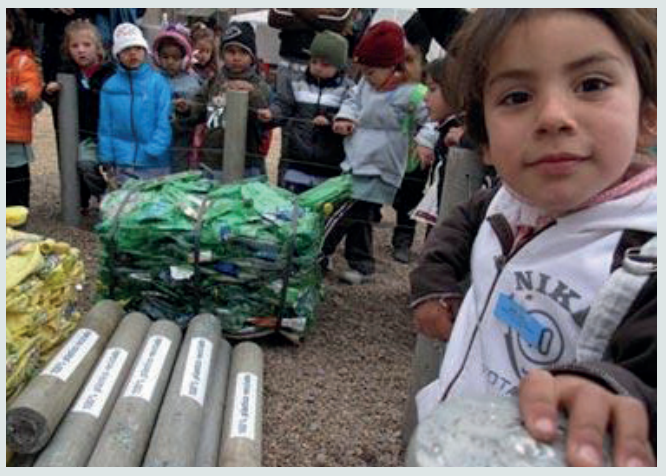

Programa Creando Conciencia: 20 mil hogares son visitados puerta a puerta. 1.200 escolares visitan anualmente el Complejo Ambiental. 33 escuelas forman parte del programa de Escuelas Más Sustentables.

Rafaela ha recibido innumerables visitas de funcionarios y técnicos municipales de Argentina y de países limítrofes interesados en conocer las políticas medioambientales.

Realización y participación en eventos masivos como, por ejemplo: festejo del día mundial del medio ambiente, día mundial del agua, la hora del planeta, expo rural.

El $85 \%$ de los hogares de la ciudad separan correctamente los residuos.

Mejoramiento del orden y la limpieza de los barrios más críticos.

\section{Eficiencia y promoción de uso de energías alternativas}

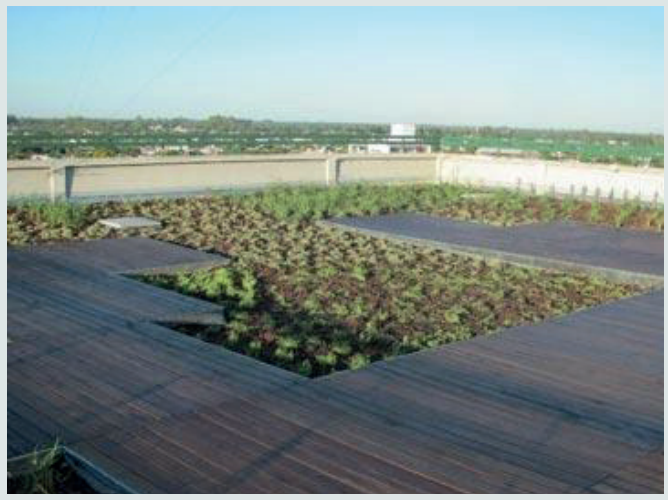

Se realizaron auditorías energéticas en organismos públicos e instituciones

Se lleva adelante el Plan de promoción de la energía solar térmica

Se concretaron Jornadas de capacitación en fabricación, instalación y mantenimiento de colectores solares.

Se acompañó el Programa Federal de Producción Más Limpia con 11 empresas de Rafaela favorecidas.

Se está realizando el Proyecto de Purificación de Biometano para uso vehicular en la Argentina siendo la primera experiencia del país.

Se reemplazaron paulatinamente las luminarias públicas tradicionales de vapor de mercurio por lámparas de vapor de sodio- bajo consumo- (que contienen menos mercurio y sodio que es menos contaminante y además que supone un ahorro del $40 \%$ debido a la menor potencia).

Desarrollo de nuevas tecnologías aplicadas a unidades demostrativas para que ciudadanos y ciudadanos y empresarios y empresarias pudieran ver el impacto positivo en relación al 
cuidado del ambiente (Terraza Verde Municipal, Plaza Eva Perón que cuenta con luminarias LED y paneles fotovoltaicos; así, se usa la energía del sol para iluminarla, Semaforización LED).

Revalorización de la Usina del Pueblo, por un lado, restaurando el patrimonio histórico y cultural que permite recordar cómo se producía la energía en el pasado, y por otro desarrollando un itinerario educativo, enfocado desde la perspectiva de la educación ambiental.

\section{Verde urbano y biodiversidad}

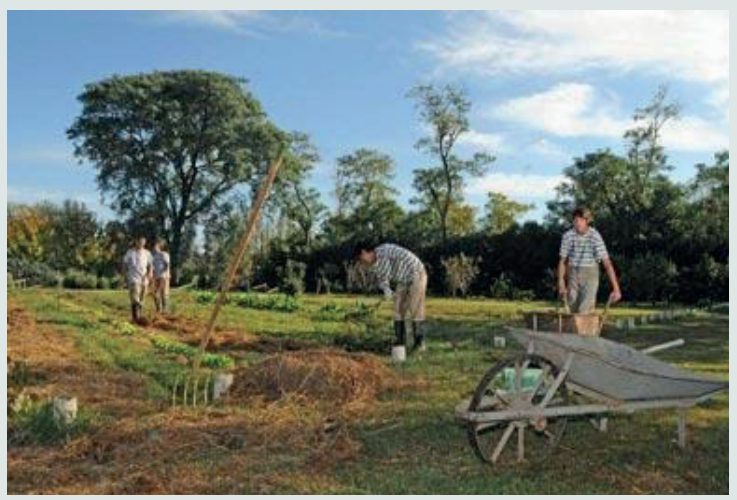

Plan de forestación anual "Rafaela que te quiero verde" y "Crecer Juntos" del que participan las y los vecinos de la ciudad haciendo su aporte al arbolado público (10 mil nuevos ejemplares entre 2010 y 2015).

Promoción del compromiso del sector privado: entrega de catálogo de especies autóctonas a los loteadores.

Producción local de árboles (prueba piloto en el Complejo Ambiental de plantación de 50 lapachos)

Construcción de una base de datos del estado fitosanitario del arbolado público (40 mil árboles relevados)

Creación de nuevos espacios verdes: Arboretum, un área reservada y dedicada al cultivo de especies autóctonas para estudiarlas y disfrutarlas. Allí mismo se instaló el Monumento al Suelo, como un recordatorio de la importancia de cuidar este valioso recurso no renovable.

Aumentó la superficie de espacios verdes públicos por habitantes arrojando las mediciones en esos años a valores de $7 \mathrm{~m} 2 /$ habitante a $7,8 \mathrm{~m} 2 /$ habitante. Se puso en marcha la ejecución del programa Balcones Verdes, con el fin de promover espacios verdes en edificios de altura.

\section{Economía Verde}

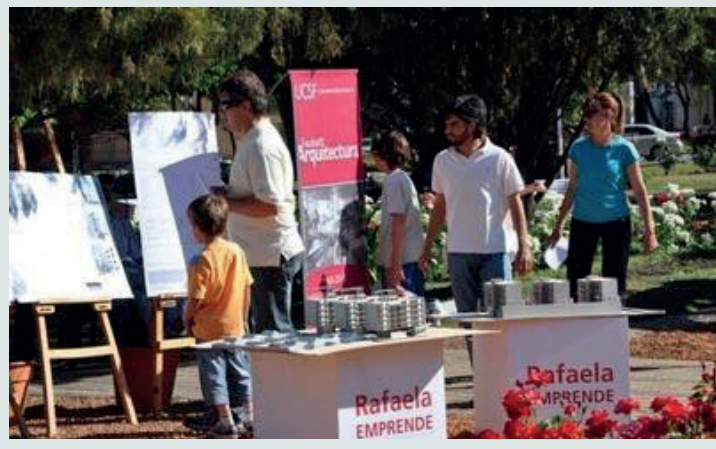

Se comenzó a darle una especial atención a los proyectos orientados a iniciativas de la economía verde. Eso supuso valorar, en las iniciativas, los aspectos que ayuden a conservar o restablecer la calidad ambiental de Rafaela y la región, en particular los que promueven la valorización de residuos sólidos urbanos o industriales y la generación de energía a partir de fuentes renovables. 
Desde el Programa Rafaela Emprende se está trabajando con varios emprendimientos vinculados a la línea verde, dedicados a la reutilización de neumáticos fuera de uso, fabricación de bolsas reutilizables, aprovechamiento de residuos orgánicos en compostaje, planta generadora de biocombustible, producción de pallets de madera fabricados a partir de residuos verdes y desarrollo de calefacción con energía solar.

\section{Cuidado del agua y producción local}

\section{Cuidá el agua.}

Hay alguien que la necesita.
Eco auditorías para incentivar el ahorro y el uso eficiente en las instituciones y empresas de la ciudad.

Se visitaron 200 grandes consumidores y como resultado se evidenció un $50 \%$ de reducción en el consumo.

Se llevó adelante una campaña de concientización para promover hábitos de uso responsable y solidario del agua.

\section{Movilidad sustentable}

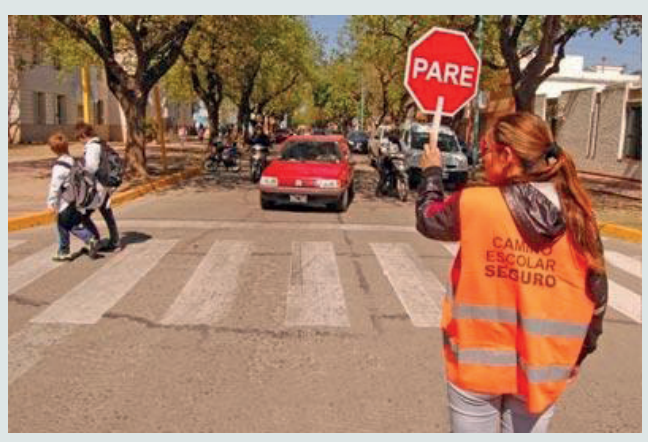

Diseño de un plan de movilidad integral que contempla alternativas al uso del auto y la moto y refuerza la bicicleta como medio para moverse en la ciudad.

Puesta en marcha del primer Camino Escolar Seguro del país, en el que se busca que los chicos vayan a la escuela de manera autónoma, a pie, tanto para brindarles más autonomía como para pacificar el tránsito a la entrada y salida de la escuela.

Se llevó adelanta la campaña "Rafaela en bici", bicicleteadas, concursos en redes sociales, Eco- Gymkanas con actividades para aprender, jugar y conocer acerca del ambiente y las trazas de ciclovías de la ciudad, Empresas amigas de la bici con campañas para que las empresas fomenten el uso de las bicicletas entre sus trabajadores.

Articulando con la Secretaria de Desarrollo Urbano, Suelo y Vivienda se ha trabajado en la colocación de nuevos bicicleteros, la señalética y semaforización para los ciclistas y peatones, se han ampliado las redes de ciclovías. 


\section{Estrategias de intervención}

De las entrevistas y de la lecturas realizadas queda claro que desde Rafaela + Sustentable se plantea una modalidad de trabajo y de estrategias de intervención que recuperan la tradición misma y la impronta que este territorio ha venido desarrollando en las últimas dos décadas, más la innovación que emerge del Programa de Competitividad Territorial que significó un estilo de gestión con nuevos temas, con alcance regional, con formación de agentes especialistas en el tema y donde se explicita que esta modalidad trae también aparejada complejidades y conflictos que se traducen en aprendizajes.

En este sentido, teniendo en cuenta la diversidad y la multiplicidad de líneas de trabajo que $\mathrm{R}+\mathrm{S}$ aborda, las estrategias de intervención necesariamente tuvieron que poner en acción el trabajo colectivo, articulado y transversal, y el permanente diálogo con un conjunto de instituciones del sector público y privado, con el claro liderazgo de la Municipalidad y una herramienta fundamental para la gestión como lo es la voluntad política para emprender acciones que en muchos casos requerían sensibilizar a múltiples sectores.

Desde su enfoque el modelo de gestión del Programa, ahora Instituto, privilegia el funcionamiento sobre la organización, bajo el supuesto de que la capacidad para establecer alianzas estratégicas con las y los actores territoriales determinará el éxito de las actuaciones. Será entonces un eje central en los aprendizajes analizar y poner el foco en estas modalidades identificando las tensiones, los aciertos y los conflictos en la manera de implementar las acciones, poniendo en diálogo la perspectiva que se enuncia con las prácticas y la realidad concreta.

Finalmente aparecen otros temas, más allá de los ejes específicos. Uno de ellos lo constituyen los procesos de formación de capacidades locales en la multiplicidad de acciones que este Programa ha desplegado. Este tema es un elemento principal del enfoque del DT en donde se entiende que las y los actores locales también se forman en las prácticas.

Otro eje, más vinculado a los procesos de gestión, tienen que ver con las modalidades de financiamiento de este tipo de políticas. Estas han sido variadas de acuerdo también al perfil del Programa: en una primera etapa fue cofinanciado por el BID-FOMIN, mientras ha sido Programa los aportes del municipio han sido constantes, siendo para cada año de $\$ \mathbf{4 0 0 . 0 0 0}$ sumado a los costos del personal. Luego fue cofinanciado por el Ministerio de Economía y Finanzas de la Nación a través de un proyecto de la Dirección Nacional de Preinversión.

Además, organismos nacionales otorgaron fondos para la realización de las obras más importantes: la Secretaría de Ambiente y Desarrollo Sustentable dispuso los fondos para la realización del Parque Tecnológico de Reciclado de Rafaela (PTRR). Es importante también mencionar los aportes del sector privado (local y nacional) sirviendo de sponsors en cada una de las campañas que se implementan y/o cofinanciando algunas obras o maquinarias. 
También desde los ministerios de Trabajo, Empleo y Seguridad Social y de Desarrollo Social de la Nación se han canalizado recursos hasta el 2015 dado que con posterioridad el cambio de gobierno y de signo político del gobierno nacional, opuesto al local, significó un corte abrupto de los recursos que se venían asignando.

La cooperación internacional como Fundación Avina y la Corporación Andina de Fomento también han aportado a este Programa.

Es importante destacar que estos financiamientos suponen un intenso trabajo de gestión y de redes de relaciones, buscando en forma permanente las oportunidades que se generan desde los contextos provinciales, nacionales e internacionales. Esta dimensión también habla de un enfoque innovador en el modelo de gestión.

A partir de la sanción de la Ordenanza que transforma al Programa en Instituto, en cuanto a la financiación del programa Rafaela + Sustentable se establece que a partir del año 2017 se incluirá en el presupuesto anual una partida específica destinada al funcionamiento del Instituto y también se podrá disponer de transferencias especiales cuando las actividades generen obligaciones que así lo justifiquen, previa autorización del Concejo Municipal.

Estas dimensiones que aquí comienzan a esbozarse serán retomadas y enriquecidas a partir de la perspectiva de las y los propios actores en el capítulo que se desarrolla a continuación sobre el análisis y los aprendizajes de la experiencia. 


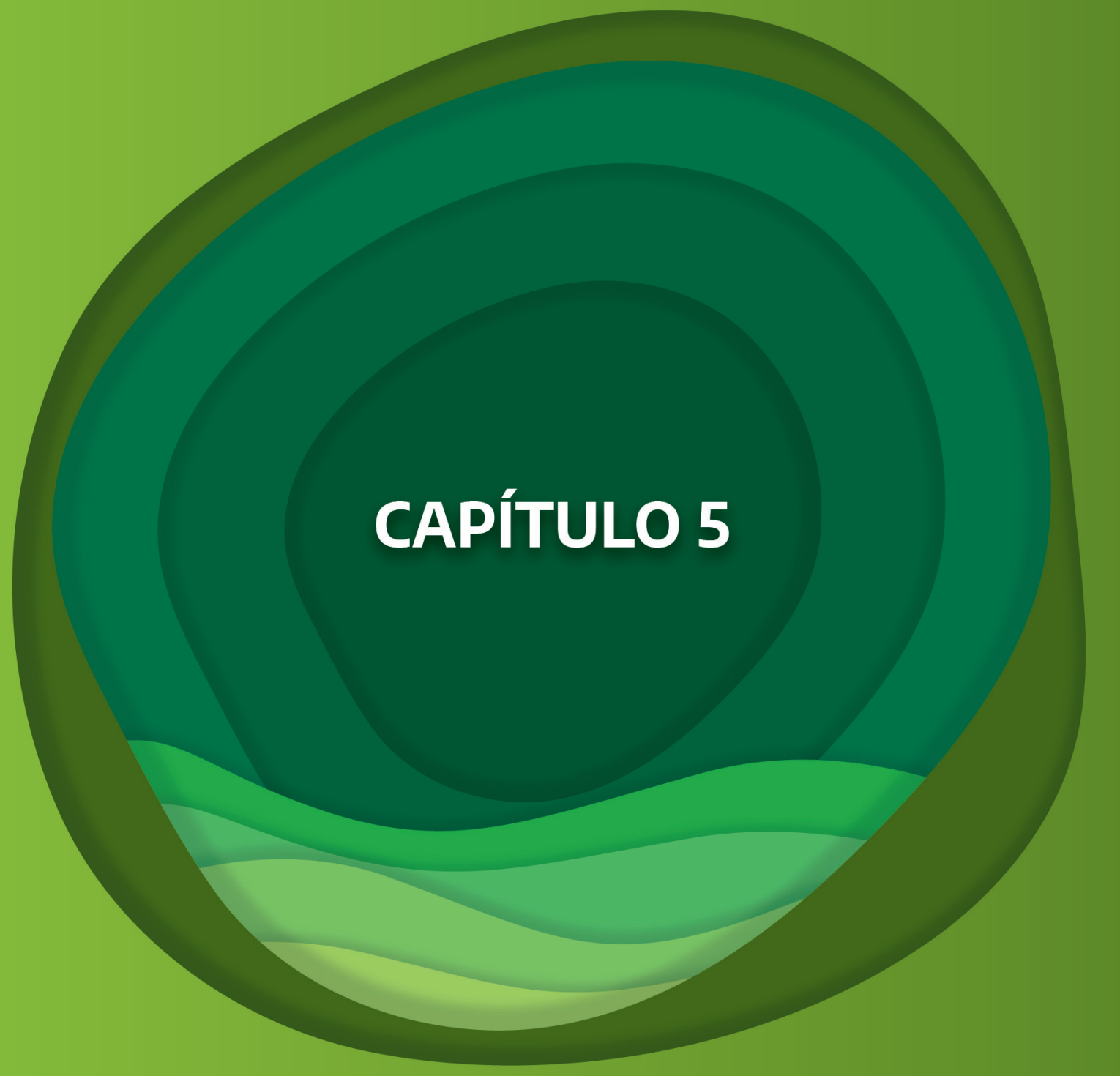

Análisis y aprendizajes del proceso 


\section{CAPÍTULO 5.}

\section{Análisis y aprendizajes del proceso}

En este capítulo, tal como se establece en la metodología que venimos abordando en la sistematización de Rafaela Más Sustentable, nos proponemos abordar la etapa reflexiva de la experiencia, lo que hemos denominado "aprendizajes del proceso".

Si bien esta instancia no ha sido lineal y ya se van visualizando momentos de reflexión sobre la práctica en el capítulo precedente, esta constituye una etapa importante porque implica mirar críticamente y hacer visibles los aprendizajes que también se cristalizan en las relaciones, tensiones y contradicciones. Un punto aquí, tal como lo hemos mencionado con anterioridad, es no reducir los aprendizajes a los resultados, ni tampoco considerar que los aprendizajes son sólo aquellos aspectos que han sido exitosos, sino que también necesitamos problematizar los conflictos y profundizar el análisis hacia aquellas situaciones que requieren revisarse, rediscutirse y transformarse.

Otro aspecto a desarrollar en este apartado es la mirada a futuro, es decir, a partir de las reflexiones, qué nuevos temas, ideas e iniciativas se piensan en forma colectiva (qué "semillas" se han sembrado hacia adelante que pueden traducirse en nuevas acciones y continuidades del proyecto realizado o en realización). El análisis crítico de la experiencia supone un ejercicio dialéctico de leer críticamente la teoría con base en la práctica e interpretar críticamente la práctica con base en la teoría. Este ejercicio de diálogo entre la práctica y la teoría, genera contribuciones a propuestas transformadoras.

Finalmente se presentarán dos apartados que completan, a nuestro entender, el proceso de sistematización y que también generan aprendizajes. Uno de ellos tiene que ver con la comunicación de la experiencia y la socialización de los aprendizajes y el otro con lo que hemos denominado "la vuelta a la academia", que en este caso ha implicado el proceso de análisis y la mirada crítica sobre los aprendizajes del proceso de sistematización de Rafaela Más Sustentable con las y los estudiantes de la Maestría en Desarrollo Territorial de la Universidad Tecnológica Nacional - Facultad Regional Rafaela de la cohorte 2017-2018.

\section{Ejes de análisis para la identificación de los aprendizajes del proceso}

El proceso de análisis e identificación de aprendizajes de la experiencia que desarrollamos a continuación ha surgido a partir de diferentes espacios de diálogo, sobre todo a través de entrevistas en profundidad y talleres, con actores claves de Rafaela Más Sustentable seleccionados a partir de su vinculación con el proceso. Se tuvo en cuenta la diversidad de perfiles y sectores de pertenencia (empresas, organizaciones de gestión pública, actores de la política, del sector educativo, del sistema científico tecnológico, de las organizaciones sociales, entre otros). 
A continuación presentamos una síntesis de las personas involucradas en la etapa de diálogos marcando también sus pertenencias institucionales:

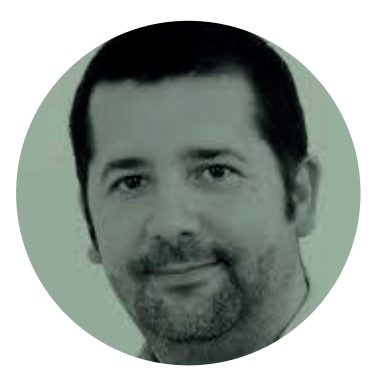

\section{Alejandro Jurado}

Coordinador y asesor desde los inicios de Rafaela Más

Sustentable hasta la actualidad en la Municipalidad de Rafaela.

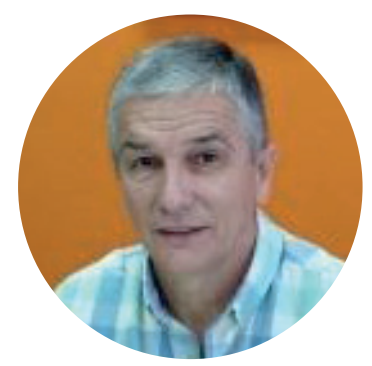

Jorge Muriel

Concejal por el Frente para la Victoria. Representante en el Consejo Ambiental del Instituto para el Desarrollo Sustentable.

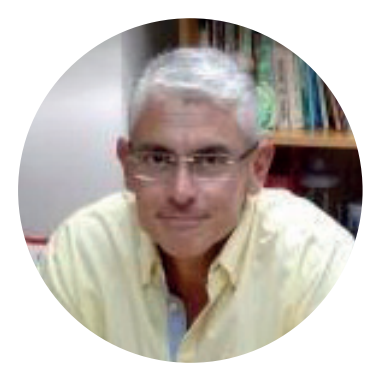

\section{Gustavo Molfino}

Director de la empresa Supermercados Pingüino.

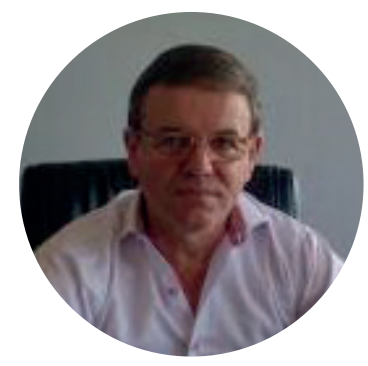

\section{Andrés Ferrero}

Presidente de la empresa DEISA y presidente del Centro

Comercial e Industrial de Rafaela y la Región.

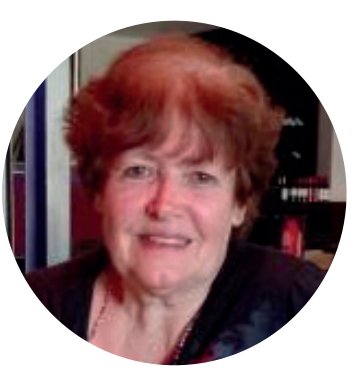

Marta Engler

Ex Secretaria de Espacios, Servicios Públicos y Ambiente de la Municipalidad de Rafaela. 


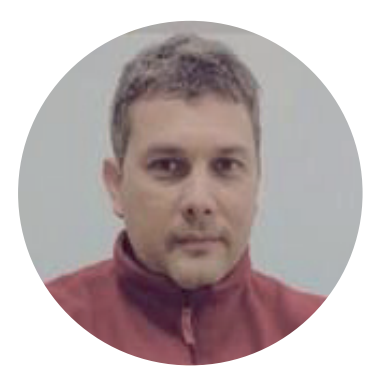

\section{Marcos Alassia}

Referente en Rafaela Más Sustentable por el INTI Rafaela.

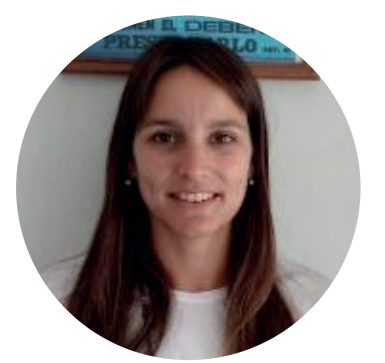

\section{María Paz Caruso}

Directora del Instituto para el Desarrollo Sustentable.

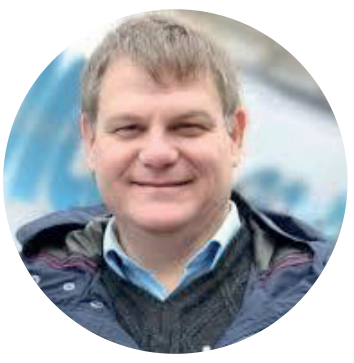

\section{Marcelo Becla}

Representante del Consejo de Pastores de la ciudad de Rafaela en el Consejo Ambiental del Instituto para el Desarrollo Sustentable.

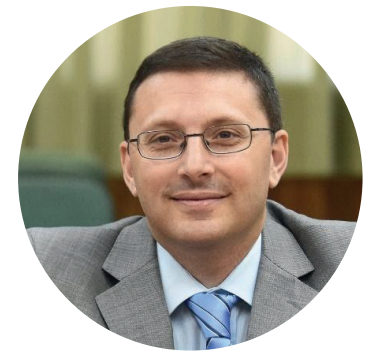

\section{Lisandro Mársico}

Concejal por el Frente Progresista Cívico y Social e integrante del Consejo Ambiental del Instituto para el Desarrollo Sustentable.

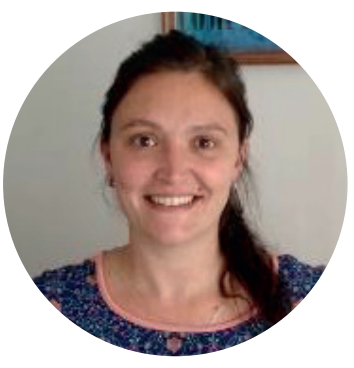

\section{Gisela Daniele}

Integrante del equipo técnico del Instituto para el Desarrollo Sustentable en el área de residuos. 


\section{Alejandro Bonet}

Representante por el Obispado de Rafaela en el Consejo

Ambiental del Instituto para el Desarrollo Sustentable.

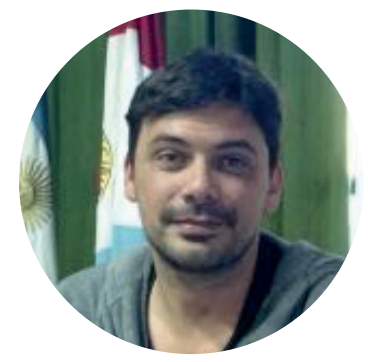

\section{Claudio Gasparotto}

Ex integrante del equipo técnico de Rafaela Más Sustentable en sus inicios en el año 2008.

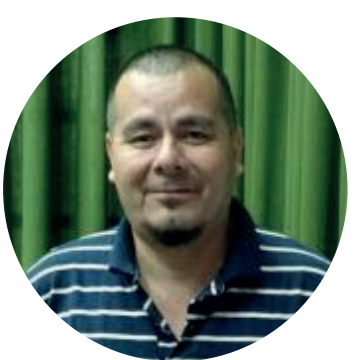

Sergio Amaya

Equipo técnico del Instituto para el Desarrollo Sustentable.

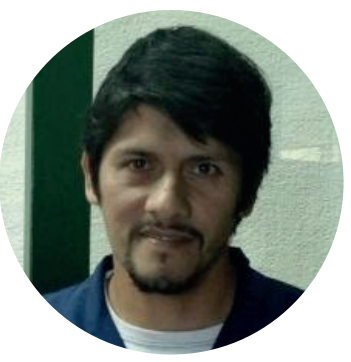

\section{Walter Tévez}

Docente de la Escuela Nro. 467 Domingo Faustino Sarmiento, trabaja en el proyecto de separación de residuos recuperables y no recuperables y disposición del papel.

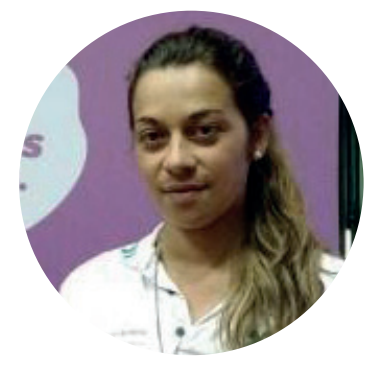

Noelia Vesoni

Pasante en Rafaela Más Sustentable por el Profesorado en Educación Primaria. 


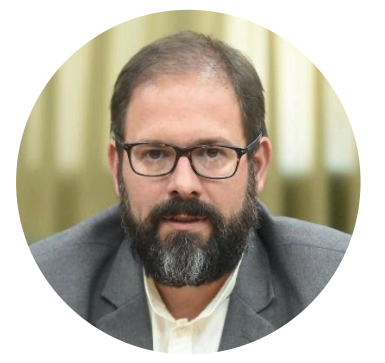

\section{Hugo Menossi}

Concejal del bloque Cambiemos y representante en el Consejo Ambiental.

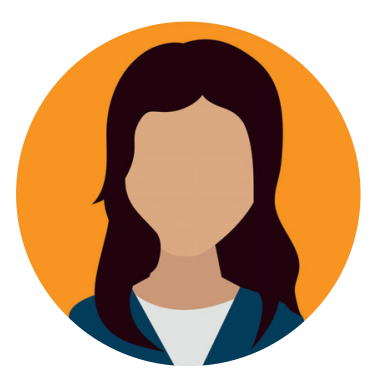

\section{María Frobelli}

Representante por la Federación de Entidades Vecinales en el Consejo Ambiental.

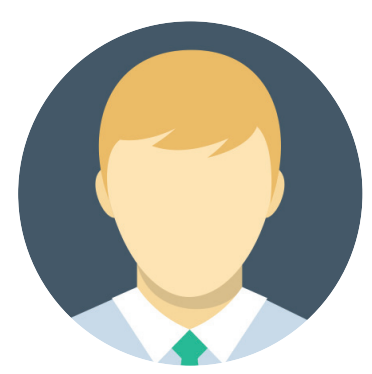

\section{Sergio Seara}

Representante en el Consejo Ambiental por el Club 9 de Julio.

Vinculando los materiales surgidos de la primera etapa de investigación (que denominamos Memoria) y las entrevistas y talleres con las y los actores del territorio, hemos establecido una serie de ejes de análisis que nos permitan ir ordenando los principales aspectos identificados. Estos aprendizajes, en algunos casos, se traducen en nuevos interrogantes o tensiones propias de los procesos que se dan en el territorio en donde se ponen en juego diferentes miradas y perspectivas sobre los temas y el modo en que se abordan; y en otros en propuestas transformadoras hacia adelante pensando en la relevancia de profundizar la gestión de políticas públicas socioambientales en la ciudad de Rafaela.

\subsection{La relevancia del tema ambiental, el contexto y la política de gestión en el territorio:}

Uno de los primeros aspectos a considerar y que surge del análisis, tiene que ver con la importancia de conjugar la innovación en las temáticas socioambientales con las condiciones de posibilidad que permiten que determinados procesos puedan darse según las características propias del territorio y sus posibilidades de acción. El enfoque pedagógico 
plantea muy claramente la idea de contexto para lo territorial, no se pueden potenciar procesos si pensamos que todos los territorios son iguales.

En este sentido a lo largo de las entrevistas hemos ido dialogando con las y los actores acerca de qué cuestiones se conforman en este territorio particular (Rafaela) para que la agenda de los temas ambientales pueda haberse desarrollado, no solo vinculado a las políticas públicas sino también a la participación ciudadana y a la adhesión de la comunidad.

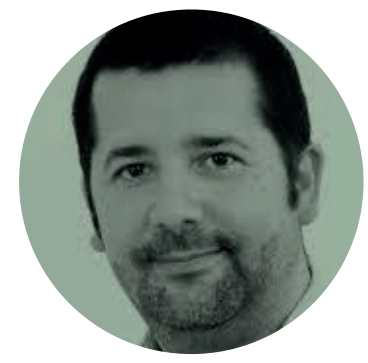

En este sentido Alejandro Jurado (comunicación personal, 17 de febrero, 2017), coordinador y asesor desde los inicios de Rafaela Más Sustentable hasta la actualidad, explica que para entender el surgimiento del entonces Programa Rafaela Más Sustentable, hay que reconocer un diálogo entre el Programa de Competitividad Territorial (mencionado como uno de los principales antecedentes), la política y las redes existentes en la ciudad que tuvieron un rol central para que se visualice con fuerza la posibilidad de incorporar la agenda y las políticas en materia ambiental.

Rafaela venía con un contexto y antecedentes en la articulación público - privada, con una fuerte institucionalización de procesos y ésa fue la oportunidad para instalar nuevos desafíos que suponía pensar en dimensiones a largo plazo en estas temáticas. Menciona que "hubiera sido distinto trabajar con un sector industrial inmaduro que no tuviera un ejercicio de articulación, donde las políticas empresariales no se articularan con las de Estado. En ese entonces se dio un contexto de un equipo del programa más un liderazgo político que sumó para que las políticas socio ambientales generaran raíces y permitió que la ciudad pensara nuevas competencias con asignación de recursos propios o de organismos nacionales e internacionales para trabajar esta agenda".

También enfatiza en que "Rafaela siempre ha sido un "laboratorio" para abordar temas innovadores con la mayor inserción institucional: la Agencia de Innovación y Desarrollo, el Consejo Consultivo Social, un Concejo Deliberante muy activo, las Cámaras Empresariales, los organismos vinculados al sistema científico - tecnológico vienen de una tradición de diálogo entre ellos y se han generado espacios donde se puede encontrar un buen contexto para la discusión. Entonces, si un equipo puede facilitar innovaciones y empujar procesos junto con el entramado, los temas van hacia adelante".

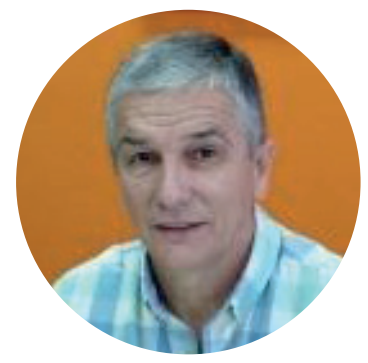

En otra línea desde su experiencia como concejal del Frente Para la Victoria (PJ) Jorge Muriel (comunicación personal, 22 de noviembre, 2016) menciona que estas experiencias se dan en Rafaela principalmente "por el compromiso que adopta lo público y lo privado, $y$ la decisión firme de la política más el compromiso de la gente. $Y$ en este sentido la creación del Instituto para el Desarrollo Sustentable constituye un salto de calidad porque llegará a muchos más sectores". 
Estos aspectos son realmente importantes para entender el contexto y la relevancia en la agenda pública que adquiere en la actualidad la temática ambiental en la ciudad y, en consecuencia, la creación del Instituto. Y no son solamente los temas sino la modalidad de gestión de las acciones, los modos de participación, los liderazgos, los aspectos innovadores y otras cuestiones que hoy constituyen un valor de Rafaela Más Sustentable, que recuperan la tradición propia de un modelo de desarrollo territorial que la ciudad viene implementando desde hace por lo menos 20 años desde la política, pero que tiene antecedentes de más antigüedad y también a través de la participación de otras y otros actores.

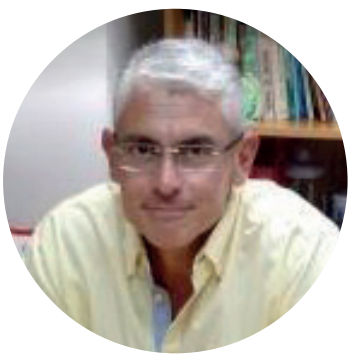

Gustavo Molfino (comunicación personal, 22 de noviembre, 2016), director de la empresa Supermercados Pingüino expresa: "Nuestra empresa está en Rafaela desde hace 40 años y desde siempre nos sumamos con la Municipalidad en los proyectos vinculados a una ciudad más limpia, más ordenada, hoy más sustentable. En aquel entonces el Municipio comenzaba con el relleno sanitario y a ordenar los residuos; enseguida nos sumamos porque vimos que era una forma de colaborar incluso con nosotros mismos porque somos unos grandes generadores de residuos. En ese momento también el Centro Comercial hace un Plan Estratégico en 2007 y allí presidimos la línea de trabajo de Responsabilidad Social Empresaria, que abordaba lo ambiental. Esa es un poco la historia: una vinculación con el Municipio desde los valores y luego un reforzamiento desde la política empresarial en el Centro Comercial que nos impulsa, nos organiza y genera ámbitos de encuentro, de intercambio, construcción colectiva y articulación”.

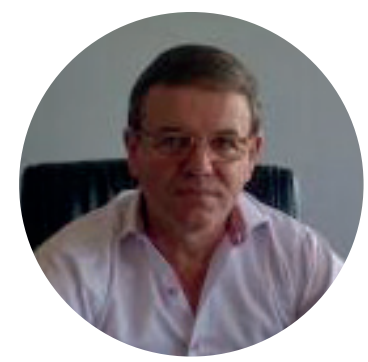

En la misma línea Andrés Ferrero (comunicación personal, 23 de noviembre, 2016), presidente de la empresa DEISA y presidente del Centro Comercial e Industrial de Rafaela y la región, plantea la importancia de lo que significó el cierre del basural a cielo abierto y la realización de acciones que trascienden las cuestiones de infraestructura para apuntar a lo social, buscando una alternativa para las familias que estaban vinculadas a esta actividad. Menciona que " $\mathrm{Al}$ margen de que nosotros teníamos ya unos cuantos proyectos en el país allá por el 2005, 2006 tuvimos la posibilidad de establecer los primeros equipos en el relleno sanitario que permitían dar una respuesta distinta a la gestión integral de residuos sobre todo en lo referido al recupero de los materiales inorgánicos que podrían volver a ser insumo industrial y vinculado sobre todo a facilitar la gestión de los grupos que estaban trabajando". 


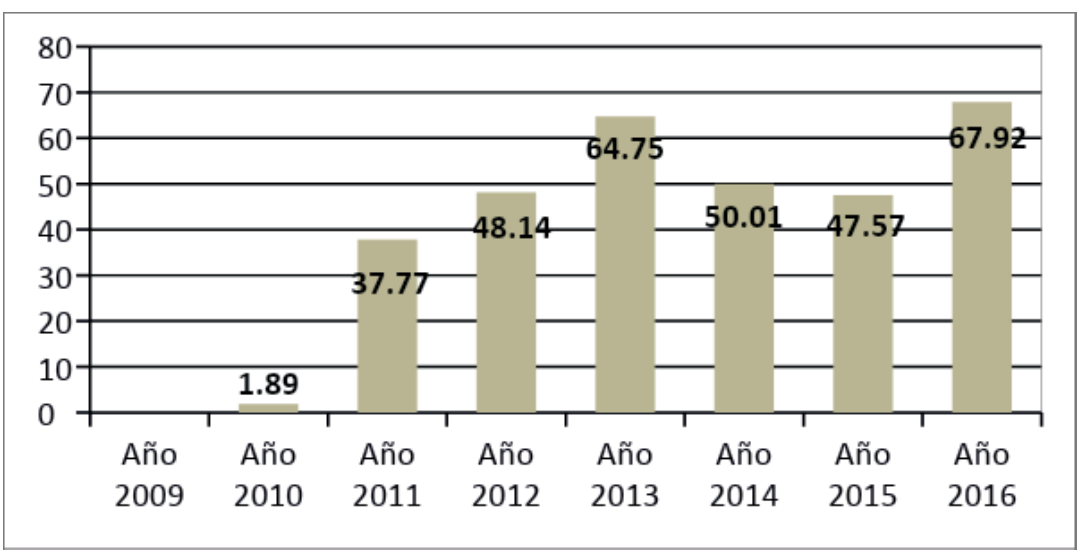

Gráfico 1: Elaboración propia. Fuente página web Municipalidad de Rafaela.

Aquí se suma otro elemento distintivo de las políticas de Rafaela que tiene que ver con priorizar lo local, en este caso una empresa de la ciudad que pudiera prestar estos servicios. Si bien también es un entorno que se caracteriza por atraer y convocar consultores y consultoras, expertos y expertas, investigadores, formadores y recursos humanos por fuera de la región, el espíritu se basa en la importancia de generar o fortalecer capacidades locales para afrontar las distintas demandas que el propio territorio va promoviendo.

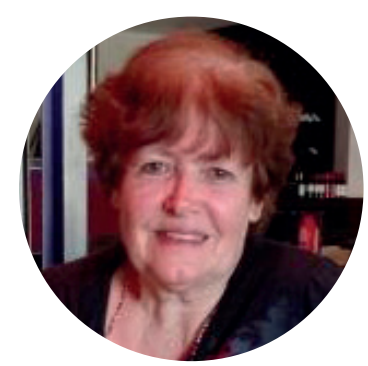

Un antecedente clave para el desarrollo de Rafaela Más Sustentable fue la gestión de Marta Engler (comunicación personal, 23 de noviembre, 2016) como Secretaria de Espacios, Servicios Públicos y Ambiente durante el período de gobierno de Omar Perotti, quien expresa: "Queríamos mejorar todos los procesos que estaban ligados a la cuestión ambiental que no tenían una mirada sistémica, no estaban con objetivos claros de mejora continua y se necesitaba definir bien cuáles eran las líneas de trabajo. Fue un trabajo monstruoso en donde Alejandro (Jurado) no sólo tenía el conocimiento técnico sino también muchísima capacidad de gestión y de negociación y conexiones muy importantes para obtener financiamientos".

Esta ex funcionaria marca una relación entre las personas y las organizaciones siempre presentes a la hora de la política pública donde son las personas las que traccionan para instalar, defender y promover los temas innovadores que requieren el apoyo y el trabajo conjunto de diferentes sectores.

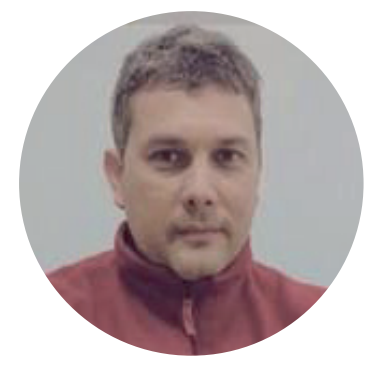

Desde la experiencia del INTI Rafaela, según lo comparte Marcos Alassia como referente de dicho organismo en el proceso de conformación de Rafaela Más Sustentable: "El programa de Competitividad Territorial fue una gran oportunidad para el INTI ya que se generaron espacios de reflexión y participación de distintos sectores del territorio: gobiernos, instituciones científico tecnológicas, 
universidades, empresas, etc., con objetivos alineados con los intereses de nuestra institución. Es por este motivo que el INTI sumó su colaboración en varios ejes de trabajo, entre ellos en los de Rafaela Más Sustentable, participando activamente del proceso previo a su creación. Nuestro interés perseguía que los gobiernos locales tomen el liderazgo de sus territorios en la búsqueda de soluciones sostenibles a las problemáticas ambientales. En nuestra ciudad, y quizás por una cuestión de cercanía, se realizaron muchas actividades con este fin, teniendo el INTI un rol protagónico" (comunicación personal, 17 de mayo, 2017)

A partir de estas reflexiones que retomamos de los diálogos como dimensiones de aprendizaje, nos parece relevante señalar como elemento de análisis la importancia de recuperar los procesos previos donde cobran sentido ciertos temas y modos de hacer. Esto también constituye un indicador del por qué consideramos que desde el enfoque del desarrollo territorial no se pueden copiar modelos y recetas a aplicar, sino que en cada territorio existe un conjunto de dimensiones que traccionan o no los cambios, en este caso, ligados a las políticas ambientales.

Esto es clave en un proceso de sistematización dado que se recupera la historia, la identidad y la cultura local que posibilitan y dan sentido al desarrollo de cada experiencia, más allá de las fórmulas exitosas, y que crean las condiciones de posibilidad para que los procesos se gesten y se profundicen. Algunas de las iniciativas que se han puesto en marcha en este territorio, nacen de años de redes de relaciones, de diálogos intersectoriales, de construcciones compartidas y también de tensiones y espacios de desencuentro. Las tradiciones del "hacer juntos" con continuidades y discontinuidades, con aciertos y desaciertos constituyen un espacio en donde se apoyan algunas de las acciones que Rafaela Más Sustentable luego implementa.

\subsection{El enfoque de la transversalidad:}

Otro de los ejes recurrentes en los aprendizajes identificados en el diálogo con las y los actores vinculados a la gestión de Rafaela Más Sustentable, tiene que ver con el enfoque de la transversalidad y las dificultades que ello conlleva. Se muestra el diálogo entre saberes, la importancia de la multidisciplina en la co-construcción de procesos. Sobre todo, a partir de la etapa en que el Programa pasa a instalarse formalmente en la órbita de la Municipalidad de Rafaela y que aún tiene implicancias y consecuencias en la reciente conformación del Instituto para el Desarrollo Sustentable.

Desde su impronta inicial el enfoque de $\mathrm{R}+\mathrm{S}$ se basó en la premisa de que las políticas y estrategias ambientales no deben ser exclusivas de un área o un sector, sino que necesitan articularse y abordarse de manera conjunta. En la práctica misma los procesos que se realizan involucran una cantidad de dimensiones que requieren del trabajo mancomunado, un claro ejemplo es la gestión integral de residuos sólidos urbanos. Por lo cual la discusión sobre la transversalidad ha sido y es un tema importante y en algunos casos un obstáculo para el desarrollo de las acciones concretas. Aparece claramente el diálogo como una herramienta y estrategia central. 
Las dificultades en torno a la transversalidad de las acciones se han debido a varios factores: por un lado, a las lógicas organizacionales y las estructuras burocráticas propias de las instituciones del Estado que no están preparadas para la complejidad que requiere el trabajo en conjunto y aún más la gestión de los procesos que involucran a varios sectores y actores. Por otro lado, pareciera también que entran en juego otras dimensiones vinculadas al poder, a los intereses encontrados y a la cuestión del liderazgo sobre los temas o "de quien es el rédito" cuando se alcanzan los resultados esperados.

Otro elemento tiene que ver con que la agenda ambiental resulta un tema mucho más secundario que otros para el día a día en un estado local, por lo cual los tiempos, los recursos en un sentido amplio y los esfuerzos que se destinan son generalmente menores en relación a otras cuestiones prioritarias para la gestión, que debe brindar respuestas a corto plazo a las necesidades y demandas de las y los vecinos. Esta situación además se vincula con la dimensión política dado que en muchos casos las prioridades tienen que ver con resultados que sean tangibles para la sociedad y que cobren sentido en términos de decisiones vinculadas a los procesos electorales municipales.

Los temas ambientales generalmente son todo lo contrario, requieren de inversiones y gestiones en donde los resultados son siempre a mediano y largo plazo e incluso demandan procesos de sensibilización, como por ejemplo la separación de residuos en origen, la instalación de equipamientos domiciliarios de energías renovables, las campañas de movilidad sustentable, las discusiones sobre ordenanzas de límite agronómico, de grandes generadores de residuos, entre otros.

Asimismo, la problemática de la transversalidad no es exclusiva del ámbito de la gestión pública, sino que también se presenta como un desafío para el abordaje de las acciones que siempre están involucrando a más de un sector (como por ejemplo las empresas) como es el caso de Rafaela Más Sustentable.

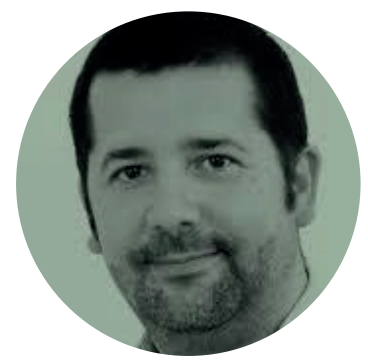

En relación a este tema Alejandro Jurado (comunicación personal, 17 de febrero, 2017) menciona que "la idea de la transversalidad significa un esfuerzo tanto en lo teórico y en lo técnico porque un tema como la industrialización de residuos por ejemplo implica un trabajo mancomunado y articulado entre sectores privados y públicos, también tiene un componente ciudadano porque la materia prima tiene diversidad de origen: es el sector agropecuario, el industrial pero también es generador la familia y el mismo municipio. Entonces los "generadores" son actores con quienes trabajar de manera transversal para encontrar un proceso de cadena de valor".

Frente a estas cuestiones surge un interrogante que es quién realiza esta tarea vinculada a la transversalidad: articular, generar espacios de diálogo, negociación y gestión. Jurado (comunicación personal, 17 de febrero, 2017) apuesta a que "este trabajo requiere de una 
persona o un grupo de personas que funcionen como facilitadores. Que es quien llama a alguien, se reúne con gente clave para que se realicen las acciones, genera espacios para que se encuentren, negocia, tira ideas. La idea siempre fue no dejar de lado ningún actor relevante ni ningún organismo del Estado, ni ninguna de las áreas de la Municipalidad. Esto no quiere decir que todo sea armonioso, sino que muchas veces se generan tensiones porque no todo el mundo entiende estas acciones como prioritarias y a largo plazo, y además a veces se esperan resultados concretos y para esto se requieren otros tiempos".

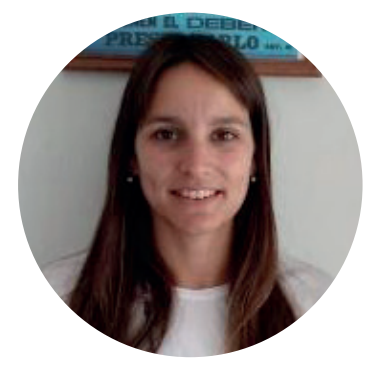

María Paz Caruso (comunicación personal, 21 de noviembre, 2016), actual Directora del Instituto para el Desarrollo Sustentable, quien ha formado parte del equipo de trabajo desde sus inicios también recupera esta dificultad y menciona que fue un proceso que fue madurando. Señala que en su momento "costaba mucho que las demás Secretarías se apropien del Programa y generar uno de los objetivos principales que nos habíamos planteado que era la transversalidad. También nos costó porque el tema ambiental era innovador y a medida que íbamos avanzando se complejizaba, teníamos que pasar del trabajo compartimentado hacia una lógica en donde más de un área tenía que involucrarse".

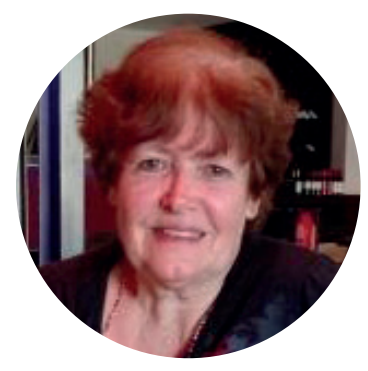

Marta Engler (comunicación personal, 23 de noviembre, 2016) también aporta en ese sentido que el Programa $\mathrm{R}+\mathrm{S}$ impulsó soluciones efectivas y nuevos esquemas frente a situaciones arcaicas y tradiciones que ya no se podían seguir sosteniendo. $Y$ fue una dificultad en ese entonces "empezar a incorporar estas ideas en la Municipalidad que es un sistema en donde cada uno está muy enfocado en su especialidad y este Programa requería una transversalidad imprescindible, sumado a que la persona que venía a articularlo era de afuera con todas las resistencias que eso genera. Esto fue lo valioso del Programa $R+S$ que con una pelea descomunal generó esa articulación transversal con muchas áreas de la Municipalidad e implicó generar una red de actores impresionante". Marta rescata en este tema la importancia de que en la base estaba presente un modo de gestión de diálogo y articulación. Haciendo un balance plantea que si bien hacia adentro fue complejo se fueron logrando muchas cosas, como por ejemplo una serie de ordenanzas municipales muy avanzadas en las que Rafaela es pionera.

Si bien la reciente creación del Instituto contribuye a trabajar con mayor autonomía, el enfoque de la transversalidad continúa siendo un desafío permanente no solo con las organizaciones públicas, sino también con el sector empresarial, educativo, el científico - tecnológico, entre otros, en donde el modelo de gestión del ahora Instituto también comienza a plantear nuevas necesidades y discusiones.

En función de este escenario surge como una de las claves a profundizar la formación del equipo, que conduce el Instituto y sus líneas de trabajo, en el rol de facilitación de procesos de 
desarrollo territorial. Porque la perspectiva de la transversalidad implica nuevas capacidades de gestión de procesos y articulación de sectores, con lo cual es importante salir de las lógicas de especialidades sectorizadas para abordar procesos complejos que requieren abordajes complejos. Este es un aprendizaje que constituye un enorme desafío hacia adelante.

\subsection{El rol y el liderazgo del Estado Local:}

Un aspecto considerado como un valor y reconocido por todas y todos los actores con quienes dialogamos tiene que ver con el liderazgo del Estado local como una dimensión estratégica para impulsar, primero la agenda ambiental y luego una política pública que se formaliza posteriormente a través de la creación del Instituto.

Este eje es trascendente porque asistimos a un contexto en el que cada vez más se vienen transfiriendo a los municipios responsabilidades que tampoco vienen acompañadas de los recursos necesarios. Tal es el caso de la agenda ambiental en donde, además, como mencionamos anteriormente, en muchos temas hay unos tiempos de los procesos que muchas veces no se corresponden con los tiempos a corto plazo que los resultados de la gestión de gobierno requieren y necesitan, son dimensiones que tampoco tienen una alta visibilidad como por ejemplo una obra de infraestructura. En este sentido entonces la decisión política ha sido fundamental no sólo en las acciones sino también destinando recursos. Asimismo, se hace visible la idea de un estado democrático que construye con espacios para diálogos y acción.

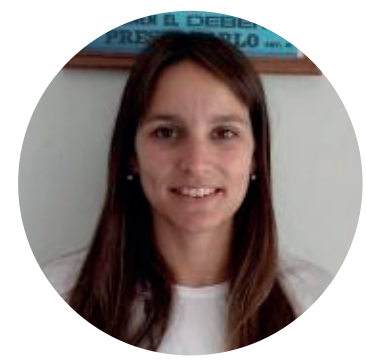

Al respecto María Paz Caruso (comunicación personal, 21 de noviembre, 2017) menciona que "uno de los aprendizajes fundamentales ha sido el liderazgo del Estado local para impulsar la política ambiental. Primero con la gestión de Omar Perotti quien define lo ambiental como una prioridad en tanto línea de trabajo y después con Luis Castellano quien ve que el propio organigrama y estructura municipal no puede albergar todo lo referido a la temática ambiental y define la importancia de potenciarlo a través del Instituto".

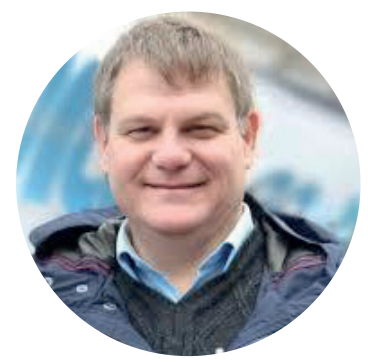

Marcelo Becla, representante del Consejo de Pastores de la ciudad de Rafaela en el Consejo Ambiental, (comunicación personal, 10 de marzo, 2017) enfatiza al respecto que "si bien en el 2015 cuando fue conformado el Consejo la convocatoria tenía que ver con algo independiente de la Municipalidad, a decir verdad, si no fuera por su liderazgo no tendría acción. Cada institución está metida en sus responsabilidades y en sus cosas, pero tendría que haber una mayor participación, que no sea únicamente alinearse, sino que cada uno se sienta como en casa, se apropie y en eso aún tenemos mucho por hacer". 


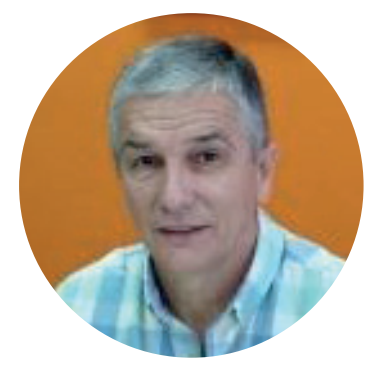

Por su parte Jorge Muriel, concejal de Frente para la Victoria, (comunicación personal, 22 de noviembre, 2017) señala la importancia de "la decisión del Intendente de convertir el Programa en un Instituto a través de una ordenanza que fue votada por unanimidad por todos los concejales, porque todos veníamos apoyando desde su sector político el trabajo que hacía el Programa $R+S$. En un proceso de estas características es clave el liderazgo del Estado con fuerza y con continuidad a largo plazo. Seguramente habrá que seguir creciendo en políticas, en nuevas ordenanzas y en darle mayores facultades al Instituto, pero siempre con la clara intención de ir hacia una ciudad verde; sabiendo que estas políticas en la mayoría de los casos no generan resultados inmediatos".

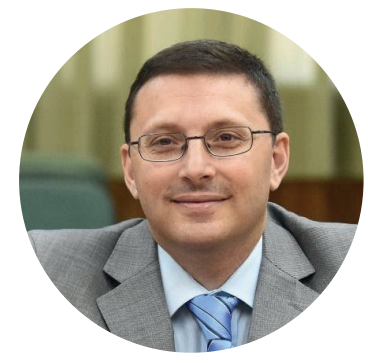

Lisandro Mársico, concejal por el Frente Progresista Cívico y Social e integrante también del Consejo Ambiental (comunicación personal, 13 de marzo, 2017) enfatiza sobre la importancia de las políticas de estado a largo plazo, más allá de las gestiones de gobierno: "difiero en muchos temas con esta gestión, pero en éste particularmente acuerdo en que se ha sido una clara política de estado sobre lo ambiental, especialmente en lo referido a la disposición final de la basura y a los puntos instalados en la ciudad para llevar residuos especiales como los de poda, plásticos, neumáticos, computadoras, maderas, vidrios en donde para cada tipo de residuo hay un contenedor. Con decirte que en mi caso he presentado un proyecto al Concejo Municipal para que se haga lo mismo en el sector este de la ciudad para quienes están más distantes no tengan que atravesar toda la ciudad. Son políticas de estado en las que el municipio está trabajando pensando en el largo plazo y cubriendo las necesidades de la gente".

Es interesante destacar como aprendizaje que estas decisiones sobre políticas a largo plazo parten de procesos previos que se van gestando y tienen que ver con la importancia de la interacción y el diálogo entre el equipo técnico, que venía pensando e impulsando los temas ambientales, y el liderazgo político. Aquí hay un valor que tiene que ver con los modos de relacionarse y cómo el equipo del Programa se va involucrando y retroalimentando con la política y sabe entender sus demandas y necesidades. $Y$ de nuevo retomamos aquí la importancia de los procesos de facilitación, porque es la persona facilitadora quien construye espacios para la reflexión y la toma de decisiones que pasen a la acción.

\subsection{El modelo de gestión:}

Una dimensión central ha sido desde el inicio un modelo de gestión que tal y como lo definen varias y varios entrevistados tiene como premisas el fortalecimiento institucional de todas las políticas, la creación de marcos regulatorios, la articulación con las y los actores de los estados nacionales, provinciales e internacionales; así como con el sector institucional, cultural, deportivo o empresarial. Sumado también a una visión de cadena de valor que implica mirar los procesos de manera integral. El modelo tiene que ver también con entender 
que para cada ciudad hay una política específica y que no se trata de "copiar y pegar", no es posible transferir.

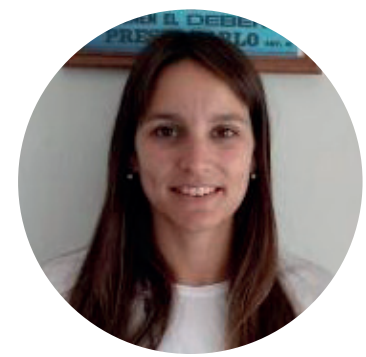

María Paz Caruso, (comunicación personal, 21 de noviembre, 2016) desde su experiencia de gestión agrega que se trata también de "entender que no se puede trabajar de la misma manera en todos los sectores de la ciudad. Rafaela tiene muchos jóvenes nuevos de otras ciudades por las universidades y otras comunidades, que tal vez no tienen la cultura del rafaelino y por eso es necesario ampliar las estrategias reconociendo las particularidades. Nosotros no tenemos incorporado como modalidad de trabajo que lo masivo es lo que llega a la gente, sino que tenemos que desarrollar diferentes estrategias con cada público que vamos identificando y ese es un desafío muy grande que se nos viene".

Otro aspecto del modelo de gestión es la mirada integral y a largo plazo y allí Caruso menciona como ejemplo "la campaña de recolección de aceite vegetal usado donde se creó una normativa, se identificaron puntos de recolección como lo fueron los supermercados, tenían claro cuál era el destino final de ese material y Rafaela entonces tiene una planta de biodiesel que ya está en marcha. Este es el ejemplo de un objetivo pensado desde cero estratégicamente y que termina con un destino final seguro del material. Esto es lo realmente difícil en la gestión pensar todo el proceso".

También se recupera como valor el trabajo en equipo que se considera un aspecto clave pero que requiere aprendizajes: manejar los tiempos, entender las dinámicas y reconocer las particularidades y habilidades del propio equipo y de las y los actores con los que se vinculan.

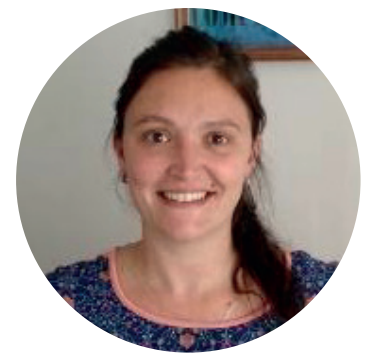

En este sentido, Gisela Daniele (comunicación personal, 21 de noviembre, 2016), integrante del equipo técnico de Rafaela Más Sustentable en el área de residuos, rescata: "aprendí un modo de trabajo de la transversalidad, del trabajo en equipo con otras áreas, en cómo articular con muchas instituciones. El último ejemplo es la ordenanza de generadores especiales en donde más allá de haber sido un proyecto que se armó desde el Instituto, se compartió con la ciudad para que todos aporten sus sugerencias y el resultado sea un producto colectivo".

Por otra parte, se rescata la importancia de la mirada de cadena de valor. Y ahí Gisela recupera que "se empezó a ver de otra manera la gestión de los residuos. En ese momento se hablaba de disposición final, a través de una de las líneas que se venía implementando, "Creando conciencia", se estaba haciendo campaña en recolección diferenciada. Pero desde el Programa $R+S$ se comienza a hablar de poner en valor la recuperación de los residuos. No se pensaba en ese entonces en el paso posterior de lo que significa valorizar un residuo que se ve materializado en lo que hoy es el Parque Tecnológico de Reciclado. Eso fue lo que hizo el quiebre a mi entender este espacio: proponer y generar una mirada más integral". 


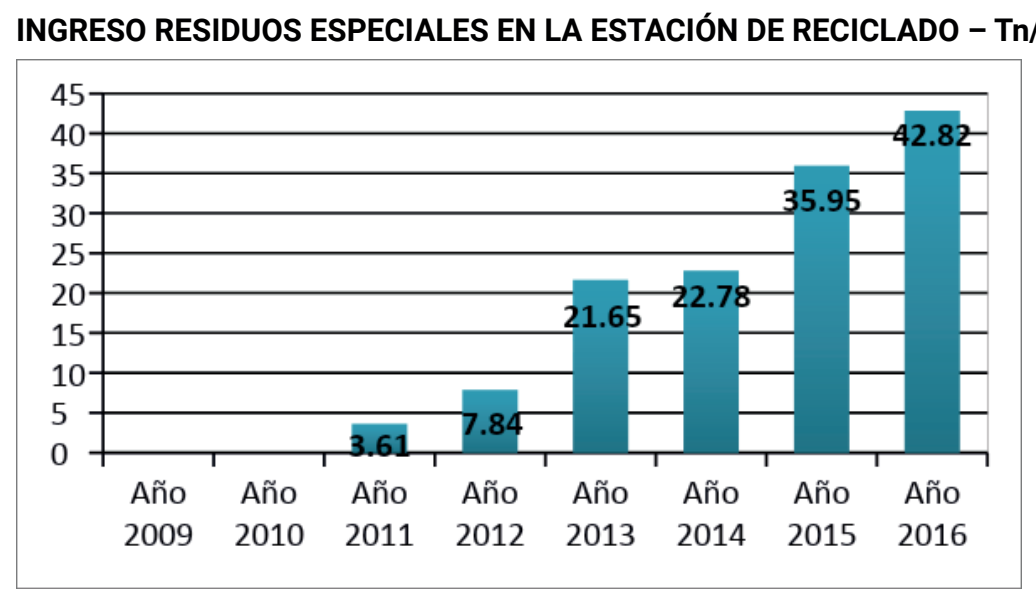

Gráfico 2: Elaboración propia con datos Página web Municipalidad de Rafaela

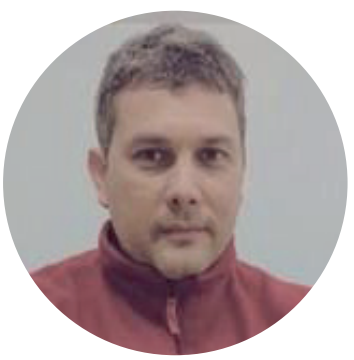

Marcos Alassia, señala la importancia de cómo el INTI es convocado a participar de las acciones ya desde el 2008, a través de las actividades del Programa R+S, con un enfoque diferente sobre la gestión de los residuos y el cumplimiento de la Legislación Ambiental donde: "Se convoca al personal técnico de los municipios y comunas de la región con el objetivo de comparar problemáticas, propuestas y de analizar el marco regulatorio local. Es de destacar que más allá de los participantes, el tema ambiental no estaba como prioritario, ni en las agendas públicas ni en las privadas de la región" (comunicación personal, 17 de mayo, 2017)

Otra característica que se señala Marcos desde la experiencia del INTI Rafaela, y que se vincula también al modelo de gestión, es que "se pensaron las actividades considerando el tema ambiental como oportunidad. Para nuestra región fue novedoso, atrayendo la atención de actores que hasta el momento habían sido muy difíciles de convocar. Precisamente este nuevo enfoque para el abordaje de la problemática ambiental constituye, a nuestro entender, una de las innovaciones más destacables que el Programa trajo y dejó en la ciudad y en algunas partes del territorio. La otra tiene que ver con pasar de considerar estas problemáticas como cuestiones particulares de cada municipio o comuna, a abordarlas como una cuestión territorial". (comunicación personal, 17 de mayo, 2017)

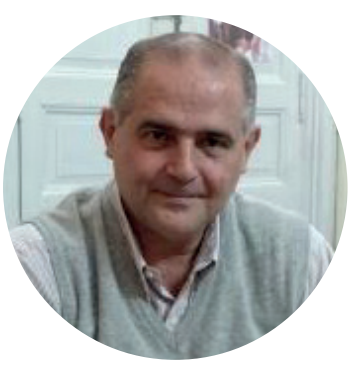

Alejandro Bonet, representante del Obispado de Rafaela en el Consejo Ambiental del Instituto, refiere a la importancia que este espacio ha generado hacia la comprensión y puesta en acción del propósito de la Encíclica Laudato $\mathrm{Si}$, tratando de concretar una respuesta local a los distintos temas planteados a lo largo del contenido de la encíclica. Afirma que "una de las cosas que más destaco del Instituto es el método tal como plantea el Papa invitando a superar la situación que vivimos hoy a través de la cultura del encuentro, del diálogo y el Instituto es la encarnación de ese método. Porque se propone poner en diálogo al conjunto de la vida social en relación a los temas que hoy nos están afectando y dañando en la manera en cómo estamos tratando el medio ambiente" (comunicación personal, 22 de noviembre, 2016) 


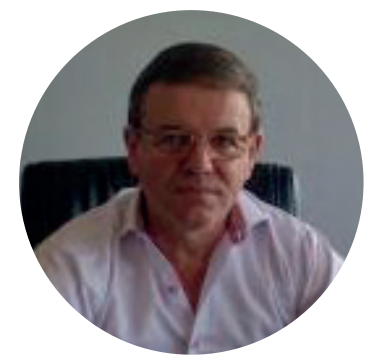

Andrés Ferrero, presidente de la empresa DEISA y del Centro Comercial e Industrial de Rafaela y la región, rescata la presencia de profesionales venidos desde afuera, que permitieron abordar contenidos innovadores "porque no se trata solamente de la cuestión de las normativas municipales sino trabajar con la comunidad y con el abordaje de un conjunto de normas y pautas de convivencia totalmente nuevas desde el entramado institucional, desde las escuelas, desde las familias. $Y$ no solamente desde el tema de residuos sino en un contexto amplio de todos los temas ambientales" (comunicación personal, 23 de noviembre, 2016)

Podemos concluir que el trabajo en red entonces es una de las grandes potencialidades que Rafaela Más Sustentable sostiene. El involucramiento de las instituciones públicas y privadas y de la diversidad de las y los actores locales, hace posible el sostenimiento de las innumerables líneas de trabajos que se han puesto en marcha en la ciudad.

A este enfoque de red se le suma un elemento más que es la vinculación que se realiza entre los temas innovadores y las fuentes de financiamiento, nacionales e internacionales, que ayudan a que las estrategias puedan implementarse acompañadas de los recursos necesarios. Este valor es clave y representa un desafío para la sostenibilidad, teniendo en cuenta que los estados locales cada vez cuentan con menores recursos, en un contexto de profunda crisis a partir de 2015.

1.5 La construcción de la agenda ambiental: anticipación y oportunidad

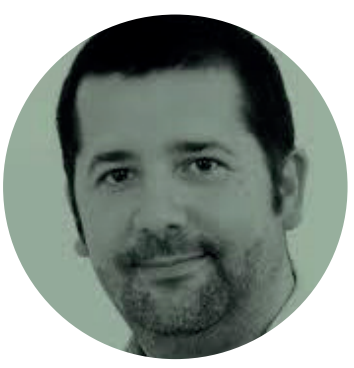

Dos elementos marca Alejandro Jurado (comunicación personal, 17 de febrero, 2017): uno tiene que ver con anticiparse a los temas y el otro se basa en la importancia de reconocer las oportunidades del contexto.

Jurado afirma que "En 2008 y 2009 había aspectos que pertenecían a lo que se llamaba la agenda de la innovación muy anclado a temas de empleo y a la solución de problemas sobre todo del sistema productivo. En ese entonces se pensaba sobre todo en cómo transformar los residuos industriales en nuevas materias primas o resolver la disponibilidad de energía en el Parque Industrial a través de políticas de eficiencia energética. Se pensaba mucho en el acceso a energías renovables, pero en un contexto de ecuación económica que no cerraba. No había marco regulatorio como lo hay ahora, que era un factor determinante para avanzar o no con esta agenda. Igualmente se podía empezar a trabajar sobre todo en unidades demostrativas y pequeñas experiencias piloto, un abanico de acciones diversificadas y con una visión integral de la gestión ambiental".

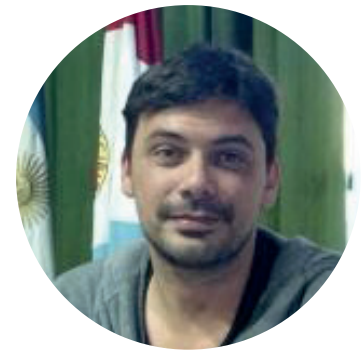

Claudio Gasparotto (comunicación personal, 22 de noviembre, 2016), quien fuera equipo técnico del Programa en sus inicios, rescata que "muchos temas en su momento fueron mirados como inversiones que no convenía realizar, como por ejemplo el tema de eficiencia energética y la escasez de agua y hoy frente al cambio de contexto adquieren relevancia y pueden llevarse adelante porque se sembró una semilla". 


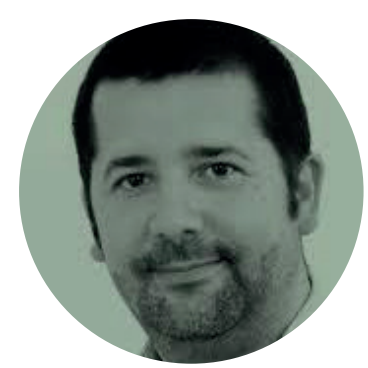

También Alejandro Jurado (comunicación personal, 17 de febrero, 2017) plantea una mirada crítica respecto a cómo en ciertos temas habría que haber profundizado la mirada previendo el futuro. Uno de ellos es "el componente de Arbolado urbano y biodiversidad que estuvo desde la primera hora, pero la ciudad nunca lo tuvo fuertemente en la agenda, si bien se fueron generando acciones en ese momento se veía más como una cuestión simbólica que un tema que brindara elementos funcionales y prioritarios para la ciudad. Durante años fue una actividad totalmente subterránea e intrascendente hasta que en el 2016 y 2017 el tema del arbolado está en el tope de la agenda ambiental. Veníamos vaticinando que el cambio climático en un momento iba a ser una realidad en Rafaela y en el mundo, sumado a un modelo de uso de la tierra en el entorno de Rafaela que también venía cambiando brutalmente, desencadenó distintas crisis: una tormenta volteó casi 2 mil árboles con daños materiales que han puesto en jaque a la ciudad. Y ahora nos damos cuenta que habría que haber creído mucho más fuertemente en adaptar el arbolado urbano al cambio climático. Esto es un buen ejemplo para darle centralidad al tema y entonces ahora sí se está encarando con un fuerte liderazgo político y con el acompañamiento del Concejo Municipal, un plan de adaptación al cambio climático que nos va a obligar a intervenir en toda la arboleda."

El otro claro ejemplo tiene que ver con la energía: "Cuando lo abordamos en la agenda de la ciudad y empezamos a implementar con subsidios nacionales programas de eficiencia energética la verdad es que la gran mayoría de las industrias no se sumaron. En ese momento la tarifa era baja y tampoco había marco regulatorio para obligar a la industria a las energías renovables como pasa ahora con un $8 \%$ a partir de la reglamentación de mayo de 2016. Los programas de producción más limpia que intentamos implementar no lograban el impacto esperado, el aprovechamiento de residuos industriales para la generación de energía a costos realmente de oportunidad como era en ese momento las grandes compañías de Rafaela, si bien se interesaron, no avanzaron. Hay que entender también los tiempos de los procesos, pero se perdió una gran oportunidad porque ahora el contexto es mucho más difícil, mucho más competitivo. Ahí creo que intentamos hacer punta, pero no estaban dadas las condiciones y tampoco había una madurez temática. Ahora acabamos de sancionar la ordenanza de calefones solares que estuvo 4 años demorada, en donde en un momento era pionera y ahora llega tarde. Hoy ya deberíamos tener entre un 20 y 30\% de los edificios y las casas de Rafaela alimentándose con energía solar térmica y estamos por debajo del 1\% que es casi inexistente".

Ambas dimensiones son interesantes para señalar como aprendizajes. Si bien trabajar sobre la sensibilización de los temas y la instalación de agendas referidas a los temas hacia el futuro en materia socio ambiental parece ser un aspecto del modelo de gestión, se renuevan los desafíos para el Instituto vinculados a cómo conjugar la mirada hacia adelante con los contextos locales, nacionales e internacionales que son complejos y cambiantes. Sumado también a la voluntad política y a la combinación con la demanda de la agenda ciudadana en temáticas que, en la mayoría de los casos, no forman parte de lo urgente y del día a día. Insistimos que para que esto suceda hay gente que trabaja la gestión de la complejidad. 


\subsection{La relevancia de los procesos participativos:}

Otro de los aprendizajes del proceso que merece especial atención tiene que ver con los modos de participación y los procesos participativos, y en ello Rafaela Más Sustentable recupera la propia tradición que la ciudad viene teniendo desde al menos los últimos 20 años donde el ejercicio participativo se promueve desde diversos ámbitos. Nuevamente aparece la figura de personas facilitadoras trabajando para potenciar procesos.

Si bien la dinámica de participación en la agenda ambiental se venía impulsando desde el Programa $\mathrm{R}+\mathrm{S}$ a partir del trabajo en red y el involucramiento de actores e instituciones públicas y privadas, podría decirse que esta modalidad tiene su correlato formal en la conformación de un Consejo Ambiental creado recientemente a partir de la formalización del Programa en el Instituto para el Desarrollo Sustentable y que aparece además como uno de los requerimientos en la propia ordenanza que le da origen.

Este Consejo se constituye como un organismo de asistencia y asesoramiento cuyos miembros son: un representante por cada uno de los bloques del Concejo Municipal de Rafaela, uno por el Centro Comercial e Industrial de Rafaela y la Región, uno por la Sociedad Rural de Rafaela, uno por el Consejo de Pastores, uno por el Obispado de Rafaela, uno por la Federación de Entidades Vecinales, uno por Organizaciones no gubernamentales de la Sociedad Civil y otro por la Confederación General del Trabajo (CGT). Si bien sus decisiones no son vinculantes, supone un modo de gobernanza en donde los temas estratégicos, las decisiones y las políticas se someten al diálogo entre sectores.

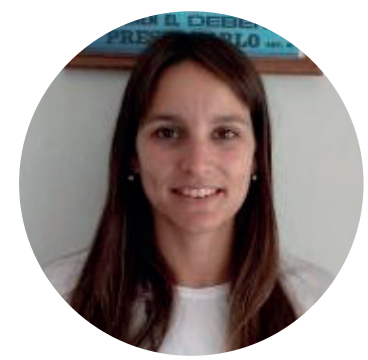

El Consejo resulta una figura interesante para, de alguna manera, materializar un modo de trabajo basado en el diálogo y la discusión de los temas estratégicos para la política ambiental de la ciudad. María Paz Caruso (comunicación personal, 21 de noviembre, 2016) plantea que "le dio más fuerza, más participación y apropiación a los temas porque no es lo mismo debatir y construir conjuntamente que sacar las ordenanzas para su cumplimiento. Es un proceso con tiempos muchísimos más largos, pero mucho más enriquecedor".

Un interrogante en este sentido tuvo que ver con el modo en que esos actores se consideraron representativos y se eligieron para conformar este espacio. La respuesta que comparte María Paz es que se decidieron en base a aquellos que ya venían vinculados y había antecedentes de trabajo en conjunto. Pero ella misma plantea la importancia y la necesidad de ampliar las y los actores e incluir otras voces que no están presentes y que tienen mucho por aportar en espacios de construcción como éste. Como por ejemplo las organizaciones sociales, dado que hoy en día sólo se encuentra presente el Club 9 de Julio y también un sector estratégico como lo es el educativo en un sentido amplio y, especialmente, las Universidades, así como también los organismos de investigación y los científico - tecnológicos. 


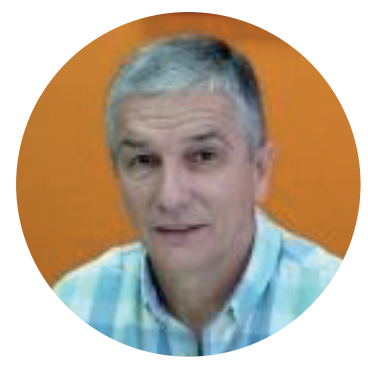

Respecto a esta nueva figura del Consejo Ambiental Jorge Muriel (comunicación personal, 22 de noviembre, 2016), como representante en dicho espacio por el bloque del Frente para la Victoria en el Concejo Municipal, afirma que "permite tener una mirada amplia en la que cada institución puede dar su punto de vista, eso realmente enriquece el debate y nos permite tener discusiones importantes como lo es por ejemplo la ordenanza de fitosanitarios y de límite agronómico, que es conflictiva porque a nivel provincia y nación no hay regulación. Allí el Instituto tiene mucho por decir y un rol muy importante porque va interactuando con la sociedad en temas que son trascendentes".

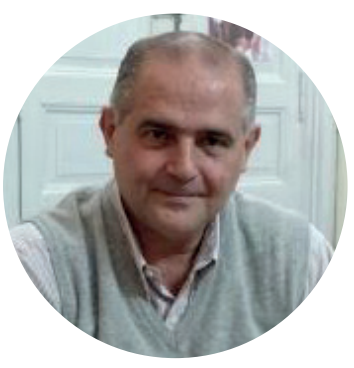

Por otra parte, Alejandro Bonet (comunicación personal, 22 de noviembre, 2016) como representante por el Obispado de Rafaela plantea que "lo importante es que en vez de mantenerse en el plano de la intencionalidad se va al plano de lo práctico y cada uno de estos proyectos se va consensuando. No se viene con la cosa armada y cerrada y nos piden prestar consentimiento para hacer determinadas cuestiones. $Y$ no sólo estamos teniendo de manera habitual la reunión que es propia del Instituto, sino que a su vez siempre somos invitados a participar a todas las actividades y a proponer lo que queramos incorporar en la agenda".

Más allá de la dinámica propia del Consejo Ambiental es importante hacer visible que los procesos participativos no significan que todo se da de manera armoniosa, sino que es casi inevitable que aparezcan conflictos y puntos de vista diversos y encontrados. Aquí es central el rol de el /los facilitadores y facilitadoras de este tipo de procesos para que el conflicto no suponga un obstáculo, sino que permita seguir avanzando.

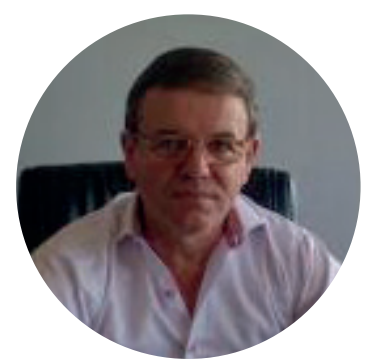

Andrés Ferrero (comunicación personal, 23 de noviembre, 2016), también valora positivamente la participación y como se plantea el abordaje no desde la imposición sino de manera colectiva considerando que "esto de la "casa común" es una temática que en Rafaela encontró más elementos comunes que dificultades porque como toda cuestión puede tener algún tema de debate o cuestiones contradictorias, pero en ningún caso las propuestas han tenido un no rotundo. Creo que en el sector empresario hay un convencimiento de que en estos temas hay que ir para adelante y ya estar en la misma dirección es un paso fuerte. Hay temas que hoy por hoy merecen un enfoque distinto y que pueden permitir a lo largo del tiempo no sólo no tener mayores costos, sino que al contrario hacer actividades más sostenibles y más sustentables. $Y$ en relación a mi nuevo rol como presidente del Centro Comercial lo que pretendo es que haya una continuidad de trabajo y que podamos seguir dándonos la discusión de los distintos temas con la mayor amplitud y las mayores posibilidades de ponernos de acuerdo". 
Vinculado a la participación, uno de los interrogantes que aparece en el proceso de esta experiencia, tiene que ver con qué otras y otros actores faltarían vincular o a quienes se considera necesario "aliar" a este tipo de iniciativas. Se parte de la base de que para llevar adelante la multiplicidad de actividades que se desarrollan debe generarse una lógica de trabajo en red e involucramiento con las y los actores locales, tal como venimos describiendo en estas páginas; más aun teniendo en cuenta que el Programa, y ahora Instituto, cuenta solamente con seis personas dedicadas a su funcionamiento. En este contexto un logro fundamental ha sido generar una red de aliados y aliadas que traccionan en conjunto los proyectos.

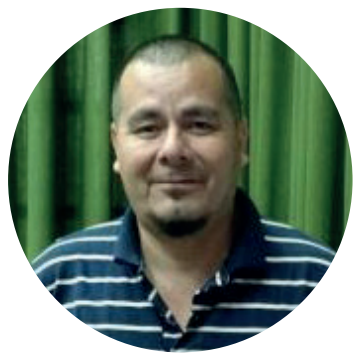

Sin embargo, en ese esquema pareciera haber algunos sectores con los cuales se requiere profundizar las relaciones para impulsar y renovar las acciones actuales y a futuro. Así lo entiende Sergio Amaya (comunicación personal, 22 de noviembre, 2016), equipo técnico del Instituto, mencionando que "hay una gran participación de un sector empresario que es el de los supermercados que articuló muy bien con nosotros desde el principio participando y poniendo recursos. Es un sector muy activo y aliado, pero en Rafaela hay aproximadamente 450 empresas y tenemos que ampliarlo. También tenemos que profundizar la participación de otros sectores como el hotelero, el gastronómico que son además grandes generadores de residuos, ahora estamos entrando en el sector de la carne. Es clave también articular con el sector sindical que por su estructura también sería un aliado muy grande".

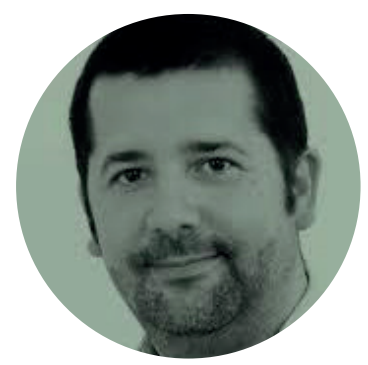

Para Alejandro Jurado (comunicación personal, 17 de febrero, 2017) otro actor que debería profundizar su participación es la Agencia de Desarrollo (ACDICAR), que según su opinión debería estar mucho más más involucrada en el día a día y debería ser un buscador de recursos natural: "Imaginando a futuro yo veo una Agencia buscando recursos y ejecutando e involucrando mucho más al sector privado, me imagino también un Concejo Deliberante mucho más activo en la formulación de nuevos marcos regulatorios como por ejemplo de cambio climático, de arbolado, de movilidad, de promoción industrial, entre otras".

Asimismo, plantea la importancia de que las universidades tengan esta temática en sus agendas y ahí aparece la necesidad de sumar al Consejo Interuniversitario local y profundizar las alianzas con el sistema científico tecnológico para que también el INTI y el INTA tengan esta línea en sus propias instituciones.

\subsection{El componente educativo y la formación de capacidades:}

Un aprendizaje que aparece también como un eje recurrente y transversal de Rafaela Más Sustentable e incluso que se desarrolla previamente desde el impulso del Municipio (a través de lo que fue el Programa Creando Conciencia), es el componente educativo como aspecto central de acciones que implican involucrar a la comunidad. 


\section{HOGARES VISITADOS POR CREANDO CONCIENCIA - Hogares}

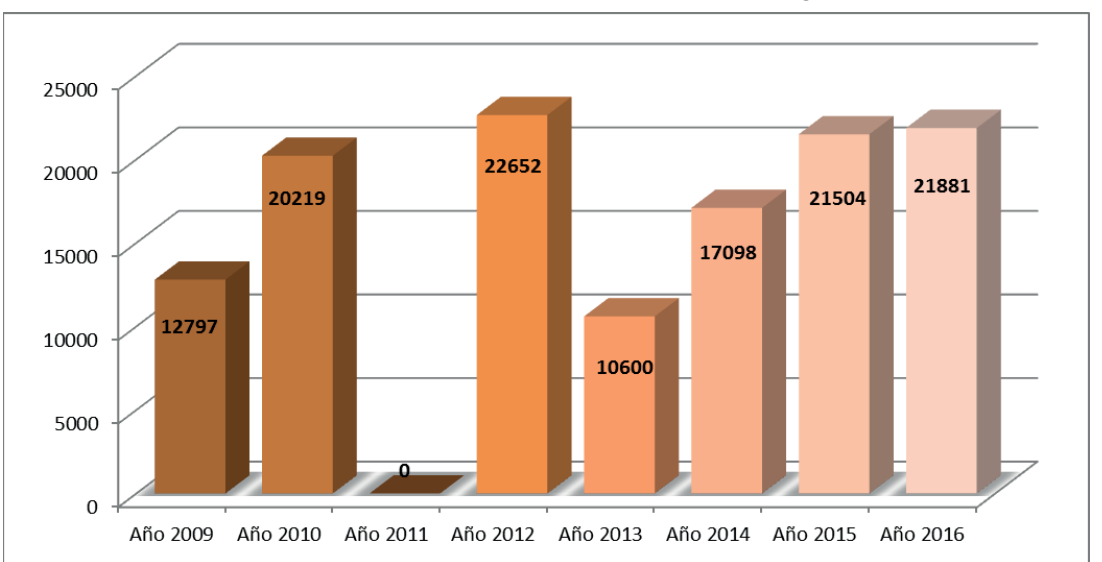

Gráfico 3: Elaboración propia con datos Página web Municipalidad de Rafaela

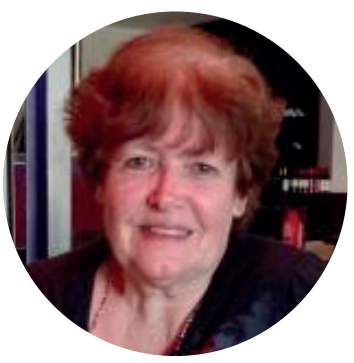

Allí se rescata la importante labor que llevó a cabo Marta Engler como Secretaria de Servicios Públicos en la gestión 2007-2011, en donde por su propia formación docente impulsa con fuerza el aspecto educativo, empezando a ir puerta por puerta, barrio por barrio para hablar con la gente y explicarle el tema de la separación de residuos. En palabras de Marta "para que un relleno sanitario tenga sentido básicamente tiene que haber basura clasificada y entonces la única alternativa era trabajar en el cotidiano con la gente y así fue como me busqué un grupo de alumnos del Instituto de Profesorado e ideamos un programa de pasantías y ellos fueron entrenados en la concepción de las ideas y en la metodología de trato con la gente, para usar el vocabulario apropiado y poseer un modo de dirigirse a los vecinos que sea comprensible y adecuado. Luego trabajamos midiendo la respuesta y con un programa de evaluación constante" (comunicación personal, 23 de noviembre, 2016).

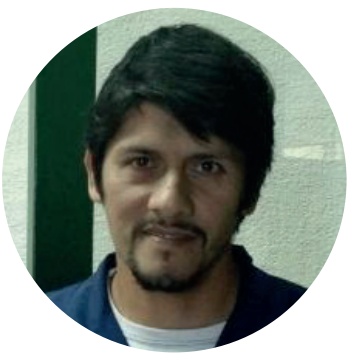

A la par de estas acciones se comienza a trabajar con las escuelas para que los chicos y chicas se conviertan también en "concientizadores" de sus propios barrios. Walter Tévez, docente de la Escuela Nro. 467 Domingo Faustino Sarmiento, trabaja con los chicos y chicas de $7 \mathrm{mo}$ grado en el proyecto de separación de residuos recuperables y no recuperables y disposición del papel. Al respecto menciona que "nos sirve mucho la concientización de los chicos hacia sus familias y hacia la comunidad, el trabajo me parece muy positivo e importante porque es una manera de cuidar nuestro ambiente. Nos falta involucrar un poco más a las familias porque nos cuesta, pero es un proceso que lleva su tiempo es como la misma educación. Estamos participando desde el año pasado y cada vez con mayores expectativas y con ganas de ampliar el trabajo" (comunicación personal, 22 de noviembre, 2016). 
ESCUELAS ADHERIDAS A RAFAELA + SUSTENTABLE

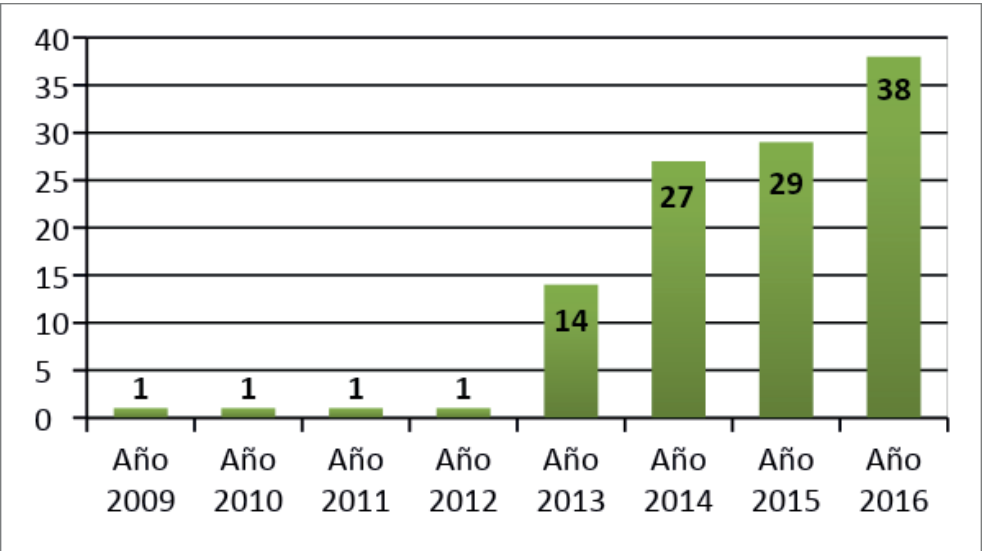

Gráfico 4: Elaboración propia con datos Página web Municipalidad de Rafaela

Ambos ejes, el trabajo en escuelas y el puerta a puerta con vecinos y vecinas, se sostienen y profundizan en Rafaela Más Sustentable y su constancia a lo largo del tiempo ha mostrado importantes resultados que se visualizan, por ejemplo, en una tasa de separación domiciliaria de los residuos de alrededor de un $85 \%$.

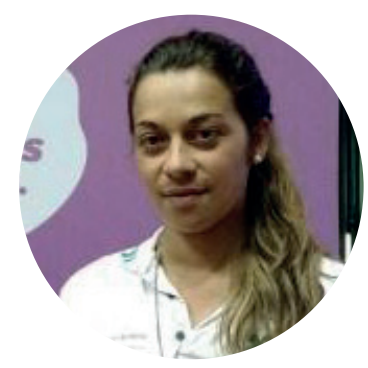

Noelia Vesoni, pasante en Rafaela Más Sustentable por el Profesorado en Educación Primaria, desarrolla tareas sobre concientización trabajando con las y los vecinos, así como también en las visitas guiadas de los chicos y chicas de las escuelas al Complejo Ambiental. Al respecto desde su experiencia comparte que: "el impacto los chicos lo tienen cuando van al complejo ambiental y ven lo que se hace en la planta de recupero donde la gente abre bolsa por bolsa y clasifica, entonces entienden claramente que clasificar mal complica la tarea de otras personas. Hay mucha gente que desconoce lo que se hace después entonces les explicamos que hay familias que trabajan con la clasificación de los residuos y hacerlo bien es vital para la comercialización y para las ganancias de esas familias. $Y$ entonces siempre entendemos que el primer eslabón es el vecino, en su casa y es cuestión de generar un hábito" (comunicación personal, 22 de noviembre, 2016).

Respecto a las dificultades que encuentran en esta tarea Noelia explica que si bien la situación va mejorando cuando visitan algunos barrios de la ciudad se generan ciertas resistencias "entonces lo primero que tenemos que hacer es entablar el vínculo con el vecino, escucharlos porque tienen muchos reclamos, sobre todos los barrios muy vulnerables que además están estigmatizados. $Y$ después entender y transmitir que si bien ellos tienen otras carencias el tema de la basura no es un tema menor" (comunicación personal, 22 de noviembre, 2016). Posiblemente, se haga necesario rediscutir las metodologías, los modos de trabajo y la formación de capacidades de los equipos en un sentido amplio para el abordaje del territorio, para el reconocimiento de los problemas y la puesta en marcha de acciones que tiendan a solucionarlos. 
Entonces también de la mano del componente educativo como eje transversal, otro de los temas vinculado a los aprendizajes lo constituyen los procesos de formación de capacidades locales en la multiplicidad de acciones que este proceso ha desplegado. $Y$ entendemos la formación de capacidades en un sentido amplio, donde no sólo se aprenden conocimientos técnicos sino también se aprende de las propias prácticas, de los "modos de hacer".

Esta dimensión cobra aún mayor relevancia en el contexto de transformación del Programa a Instituto y el nuevo rol que se le presenta asociado a transformarse en un referente en capacitación y educación de temas socioambientales. Esto requiere también volver a discutir esa agenda en relación al contexto y a las problemáticas de la ciudad y la región.

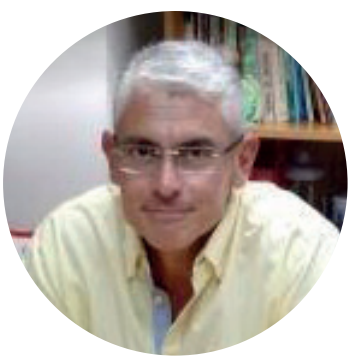

Así lo expresa por ejemplo Gustavo Molfino, director de Supermercados Pingüino cuando plantea: "me parece que hay que formar gente también para el futuro y entonces tendríamos que destinar parte de los recursos a formar tanto a la propia gente que maneja el Instituto, al empresario que se viene formando para liderar, a la comunidad, a las ONG, formar ONG ambientales, porque hay un entramado muy grande de instituciones a nivel nacional e internacional con las cuales no nos vinculamos $y$ podemos tener mayores vinculaciones y ser objetivo de crédito y de ideas, porque tenemos buena gestión y ese es un poco el desafío que se nos viene para el Instituto. Si nos abocamos sólo al día a día su labor va a quedar en lo cotidiano cuando le podríamos dar una proyección mucho más importante, donde podamos volcar toda nuestra preocupación y generar ámbitos de educación, emprendimientos, empresas $B$, un montón de cuestiones que se vienen y que podríamos canalizar. El Instituto podría ser el marco de un montón de agendas que estén pensando estrategias desde lo sustentable" (comunicación personal, 22 de noviembre, 2016).

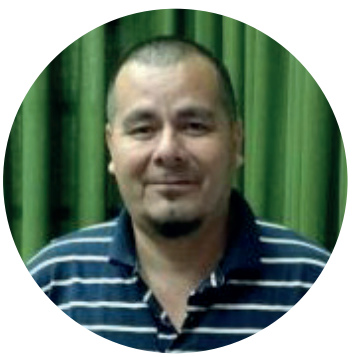

También Sergio Amaya, equipo técnico del Instituto, señala este desafío: "falta mejorar la formación de capacidades y encontrar momentos para ver qué está haciendo el otro, nos absorbe tanto el día a día que quizás nos perdemos en lo que está trabajando el compañero o por ahí no compartimos la información, nos hace falta reunirnos y darnos tiempo para encontrarnos. Es algo que tenemos pendiente." (comunicación personal, 22 de noviembre, 2016).

Podemos concluir entonces que quizás ha primado en estos años la necesidad de gestionar, del hacer por la propia importancia de instalar los temas, por sobre las reflexiones del proceso. Quizás es un buen momento y aparece en este contexto la demanda de volver a construir capacidades con temas nuevos que se presentan hoy como un desafío para la consolidación y el nuevo rol del Instituto. 


\section{Las propuestas de transformación: nuevos temas, roles y desafíos}

A partir de la identificación de los principales aprendizajes que hemos realizado en las páginas anteriores agrupadas en diferentes ejes temáticos del análisis y de los diálogos con actores surgen diferentes propuestas transformadoras desde ellos y ellas que constituyen un aspecto sustancial en el marco de un proceso de sistematización de experiencias desde el enfoque del Desarrollo Territorial como el que estamos compartiendo en este trabajo de tesis.

Con esto nos referimos a que para que estos esfuerzos en clave de sistematización valgan la pena deben articularse realmente con las prácticas y los espacios de diálogo para luego pasar efectivamente a la acción.

Y esto es lo que intentamos trabajar en este apartado, dando cuenta de todas las situaciones referidas al futuro de la implementación de las políticas socioambientales en el territorio, a partir del nuevo rol del Instituto para el Desarrollo Sustentable que han surgido de las y los propios participantes. Primero desde la instancia de entrevistas, que fueron ampliadas a otras y otros miembros del Consejo Ambiental como el caso de dos concejales pertenecientes a otras fuerzas políticas (opositoras a la gestión del gobierno local) como el caso de Lisandro Mársico del Frente Progresista Cívico y Social y Hugo Menossi del bloque Cambiemos; Marcelo Becla, presidente del Consejo de Pastores de Rafaela, María Frobelli representante de la Federación de Entidades Vecinales y Sergio Seara participante por el Club 9 de Julio. Segundo, a partir de la realización de un taller específico con los integrantes del Consejo Ambiental.

Recuperando entonces los aportes realizados en las entrevistas y las conclusiones surgidas en el taller con actores donde se debatieron ideas, a continuación desarrollamos las propuestas de transformación, que también hemos agrupado a partir de diferentes ejes temáticos:

2.1 Sobre los temas a futuro, la discusión de la agenda ambiental de la ciudad y el rol de Instituto para el Desarrollo Sustentable:

A partir de las entrevistas las y los actores vinculados al Consejo Ambiental coinciden en la importancia de anticiparse a los temas y a las discusiones que se vienen hacia adelante. En ese aspecto surge la propuesta de revisar el rol del Instituto para que lidere este proceso de "mirada a futuro" a partir de investigar, presentar alternativas y generar espacios para revisar y rediscutir la agenda ambiental, por ejemplo, en el tema de agroquímicos, usos del suelo y agua.

También se señala que los procesos deben estar acompañados de la gestión política que no sólo se vincula a las decisiones del gobierno local sino a las normativas (ordenanzas) que requieren del compromiso de todos los sectores. En este aspecto se marca como tema pendiente la ordenanza de grandes generadores de residuos que se encuentra en discusión, pero en la que todas y todos coinciden que hay que avanzar, con el acompañamiento del Instituto y del Municipio, sancionando una norma que comprometa a las y los actores locales. 
En este contexto de consolidación de las políticas socioambientales, aparecen además de nuevos roles para el Instituto, como mencionamos anteriormente, nuevos temas y desafíos hacia adelante para impulsar en el territorio.

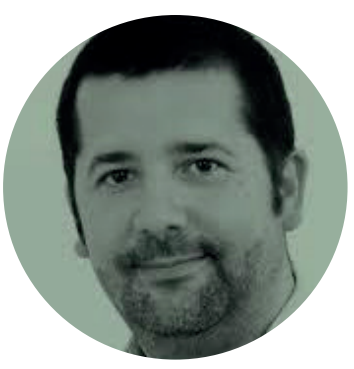

Para Alejandro Jurado lo que se viene respecto al futuro de la ciudad es el acceso al agua: "la ciudad tiene claro que necesita más agua, pero todavía está inmadura la reflexión sobre el uso de micromedidores en el $100 \%$ de los vecinos, donde probablemente con la misma cantidad de agua lograríamos una justicia ambiental en términos de distribución. Eso requiere una decisión colectiva y un fuerte liderazgo del Estado local porque la competencia en la distribución es provincial. Yo soy de los que cree que a Rafaela no se le resuelve el problema del agua con un nuevo acueducto o con uno más grande sino con una política de largo plazo de uso racional del agua y que cada industrial y cada ciudadano paguen por el agua que consuman. Sin micromedición eso no se puede lograr" (comunicación personal, 17 de febrero, 2017)

También plantea la necesidad de ir hacia otras discusiones más profundas como es por ejemplo una fuerte dominancia del modelo de monocultivo y de uso intensivo de agroquímicos que afectan claramente a las personas: "elevamos un informe al Concejo Municipal que tiene que decidir sobre un aspecto central de ese modelo que es su proximidad a la ciudad, lo que denominamos la línea agronómica, que hoy se está discutiendo y diría que no hay ciudad que no tenga este tema en la agenda. Nosotros, en Argentina, estamos entre los primeros en el mundo de consumo per cápita de glifosato. Entonces en las ciudades que tienen políticas de prevención tenemos que hacer algo para resguardar la calidad de vida y la salud de las personas. Hoy se está discutiendo solamente como minimizamos el impacto de esta actividad (de los agroquímicos para las plantaciones de soja y otros cultivos) en las zonas periurbanas de la ciudad, pero tal vez habría que discutir algo que no es de la agenda de hoy, como por ejemplo cuál es el modelo agrícola - ganadero que requiere el entorno urbano y rural para resguardar los servicios ecosistémicos que necesitan los rafaelinos para vivir" (comunicación personal, 17 de febrero, 2017)

Jurado afirma que discutir la línea agronómica es el principio de un debate donde el fondo no está en la línea sino en el modelo. Y ahí recupera un nuevo rol del Instituto como referente en temas con oportunidad para generar políticas públicas a largo plazo: "el aporte que le hicimos al Concejo fue actualizar el debate público sobre el glifosato que incide en la determinación de la zona de resguardo. Este rol es nuevo porque hoy se le ha dado un carácter más institucional a la opinión de aquel que tiene que diseñar y guiar las políticas socio ambientales, el Instituto tiene esta misión de trabajar en el diseño, la evaluación y acompañar en la implementación público - privada de estas políticas" (comunicación personal, 17 de febrero, 2017)

Otro aspecto a futuro que hay que discutir para Alejandro es el suelo como recurso natural más importante que tiene la ciudad y que está más amenazado: "es un tema que no está en la 
agenda y tampoco lo ha sabido poner en agenda ni el Programa ni el Instituto. Es el recurso de largo plazo, el intangible que está más amenazado y que no hay nadie diseñando políticas sobre él" (comunicación personal, 17 de febrero, 2017)

Como desafío menciona que hay que trabajar mucho con el sector industrial porque se presenta una gran oportunidad para abordar fuertemente la eficiencia, la producción más limpia y las energías renovables, aunque también es importante reconocer un momento atravesado también por la crisis económica: baja de las importaciones, del consumo, de las ventas, de la productividad y del empleo. Ahí Jurado afirma que "nunca es el mejor momento para anticiparse a los temas, entonces hay que anticiparse igual independientemente de que el contexto no sea el favorable. En algún momento las condiciones cambian y esa discusión previa que tuviste debería resultar en que tu nivel de inicio de la actividad es diferente porque empezás con la temática instalada" (comunicación personal, 17 de febrero, 2017)

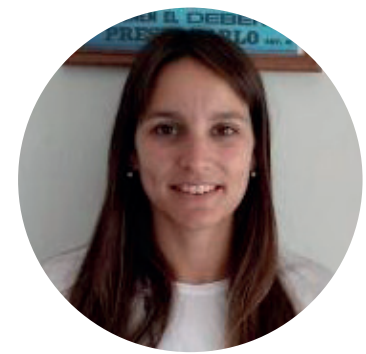

Por su parte María Paz Caruso, (comunicación personal, 21 de noviembre, 2016) Directora del Instituto, plantea como desafío hacia adelante la importancia de socializar la política ambiental de Rafaela con el área de influencia, con la región. Allí señala como un hito a profundizar el proyecto de "Comunas más sustentables" donde se sumaron 26 comunas en capacitación sobre gestión integral de residuos y eso ha permitido anticiparse a la ley de Área Metropolitana que ahora tiene la provincia de Santa Fe en donde Rafaela es referente.

También expresa que "la idea es continuar con las líneas de acción que se fijaron desde un principio que son: verde urbano y biodiversidad, cuidado del agua, energías renovables, pero el desafío es articular más fuerte con las instituciones de la ciudad. Entonces cada línea de acción puede tener una institución referente que nos ayude a llevar adelante esa política ambiental" (comunicación personal, 21 de noviembre, 2016).

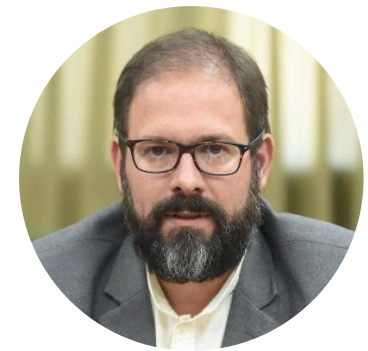

Hugo Menossi, concejal del bloque Cambiemos y representante en el Consejo Ambiental por dicha fuerza política, menciona que "otra cuestión a futuro que demanda inversión y que considero que hay que articular con la provincia y la nación para conseguir financiamiento, es el tema de los colectores solares. Nosotros a instancias del Instituto, aprobamos una ordenanza en donde se hace un descuento para la compra de colectores solares y creo que ha faltado difusión e incentivos" (comunicación personal, 17 de mayo, 2017).

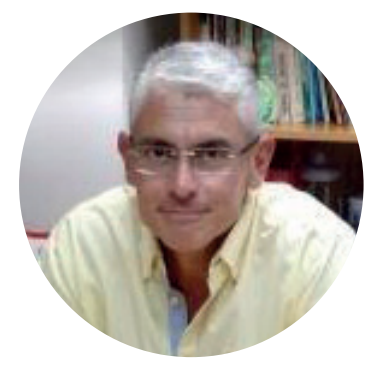

Para Gustavo Molfino desde su preocupación como empresario del rubro supermercados algo que se viene y que hay que abordar es el tema del compost: "estamos viendo en conjunto con el Instituto cómo buscarle la vuelta y organizar el verde de poda, más lo que nosotros mandamos de verdulería para que sea reutilizable y para realmente generar una compostera. A nosotros la verdad nos interesaría porque 
somos un gran generador. Y tengo la convicción de que más adelante podemos hacer algo de este tipo, algún proyecto de industrias verdes" (comunicación personal, 22 de noviembre, 2016).

Y suma otro elemento que tiene que ver en cómo trabajar fuertemente con incentivos: "la dificultad que tenemos para la separación de residuos de grandes generadores para mi tiene que ver con una cuestión de incentivos, a veces da un poco de temor avanzar en este sentido. Nosotros que fuimos unos de los primeros que empezamos con este tema lo vimos como una forma de evolucionar y de bajar costos. Es una buena estrategia trabajar con incentivos como pasó en nuestro caso que nos dijeron que si entregábamos todo al relleno nos bajaban la tonelada a la mitad durante 3 años y se cumplió perfecto y con esos recursos se pudo financiar todo el proceso que implicó la separación, desde la implementación hasta la formación del personal" (comunicación personal, 22 de noviembre, 2016)

\section{RECOLECCIÓN DE CARTÓN EN GRANDES GENERADORES - Tn/Año}

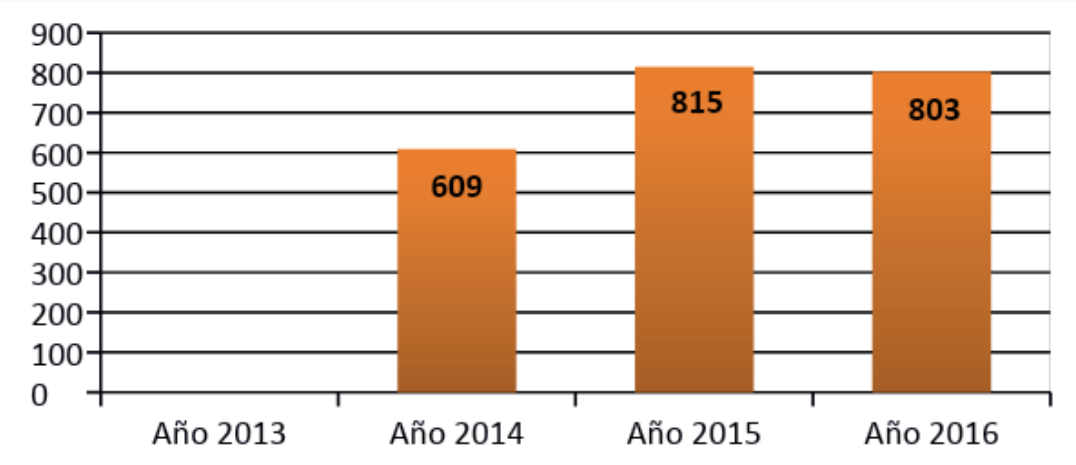

Gráfico 5: Elaboración propia. Fuente página web Municipalidad de Rafaela.

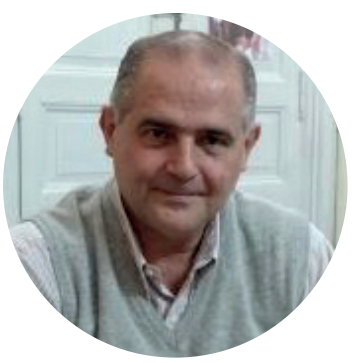

Para Alejandro Bonet, representante del Obispado de Rafaela en el Consejo Ambiental, es importante profundizar la cuestión de las energías limpias y el abastecimiento del agua y su uso racional: "en estos temas el Instituto puede convertir a Rafaela en una ciudad líder a nivel del cuidado del ambiente en todo el país, tiene todas las condiciones para hacerlo porque hay un entramado social e institucional que hace que la gente se sume a las cosas que contribuyen al bien común y en eso la función que puede llegar a cumplir el instituto es extraordinaria" (comunicación personal, 22 de noviembre, 2016)

Otro desafío que retoma Alejandro Bonet es dar un paso decisivo a la regionalización de la actividad, que las comunas y municipios que forman parte del área metropolitana puedan generar acciones en conjunto, en principio con el tema de los residuos. 


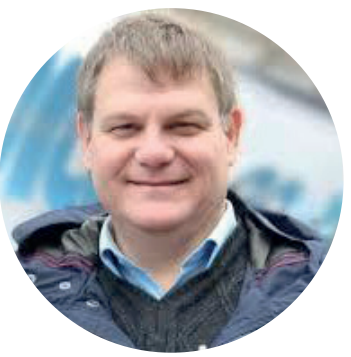

Marcelo Becla, integrante del Consejo Ambiental en representación del Consejo de Pastores de la ciudad de Rafaela, respecto a los desafíos hacia adelante plantea "este proyecto en el ámbito teórico es trascendental, significativo, espectacular, pero el desafío mayor es materializarlo. El hecho del trabajo que se está haciendo, de la constancia, eso lleva a una concientización, por ahí habría que ver cómo llevarlo a la práctica para que la gente lo vaya recibiendo. Hay un avance respecto al tema de la basura, pero ahí está la cosa, el hecho que esto no únicamente quede en comisión o en el ámbito de investigar, analizar, sino que se vea en la práctica, en la ciudadanía. Estaría feliz si eso se materializa. Con la palabra materializa, me refiero a que hay un porcentaje de la ciudad que falta y es necesario articular todo lo que tiene que ver con el Consejo Ambiental porque hay muy poca gente que lo sabe" (comunicación personal, 13 de marzo, 2017).

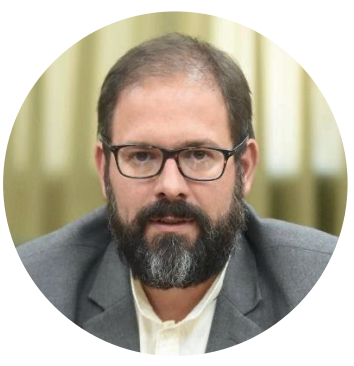

Hugo Menossi, desde su rol de concejal por el bloque Cambiemos, enfatiza que "uno de los desafíos del Instituto sería la capacitación para empresas y particulares para generar menos basura, o sea, no solo trabajar y recuperar la mayor cantidad de basura posible, sino reducir. En Rafaela somos modelo para muchísimas localidades del país y de Latinoamérica, pero nosotros ya estamos en condiciones de hacer un salto de calidad" (comunicación personal, 17 de mayo, 2017).

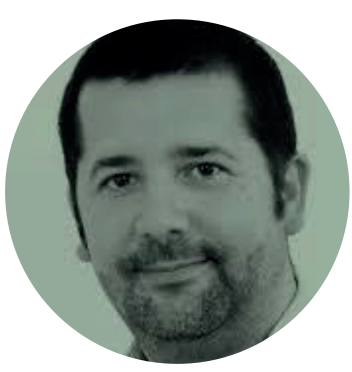

Finalmente, como balance de la gestión y la apuesta a futuro Alejandro Jurado menciona que la expectativa es dar un salto cualitativo al debate y a la incidencia de las políticas públicas y privadas: "esto sólo lo podemos lograr involucrando mucho y en cada acción a las instituciones y a los actores claves para que lleven temas. Trabajar mucho en la búsqueda de financiamiento y poder contar con recursos humanos con financiamiento externo fuera del presupuesto de la ciudad que está muy orientado por los temas de prioridad en la agenda. Entonces las políticas ambientales tienen que "asegurarse la vida" buscando financiamientos complementarios y también generando iniciativas en las que por ejemplo el canon que van a pagar las industrias del reciclaje también repercuta en el Instituto agregando recursos" (comunicación personal, 17 de febrero, 2017)

Lo que se está pensando hacia adelante es que cada institución tenga sus propias políticas con sus propios recursos: "Esto va a ser más articulador de la agenda porque tenemos que trabajar distinto, acordar que temas lleva cada institución para que no nos sea tan difícil gestionar. Una cosa es coordinar y apoyar y otra cosa es intentar ejecutar todo, ahora están dadas las condiciones para que el problema ambiental sea una responsabilidad compartida. Este es el cambio de paradigma de este año, pasar de las instituciones aliadas a las instituciones liderando los temas y nosotros acompañando" (comunicación personal, 17 de febrero, 2017)

Este cambio de paradigma representa un gran desafío que tendrá que ver también con, de alguna manera, aumentar la capacidad de gestión en una multiplicidad de temas que es difícil de afrontar con el personal y los recursos con los que el Instituto actualmente cuenta. 
Se trata entonces de una búsqueda de innovar en los "que" y también mejorar el "cómo" desde el Instituto, intentando potenciar el modelo profundizando la gobernanza y construyendo capacidades para una renovación o incorporación de nuevos ejes. Se hace necesario entonces el planteo de nuevos temas conceptuales que vengan acompañados de formación de capacidades para dar respuestas a nuevos desafíos.

\subsection{Sobre las y los actores participantes del Consejo Ambiental:}

Otro de los ejes respecto a propuestas de transformación a implementar y que ha aparecido recurrentemente en la identificación de los aprendizajes, tiene que ver con la participación de nuevos actores en el espacio del Consejo Ambiental como nueva institucionalidad para generar, construir y tomar decisiones sobre políticas socioambientales en la ciudad.

Aquí se encuentran algunas posiciones diferentes, por un lado aquellos y aquellas que opinan que es necesaria la ampliación del Consejo hacia otros sectores que hoy no se encuentran representados como es el caso por ejemplo del sector educativo (que hoy tiene un peso muy fuerte con dos universidades públicas nacionales: la Universidad Tecnológica Nacional - Facultad Regional Rafaela y la Universidad Nacional de Rafaela, de reciente creación en el año 2014), el científico tecnológico, contar con nuevas voces de las organizaciones de la sociedad civil, más allá de los clubes, como son las asociaciones de ambientalistas que, paradójicamente, no tienen representatividad. Por otra parte, hay otros que consideran que de ampliarse complicaría la dinámica y la gestión de los temas.

La presencia de las universidades y del sector educativo en general (en sus diversos niveles y modalidades) sería relevante en lo que tiene que ver con investigación de temas estratégicos y la producción de conocimiento, así como también, en que el Instituto pueda tener un rol más activo y vinculado con la formación de estudiantes en temas claves para la ciudad y la región, a partir de su experiencia en gestión de políticas socioambientales. Incluso potenciando iniciativas de distintos vecinas y vecinos que se vienen dando en forma aislada, sin registro ni acompañamiento.
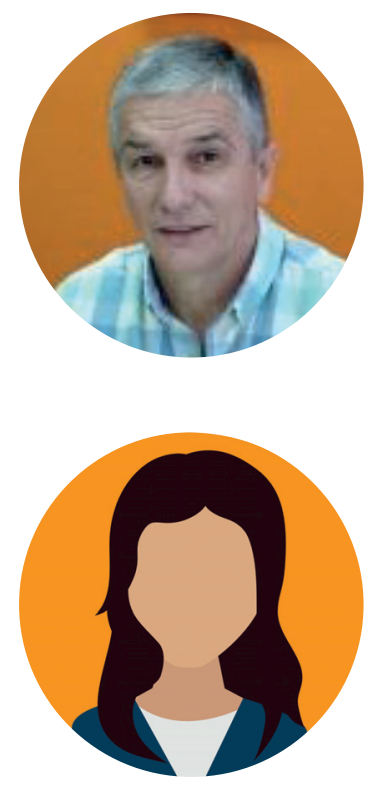

Jorge Muriel, como concejal y participante del Consejo Ambiental es claro en enfatizar que "Ampliar el Consejo Ambiental sigue siendo una materia pendiente, sumar nuevas voces y una nueva visión que lo haga crecer. Por ejemplo, hay un solo club que participa y desde los clubes se pueden hacer cosas importantes porque son lugares en donde transitan muchos jóvenes y es el espacio para concientizar". (comunicación personal, 19 de mayo, 2017).

En cambio, María Frobelli, representante por la Federación de Entidades Vecinales, considera que incorporar nuevos actores complicaría el funcionamiento del espacio y dificultará la gestión de los temas. Según su opinión más que involucrar nuevos actores habría que revisar el rol del espacio y los modos de participación, tal como se desarrolla en el próximo apartado. 


\subsection{Sobre el modo de participación en el Consejo Ambiental:}

A partir de las entrevistas iniciales, más la ampliación de las mismas y el taller realizado con las y los integrantes del Consejo Ambiental, podemos afirmar que hay una coincidencia en que se debe fortalecer el modo de participación en este organismo. Aún con todos los avances, sus participantes lo sienten más como un espacio de validación de aspectos ya definidos previamente que como un espacio de participación, discusión y toma de decisiones. También marcan que han sido escasas las reuniones y señalan que el contexto de año electoral ha sido complejo para poder reunirse con mayor asiduidad. Hay un reclamo de mayores diálogos.

Se menciona la importancia de que las y los integrantes del Consejo sean facilitadores y facilitadoras de los temas y las propuestas, que puedan multiplicar y difundir acciones, que puedan trasladar a sus espacios de referencia las discusiones y las actividades. También sería importante que este sea un espacio en donde puedan plantear y canalizar proyectos de sus instituciones y revisar las problemáticas de la agenda de la política local vinculados a temas socioambientales.

Otra de las cuestiones que surge como propuesta a implementar y transformar es que las y los miembros del Consejo puedan tener acceso a la información de los proyectos y su financiamiento de manera previa a las reuniones a modo de poder avanzar en otras discusiones. La sensación es que hasta ahora se han reunido para avalar y aprobar las acciones que ya fueran anteriormente definidas, con énfasis casi exclusivo en los aspectos presupuestarios.

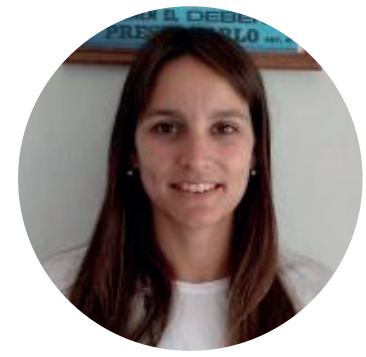

Y esto claramente lo expresa la Directora del Instituto para el Desarrollo Sustentable María Paz Caruso como una inquietud: "todavía no le encuentro la vuelta al Consejo Ambiental al rol que debe tener, es difícil porque a veces nos pasa como Instituto que sentimos que imponemos las cosas. Pero cómo hacemos para sumarlos a los procesos del día a día, me cuesta buscarle la vuelta para que sea participativo. Sinceramente creo que no se dan los tiempos necesarios para la discusión y el debate y nos atraviesa mucho más el día a día. Particularmente en este tema creo que tendríamos que pensar dos o tres cosas puntuales que queramos definir con el Consejo Ambiental, como por ejemplo abordar el modelo de producción y consumo pensando en algo que nunca trabajamos y qué implica realmente mirar hacia adelante" (taller del Consejo Ambiental, 18 de mayo, 2017).

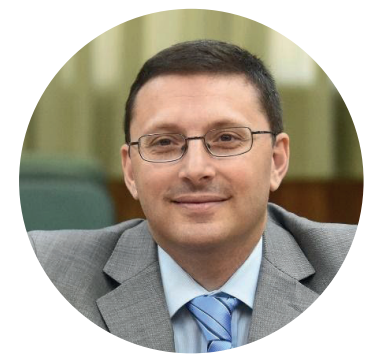

Lisandro Mársico, concejal por el Frente Cívico y Social e integrante del Consejo es crítico respecto al rol de ese organismo y enfatiza en que en algunos temas "el Consejo Ambiental más que un consejo consultivo debería ser un espacio que se expida como por ejemplo en el tema de los agroquímicos. En este tema se trajo un dossier con opiniones y se le había pedido un dictamen, pero el Instituto recopiló diferentes opiniones sin emitir un juicio propio y se le había pedido, como organismo 
especializado, que se expida para ver de cuanto tenía que ser el límite. Construyó información, pero no emitió dictamen" (taller del Consejo Ambiental, 18 de mayo, 2017).

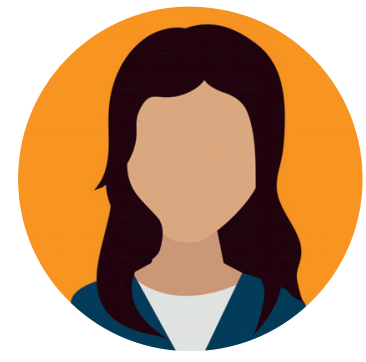

María Frobelli, representante por la Federación de Entidades Vecinales, profundiza una mirada crítica respecto al rol del Consejo "lo importante es que haya diálogo, tampoco tiene que ser un espacio tan grande, después cada uno es responsable de compartir la información en sus espacios, pero para ello necesitamos la información, que tendría que estar sistematizada, para que yo pueda plantearle a la gente que se podría hacer en los barrios, que mejorar. Ahora tenemos 39 barrios, muchos de ellos con poblaciones vulnerables. A mí como representante en el Consejo Ambiental me gustaría primero difundir lo que se está haciendo, segundo escuchar a los vecinalistas para ver qué opinan de lo que uno les lleva y recoger eso y poder llevarlo porque si no es un sin sentido. Uno tiene que sentir que algo pasa, que tu opinión se escucha no sólo ir a validar algo que ya está definido con anterioridad" (taller del Consejo Ambiental, 18 de mayo, 2017).

A partir de estas referencias que hacen las y los propios actores respecto al rol del Consejo hay una fuerte y clara línea de acción para implementar como propuesta de transformación a futuro para reconvertir y potenciar un espacio que cuenta con actores comprometidos con el tema, líderes en sus instituciones y con posibilidades de asumir otros desafíos, pasando de lo meramente deliberativo a lo verdaderamente participativo.

\section{La comunicación de la experiencia:}

Tal como establecimos al inicio de este capítulo una de las etapas que se constituyen como relevantes del proceso de sistematización tiene que ver con la comunicación de la experiencia. Esta etapa es de gran importancia porque de nada sirve sistematizar un proceso sino comunicamos los aprendizajes a quienes han formado parte del mismo y a otros y otras que se encuentren en procesos de similares características.

Tanto los procesos de comunicación como la sistematización desde el Desarrollo Territorial, poseen un importante diferencial si ambos se vinculan directamente con las y los actores, que las y los sujetos sean partícipes como protagonistas y no espectadores. Requiere de un ejercicio permanente de abrir espacios en dónde abordar esta perspectiva dado que estamos más acostumbrados a ser receptores antes que productores de nuevos sentidos y aprendizajes.

Es importante relatar en este aspecto que tanto de los aprendizajes como de las propuestas de transformación se construyó un primer documento, que es en parte el cuerpo de análisis de este trabajo de tesis. Este documento fue compartido con cada uno y cada una de los entrevistados a modo de recuperar sus impresiones, sugerencias y comentarios que fueron retomados para la elaboración final que este trabajo posee. 
Pasados unos meses se volvió a tomar contacto con las y los entrevistados, especialmente con las y los del Consejo Ambiental, a través de un espacio de taller para hablar específicamente sobre la utilidad y la comunicabilidad del documento de sistematización.

En líneas generales las y los entrevistados nos han compartido muy buenas impresiones acerca del documento, les ha resultado claro y afirman haberse interiorizado de temas que desconocían acerca del Programa y luego del Instituto. También coinciden en la importancia de haberlo historizado y contextualizado, dando cuenta de las continuidades de una política ambiental a largo plazo en la ciudad y la región que todos y todas rescatan y valoran como consolidada y que a través del Instituto sienten que están dadas las garantías para su continuidad, más allá de las gestiones de gobierno. También mencionan el documento realizado como una fuente de nuevos conocimientos ya que permite aprender y volver a debatir e ir construyendo un relato colectivo.

Se visualiza que para las y los propios actores que lideran el Instituto el documento les ha sido importante pero no han aprovechado su utilidad como herramienta de comunicación, ya sea para destinatarios externos que reciben asiduamente en visitas a Rafaela, así como también al propio equipo de trabajo y promotores que trabajan en el Instituto.

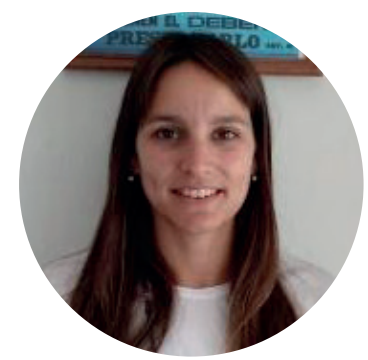

María Paz Caruso como responsable de la gestión explicita claramente: "lo que me di cuenta es que no difundimos el documento al interior de la propia gente del Instituto y lo que podríamos haber hecho es incorporarlo a la capacitación de las chicas que están haciendo el puerta a puerta en el programa Creando Conciencia. No lo usé como herramienta con la potencialidad que podría tener. $Y$ también como insumo para las visitas que recibimos que son de diferente índole desde estudiantes, hasta intendentes de otras localidades y en ese punto será muy útil". (taller del Consejo Ambiental, 18 de mayo, 2017).

Aquí recuperamos un tema que mencionamos al inicio de este trabajo que tiene que ver con el sentido del proceso y cómo es absolutamente relevante asumir la sistematización como un espacio de formación desde el involucramiento de sus actores. Nos queda la sensación que la demanda siempre estuvo más focalizada en un producto de comunicación que a un proceso de aprendizaje. Retomaremos este aspecto luego en las conclusiones.

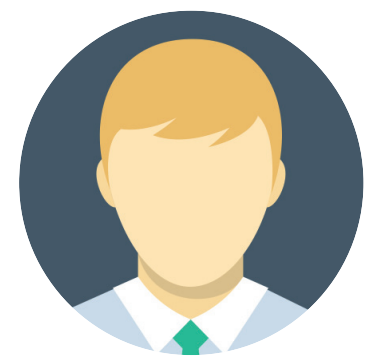

Sergio Seara representante en el Consejo Ambiental por el Club 9 de Julio nos compartió: "me agradó mucho el trabajo y pienso que es muy importante porque como cuesta escribir, como cuesta dejar registro de los hitos que van pasando y considero que eso es una debilidad dentro del entramado del que formamos parte" (taller del Consejo Ambiental, 18 de mayo, 2017) 
Las y los integrantes del Consejo Ambiental, en el espacio de taller, acuerdan en que hizo falta hacer circular el documento hacia sectores más amplios e incluso generar algún documento abreviado para compartir con sus espacios de referencia. Incluso mencionan que hay muchas actividades que desarrolla el Instituto que se desconocen y que ellos y ellas pueden tener allí un rol que puede aportar a ser multiplicadores de esas experiencias, para lo cual necesitan contar con algunas herramientas para poder realizarlo. Esto implica también revisar el rol que están teniendo en el Consejo y poder tener una participación más activa en la representación que están teniendo.

Se menciona que sería importante fortalecer su difusión y generar espacios de discusión colectiva del documento porque esto no se ha replicado en cada una de las instituciones y es necesario profundizar en ese sentido.

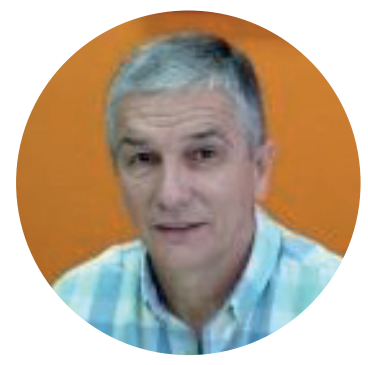

Jorge Muriel, concejal del Frente para la Victoria, es claro cuando afirma que "el documento es una herramienta fundamental, pero no sé si tuvo la discusión que debería haber tenido porque quienes conocemos algunas cosas naturalizamos el resto, creo que hay que seguir profundizando sobre el documento porque es una herramienta válida. $Y$ los actores del Instituto después no lo replican en el seno de su entidad. Entonces creo que habría que hacer un trabajo de difusión desde el Instituto y después con cada institución en particular porque va a aportar conocimiento a la ciudadanía porque hay muchísima gente que no sabe de qué se trata. Como toda política pública hay que difundirla más y discutirla, porque seguramente esta discusión con las instituciones va a enriquecer el próximo documento" (taller del Consejo Ambiental, 18 de mayo, 2017)

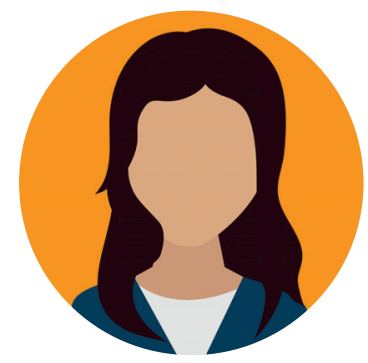

Más allá del documento en particular surgen reflexiones sobre los procesos de comunicación en general como temas pendientes. María Frobelli, de la Federación de Entidades Vecinales, es enfática en este sentido: "insisto que el tema de la comunicación en un municipio que es tan activo es fundamental. Esto es un punto fundamental en la política pública porque cuando vos haces un proyecto la gente tiene que hablar del proyecto. El espacio de la comunicación es fundamental que sepas a quién elegís, el cómo y el con quien. Cuando yo planteé este tema en la reunión me dijeron "sí, pero está todo en Facebook e Internet", pero no todo el mundo tiene internet ni se informa a través de ahí. Entonces me parece que hay que tomar a la comunicación en ámbitos más amplios, pensemos el cómo porque tiene que haber otras estrategias. Si no expandís queda todo acá" (comunicación personal, 17 de mayo, 2017)

Cabe entonces retomar la pregunta por la comunicación en procesos de Desarrollo Territorial, y que dimensiones implica porque pareciera que siguen primando las lógicas de los productos comunicativos (medios y redes) por sobre los procesos, por sobre las reflexiones, por sobre la generación de capacidades comunicativos en las y los actores y en las y los facilitadores. Sobre este eje también retomaremos algunas discusiones e impresiones en las conclusiones y consideraciones finales. 


\section{La "vuelta a la academia".}

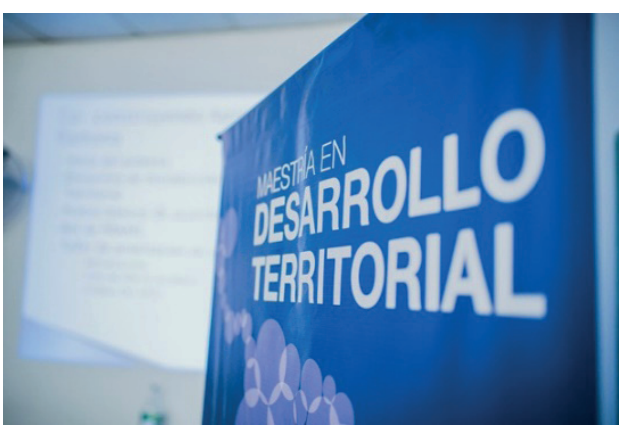

Como ya lo hemos mencionado, recuperando la perspectiva de la Investigación Acción Participativa es clave compartir estos procesos de acción, reflexión, acción en el marco de los procesos educativos formales y no formales, en nuestro caso en la Maestría en Desarrollo Territorial de la Universidad Tecnológica Nacional, Facultad Regional Rafaela, en donde además tenemos un espacio curricular específico donde se trabaja el enfoque y la metodología de la sistematización de experiencias desde la perspectiva del Desarrollo Territorial (Taller de Reflexión sobre la Praxis I y II).

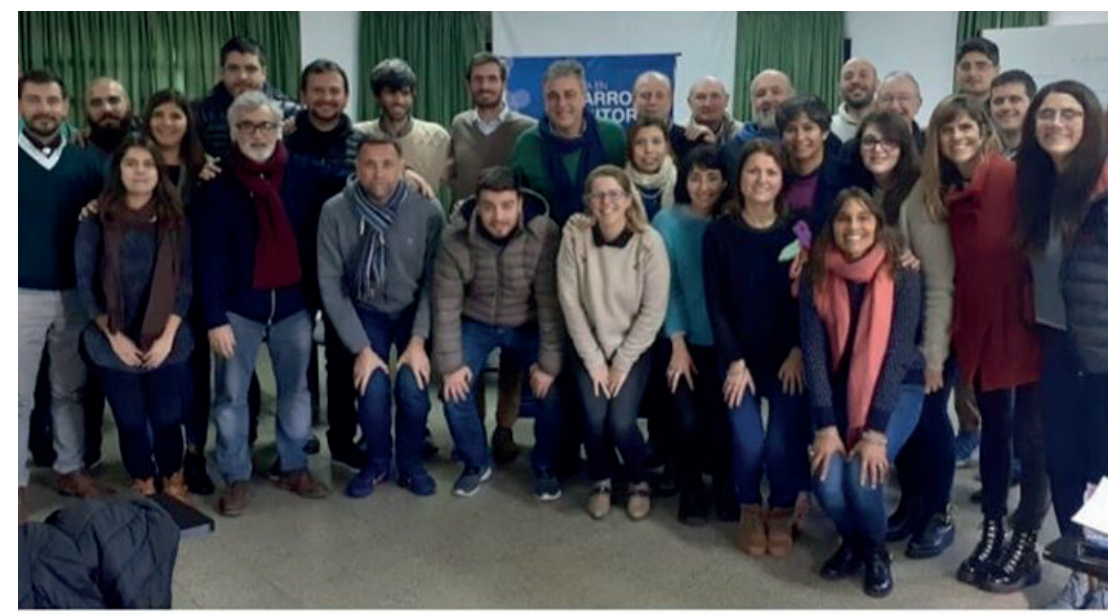

En este marco con estudiantes de la cohorte 2017 - 2018 hemos realizado una instancia de discusión y análisis del proceso de sistematización de Rafaela Más Sustentable que nos permitió, además de tener un espacio de aprendizaje con una experiencia muy concreta que entra muy bien en el enfoque pedagógico, obtener aportes de nuestros y nuestras estudiantes tal como desarrollamos a continuación a partir de algunas preguntas para trabajar en clase. Hay que tener en cuenta que esto vuelve a tener un significado interesante por la diversidad de perfiles de las y los maestrandos en cuanto a su formación, a sus pertenencias institucionales y a su procedencia geográfica.

De este ejercicio surge que el elemento/cuestión más innovadora es la creación del Instituto de Desarrollo Sustentable como un ente autárquico del Estado Municipal.

Los y las estudiantes expresan que esta estructura permite la generación y desarrollo de políticas, programas, acciones de forma independiente, pero de aplicación en lo municipal y destacan como relevante:

- La flexibilidad para la articulación entre oficinas, secretarias para la implementación o abordaje interinstitucional.

- La generación, promoción de políticas inclusivas de empleo a partir del trabajo en cooperativas. 
- Planta clasificadora de residuos, resultado de una larga trayectoria en la concientización sobre el cuidado del medio ambiente la reparación de residuos.

- Institucionalización del programa de gobierno, teniendo una llegada diferente al resto de la estructura municipal.

- Complejo ambiental

- Bolsa orgánica y fabricación local

- El trabajo con las y los actores del territorio que forman parte del consejo y que asumen responsabilidades y participan de la creación de la agenda.

- Participación ciudadana.

- Generación de cooperativas.

- Presencia de la universidad generando red y articulando con instituciones locales y ciudadanía.

- Liderazgo de gobierno local.

- Compromiso político.

- Generación de capacidades en la comunidad local.

- Proceso integral desde la captación de los residuos hasta la captación de compradores.

- Se valora la etapabilidad y continuidad de las acciones del proceso.

También el grupo planteó algunas problemáticas, discusiones que resultan importantes profundizar o incorporar en relación a la agenda ambiental desde el punto de vista del enfoque del DT, tales como:

- Incorporación de la escala regional a los abordajes temáticos.

- Incorporación de la visión a futuro con escenarios de crecimiento urbano y poblacional.

- Profundización en la construcción de indicadores para el monitoreo continuado con participación activa de la población local en el levantamiento de datos.

\section{- Es importante profundizar e incorporar:}

- Tratamiento de los desechos de los grandes generadores

- Un paradigma de reducción de generación de residuos en simultáneo a la separación.

- Cambio de paradigma producción- consumo:

- Ámbito regional de alcance de la responsable política ambiental.

- Aprovechamiento de áreas metropolitanas.

Captación domiciliaria de agua

- Abordar el tema del cambio climático y las problemáticas que generen el incremento de la intensidad de los fenómenos climáticos:

- Avanzar en la regulación del uso de fitosanitarios. 
- Promover, concientizar, trabajar por la reducción de generación de RSU avanzando sobre prácticas de uso y consumo.

- Proyectar problemáticas que va a tener el territorio dentro de 20 años con una población mucho mayor a la actual.

- Regular la disposición de los grandes generadores.

- Fortalecer la participación.

\section{- Temas importantes a profundizar:}

- Modelo del desarrollo urbano

- Abordar la problemática desde un punto de vista regional (ejemplo: trabajar en gestión de residuos a nivel regional, trabajar parque industrial a nivel regional)

- Abordar la complejidad del territorio a nivel regional, en dimensiones como la sociopolítica, físico espacial, ecosistema, histórica, entre otras.

Asimismo, para el grupo fue clave el trabajo en red y el liderazgo llevado por el Estado, el Consejo Ambiental y articulado por el Instituto Para el Desarrollo Sustentable pero como recomendaciones plantearon que deberían y podrían incorporarse; empresas privadas de forma más amplia y los clubes o instituciones sociales y recuperar la presencia de otras y otros actores como las vecinales. Además, fue fuerte la idea de la necesidad de profundizar el trabajo regional como cuenta pendiente y dimensión a futuro.

Estos tres puntos fueron trabajados nuevamente con las y los actores protagonistas de la experiencia luego de comenzar a cerrar la tesis y son nuevos insumos que, desde un ejercicio académico, contribuyen a la construcción de capacidades de las y los dirigentes continuando el proceso de aprendizaje. 


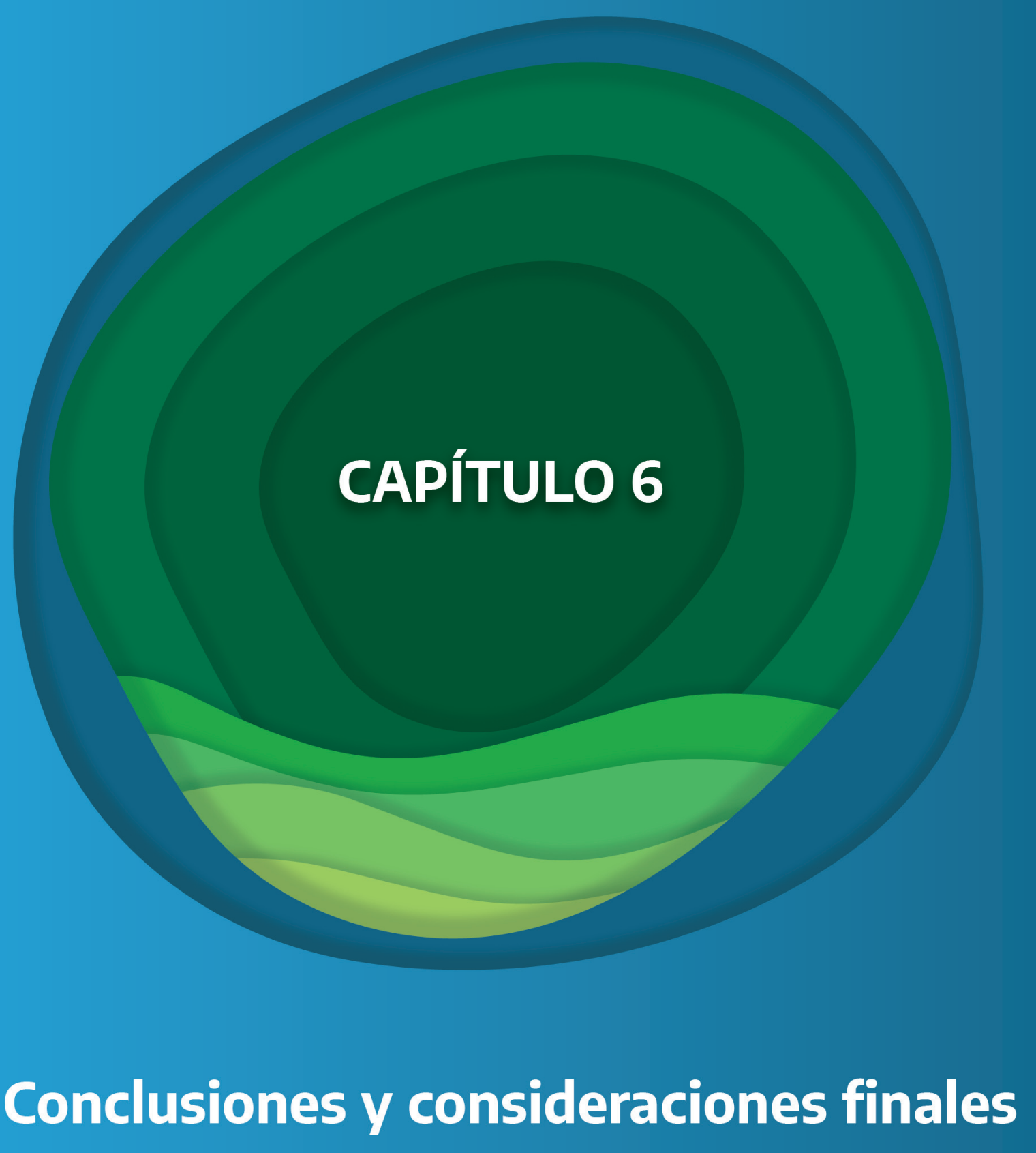




\section{CAPÍTULO 6}

\section{Conclusiones y consideraciones finales}

En este apartado, nos proponemos compartir algunas reflexiones y consideraciones finales en términos de aprendizajes del proceso generado. Estas conclusiones no pretenden ser de ninguna manera definitivas, sino que en muchos casos se traducen en "pistas" para seguir pensando y profundizando a futuro.

En términos analíticos las hemos agrupado a través de diferentes ejes que nos permitan ir ordenando los argumentos de acuerdo a distintos aspectos que han sido identificados a lo largo del trabajo de tesis, tal como se detalla a continuación.

\section{Aprendizajes vinculados a la perspectiva de comunicación / educación y su articulación con el enfoque del desarrollo territorial.}

Una de las primeras reflexiones que nos gustaría expresar como punto de partida de las conclusiones, se vincula con la propia perspectiva conceptual que hemos asumido en este trabajo y su puesta en diálogo con el campo material que abordamos.

Consideramos que hemos podido construir nuevas articulaciones, o más bien puentes, entre teoría y práctica en la realización de esta sistematización, especialmente en lo referido a la vinculación de la comunicación y las perspectivas educativas, entendidas éstas últimas como procesos de formación de sujetos en un sentido amplio (Huergo, 2003), con los procesos de desarrollo territorial.

Tal como se mencionaba en el capítulo sobre perspectivas conceptuales, la comunicación en los procesos de desarrollo comúnmente se ha limitado a la difusión de información y conocimiento, a la promoción de los beneficios o resultados de una iniciativa o al uso de tecnologías sin conexión con la realidad local. Y, por otro lado, los procesos comunicativos vinculados al diálogo, al reconocimiento de saberes y a la construcción de otros sentidos y relatos posibles en las experiencias de desarrollo, se visualizaban como posibles de ser realizados en iniciativas de comunicación destinadas a organizaciones más de una micro escala, como, por ejemplo, los emprendimientos de la economía social y solidaria.

Desde el aporte de nuestro trabajo de tesis e incluso de manera previa en distintas instancias en las que hemos participado vinculadas a proyectos de desarrollo territorial en la ciudad de Rafaela y la región, hemos asumido la convicción política de abordar la comunicación desde otros lugares posibles que contribuyan a transformar y transformarnos. Este ha sido un ejercicio complejo porque los sentidos que se construyen y las expectativas que se depositan 
del abordaje de la comunicación, tienen que ver en la mayoría de los casos con los "modos de hacer" más tradicionales e instrumentales, que se traducen generalmente en resultados bien concretos y visibles: los productos de difusión.

En estos "modos de hacer" tradicionales además prima una lógica del trabajo individualizado, en donde hay un expertise (el del comunicador o la comunicadora) responsable exclusivo de la tarea, mientras que las demás personas vinculadas al proceso son sólo fuentes de información y consulta. Como si fuera un trabajo más de gabinete, en soledad, perdiendo el anclaje de lo colectivo, de lo creativo, de lo vincular, que es casi inherente al enfoque de comunicación / educación desde el cual apostamos a pensar y a actuar.

Desde nuestra perspectiva, estamos haciendo otra apuesta. $\mathrm{Y}$ por ello aparecen tan fuertemente ligados los procesos educativos. Porque estamos apostando al reconocimiento, en clave freireana, de los saberes de todas y todos los actores territoriales que participan de los procesos de desarrollo, en este caso de las políticas públicas socioambientales.

Y estos actores y actoras del desarrollo territorial no son sólo provienen de sectores de la micro escala, o exclusivamente de las organizaciones autogestionadas y comunitarias, sino que desde nuestra perspectiva política es posible concebir, construir y gestionar la comunicación en procesos de desarrollo territorial desde el corazón mismo de las políticas de estado locales que involucran una cantidad diversa y compleja de sectores que, a veces, hasta suponen contradicciones y conflictos entre sí ligados a intereses particulares, sectoriales, políticos e institucionales.

Desde este lugar es que entra en juego fuertemente la figura del comunicador / comunicadora como una persona facilitadora de los procesos locales, especialmente de los de diálogos multiactorales en el desarrollo territorial. Para ello es clave el posicionamiento entendiendo también la idea de puente con que comenzamos el apartado. Con esto nos referimos a que podríamos haber tomado la opción de realizar un documento de difusión e historización de esta experiencia, tal como se nos solicitó en un principio, sin construir espacios de diálogo, desde la mirada de un investigador externo y neutral. Incluso nos animamos a decir que la lógica de realizar un documento en donde prima el producto por sobre el proceso, quizás les hubiera sido más funcional, o "eficiente", a los responsables de esta política ambiental que fueron quienes nos propusieron la tarea.

En este marco sin lugar a dudas uno de los aprendizajes de nuestro proceso tiene que ver con el posicionamiento político y la acción del y la investigadora y de la persona facilitadora y del resto de las y los actores, con las negociaciones permanentes que deben realizarse en la práctica para poder generar un proceso colectivo que tiene matices, tensiones, con desaciertos, en definitiva, con aprendizajes. Que implica ir "dando batalla" en la práctica para construir no sólo otros modos de narrar comunicativamente las experiencias, sino otro modo de abordarlas metodológicamente, trabajando para crear espacios donde las cosas sucedan. 
Lejos nos sentimos aún de haberlo logrado con la sistematización de esta experiencia, pero cerca tenemos la convicción de que es el camino que queremos transitar hacia adelante.

Es por ello que también insistimos en el enfoque, asumiendo el desafío de la sistematización como práctica reflexiva y colectiva, como un texto en contexto, como un proceso formativo, con las huellas y las voces de quienes lo protagonizan en el día a día y señalando sobre aquellas y aquellos que deberían ser decisores y hoy no están presentes en las discusiones. La metodología y la perspectiva conceptual se hacen entonces trama política aclarando siempre que, esa trama, no se construye sola.

Esta perspectiva de comunicación / educación, nos ayuda a repensar una mirada acerca de las políticas ambientales como parte de la estrategia de desarrollo de las comunidades locales en donde el enfoque no se reduce a una dimensión sectorial, sino a una construcción social del territorio en donde intervienen una multiplicidad de aspectos. En esa construcción cobra valor la creación de redes, la participación de las instituciones y de las y los actores de diversos sectores en la elaboración de la agenda y la gestión de las políticas locales, poniendo especial énfasis en el aprovechamiento de los recursos y potencialidades endógenas por sobre las recetas y las "formas de éxito" descontextualizadas.

Muchos de los procesos del desarrollo territorial se abordan como problemas técnicos, en los que frecuentemente falta una reflexión profunda sobre las causas que las provocan, o modos alternativos de hacer las cosas.

Por eso insistimos entonces en revisar y proponer en este tipo de experiencias locales otras perspectivas comunicacionales que contribuyan no sólo a la reflexión sobre nuestras propias prácticas, sino más bien a la acción y a la transformación que en definitiva tienen como fin último mejorar la calidad de vida de las personas en sus comunidades. Y aquí el aporte de PLANGESCO ha sido fundamental en términos de profundizar, problematizar y discutir otras modalidades posibles de abordar la comunicación en el territorio, más allá de las tradicionales, que son a nuestro entender el corazón de la planificación y la gestión de la comunicación para generar procesos de estas características.

\section{Aprendizajes sobre la metodología de sistematización de experiencias desde el enfoque del desarrollo territorial.}

El segundo elemento que nos gustaría compartir en estas reflexiones finales tiene que ver con qué aprendimos nosotros y nosotras, como equipo que llevó adelante la sistematización de este proceso, en términos metodológicos.

Desde nuestra experiencia veníamos trabajando como docentes / facilitadores en el espacio de la Maestría en Desarrollo Territorial de la UTN, Facultad Regional Rafaela, en los espacios 
curriculares de los Talleres de Reflexión Sobre la Praxis I y II, en la construcción de un nuevo corpus conceptual y metodológico sobre la sistematización de experiencias en articulación con el enfoque del Desarrollo Territorial, nutriéndose de diferentes autores y perspectivas tal como hemos compartidos en diferentes apartados de este trabajo de tesis.

Volver a "poner en acción" esos marcos a partir de sistematizar "Rafaela Más Sustentable" nos ha permitido, nuevamente, identificar una serie de dimensiones que mencionamos aquí como aprendizajes. Pensando también hacia adelante no sólo desde nuestro lugar en la docencia, sino también desde nuestra posición como comunicadores y comunicadoras y al aporte que podríamos realizar en la sistematización de otras políticas públicas locales. La praxis siempre es necesaria, es un posicionamiento epistemológico.

A partir del camino recorrido, de transitar la experiencia de sistematizar este proceso, nos proponemos compartir entonces nuestros aprendizajes respecto a la metodología de sistematización, enfatizando en las dificultades, complejidades propias del proceso de la práctica que nos han hecho pensar en la metodología como un camino que se modifica en el hacer, transformando incluso la propia construcción teórica.

Para realizar este ejercicio volveremos a retomar las etapas que hemos empleado en la metodología de sistematización de Rafaela Más Sustentable para revisarlas críticamente, estableciendo algunas conclusiones respecto a su puesta en práctica. La intencionalidad es poder presentar otras dimensiones posibles respecto a una metodología que se modifica conforme a cada práctica y que seguramente se transforme de acuerdo a cada experiencia particular, vinculada a los contextos, las tradiciones y las identidades territoriales.

En el inicio de estos procesos, si bien nunca lo hemos entendido de manera lineal, está la conformación del equipo de sistematización. A partir de nuestra experiencia nos parece relevante agregar nuevos elementos, como una especie de etapa cero, que denominamos, "el proceso de negociación". Con esto nos referimos a que en la literatura que hemos estudiado y en la implementación de la metodología no aparece este momento y lo estratégicas que resultan las negociaciones institucionales y políticas que deben generarse para que el proceso se oriente hacia el sentido deseado. En algunos casos pueden aparecer en el mientras tanto, pero identificamos que lo mejor es que se evidencien en el momento donde se inician los diálogos.

La voluntad de realizar una sistematización aparece como algo ya establecido en la metodología, con compromiso de las y los actores que gestionan las políticas y procesos como algo asumido de por sí. Nuestra experiencia indica todo lo contrario, tal como lo hemos anticipado en algunos de los apartados de este trabajo.

Tiene que hacerse explícita la decisión política e institucional para generar este tipo de metodologías para el abordaje de las prácticas. En nuestro caso trabajamos fuertemente el énfasis de que como equipo no teníamos intención de construir un documento que fuera un 
producto tradicional de comunicación de resultados de gestión, sino que queríamos producir un proceso reflexivo que, además, mientras se lleva adelante va provocando procesos formativos en quienes lo transitan.

Para lograr ese objetivo, o al menos intentar ir hacia él, se requirió de un proceso de negociación previa al inicio del trabajo en donde se abordara en distintas reuniones que la decisión política de avanzar hacia un proceso de sistematización de experiencias implicaba asumir otros compromisos. No era solo la tarea de brindar la información necesaria a quien realiza la sistematización o garantizar la llegada a los entrevistados, sino involucrarse en el proceso.

El compromiso implicaba que paralelamente al desarrollo del proceso, el equipo del Instituto para el Desarrollo Sustentable, se fuera formando en la práctica de la sistematización, tanto teórica como metodológicamente. Creemos que esto no sucedió como se esperaba, incluso en muchos casos fuimos sólo nosotros y nosotras quienes traccionamos y motivamos en forma permanente e insistente la generación de los espacios de diálogo, la revisión de los documentos parciales entre otras actividades involucradas en la sistematización.

La experiencia nos ayuda a pensar en la instancia de negociación como un proceso clave en donde quizás también se requiere darse el tiempo para discutir el enfoque y el sentido político de avanzar hacia la producción colectiva de un material que no sea únicamente un documento de difusión de los aspectos exitosos. Sabiendo que, en algunas ocasiones, hasta que el proceso no comience a caminar, muchos actores consideran estos diálogos como sólo "teoría". Consideramos que este tipo de iniciativas de sistematización son centrales para la consolidación y profundización de las políticas públicas de estado, como sucede en este caso, y entendemos que para quienes participaron como actores y actoras del proceso y que pertenecen a diversas instituciones y organizaciones locales, les ha sido relevante y formativo.

Aquí también se juega una variable que tampoco aparece demasiado explícita en los marcos metodológicos y conceptuales, del enfoque de la sistematización de experiencias, que tiene que ver con la tensión entre los tiempos, en este caso los tiempos de la gestión política y los tiempos del proceso de la sistematización. Generar este tipo de iniciativas que tienen en su génesis procesos de diálogo, de negociación, de gestión y de reelaboración lleva mucho más tiempo y dedicación que recopilar y escribir un documento de difusión de resultados alcanzados. Con esta tensión hemos atravesado este proceso, entendiendo la necesidad de la lógica de la gestión pública, pero necesitando construir y promover espacios para la reflexión y el análisis.

Este es un elemento de gran relevancia que se debe conversar en el proceso de negociación e incluso establecer en el documento inicial del plan de trabajo, que en alguna medida se queda más en la formalidad que en un instrumento de verdadera planificación del proceso.

En lo que se refiere a la reconstrucción de la experiencia, que denominamos en este trabajo como Memoria, nos parece interesante recuperar la importancia que le han dado los distintos actores y actoras vinculados a la sistematización. 
En nuestra práctica constituía un aspecto más de tipo documental, de antecedente para los espacios de diálogo y de mapeo de actores, y resultó ser un insumo casi fundamental en términos de recuperación histórica. No habíamos valorado de tal manera la relevancia de contar un proceso de casi 10 años de trabajo en materia ambiental, que se encontraba en las experiencias y la memoria de las personas y en los documentos, publicaciones y materiales dispersos. Verlo plasmado en un documento de trabajo permitió ver la potencialidad del proceso y rastrear las tradiciones que generaron las condiciones de posibilidad para que este tipo de iniciativas se hayan gestado en este territorio particular.

Por lo cual consideramos que la Memoria es una etapa a la que quizás, dependiendo de las circunstancias, deberíamos darle una entidad diferente e incluso en una dinámica de diálogo más que una elaboración del equipo de sistematización, como lo fue en este caso.

El momento de análisis e interpretación reflexiva de la experiencia y los procesos de diálogo en la sistematización ha sido uno de los mayores desafíos en la construcción metodológica y en la relación entre teoría y práctica. Aquí ha sido clave "escuchar antes que hablar" tal como nos ha enseñado Mario Kaplún (2002), enfatizando en la relevancia de que este tipo de procesos de aprendizaje no lo hacemos las y los investigadores solamente, obteniendo conclusiones a partir de nuestras observaciones, sino que el conocimiento es una construcción colectiva, un proceso de co construcción (Costamagna y Larrea, 2015).

\section{Es entonces, absolutamente imprescindible la construcción de espacios de diálogo con las y} los actores. Y con espacios de diálogo no nos referimos solamente a la realización de instancias de entrevistas o talleres en donde se generan conversaciones sobre los temas, o se "validan" las definiciones que se construyen a priori y por fuera de la práctica; cuando hablamos de diálogo entendemos que nuestros horizontes deben estar orientados a la reflexión - acción, que es praxis (Freire, 1997). El diálogo entonces se constituye como dimensión central, trabajando en clave de reconocimiento (Huergo, 2003) de los saberes de las y los actores del territorio y se transforma en el "corazón" de la sistematización. Consideramos que este aspecto debe fortalecerse, enunciarse con mayor potencia y profundizarse metodológicamente aun cuando los tiempos apremian.

Entendiendo también que a medida en que vamos avanzando vamos formando capacidades en procesos de diálogo multiactorales, en nosotros y nosotras quienes sistematizamos y facilitamos la experiencia y en los otros y otras protagonistas de la misma. La mayor dificultad que transitamos en el hacer, fue que en la mayoría de los casos nos encontrábamos que la primera identificación era reducir los aprendizajes a los resultados, o sólo a los aspectos que habían sido exitosos. Por ello insistimos que en este tipo de procesos a la vez que avanzamos en el camino metodológico nos vamos formando (nosotros, nosotras y los otros y otras) sin recetas, sino construyendo momentos para trabajar juntos y juntas en el tipo de reflexiones que queríamos generar. Poniendo especialmente en valor los saberes de las personas, reconociendo su jerarquía en términos de "igualdad de honor para jugar los asuntos en juego", 
retomando a Jorge Huergo (2003), y su potencialidad en los procesos de desarrollo territorial. La etapa de desarrollo de propuestas transformadoras y co construcción se constituyó como un momento también relevante y novedoso del proceso. Desde nuestro marco conceptual y metodológico desde la Maestría en Desarrollo Territorial, en el dictado de los Talleres de Reflexión sobre la Praxis I y II, no veníamos trabajando sobre esta dimensión sino más bien sólo llegábamos a la etapa reflexiva de identificación de los aprendizajes.

El momento de co construcción fue claramente un aporte que retomamos de la literatura de la Investigación Acción Participativa para el Desarrollo Territorial (IAP) que veníamos recuperando del intercambio con Orkestra (Instituto Vasco de Desarrollo Territorial de la Universidad de Deusto con sede en San Sebastián, España) donde en mi caso tuve la oportunidad de realizar una estancia de investigación en el año 2016, momento en el que con el equipo de investigación de allí compartimos e intercambiamos las perspectivas de sistematización en el marco del desarrollo territorial, que cada uno y cada una implementa y enseña en sus países, generando una muy buena experiencia de comunidad de aprendizaje, que aún hoy continúa.

Es a partir de esos aprendizajes e intercambios que incorporamos la etapa de co construcción, también bajo el sentido político de que la sistematización no debería quedarse en la mirada diagnóstica y/o analítica sino también comprometerse a futuro. Desde ese lugar es que abordamos, con dificultades y aún con mucho para mejorar, las propuestas de transformación sobre Rafaela Más Sustentable, enunciadas, identificadas y construidas por las y los propios participantes.

Estas propuestas se centraron en dos ejes relevantes que consideramos que han constituido un gran aporte que ha sido retomado por los gestores y decisores de la política. Estos ejes fueron: por un lado, la revisión y construcción colectiva de la agenda a futuro de los temas ambientales de la ciudad y la región y, por otro, la redefinición del rol de Consejo Ambiental con ampliación a otros sectores que no estaban teniendo voz y participación allí, pero que poseen una gran incidencia para la construcción de las políticas, como, por ejemplo, el sector educativo en todos sus niveles y modalidades.

Un tema que requiere de mayor profundidad tiene que ver con la socialización y la comunicación de la experiencia de sistematización. Tal como lo analizamos en el capítulo precedente el documento generado no fue compartido ni puesto en circulación como hubiéramos deseado. Sí en nuestro caso pudimos publicarlo en el ámbito académico donde tuvo muy buen eco y sabemos que fue abordado en otros espacios curriculares de formación de posgrado vinculado al desarrollo territorial, además del propio espacio de la Maestría.

Pero en el ámbito del Instituto para el Desarrollo Territorial, si bien se generó una versión reducida para publicar en el sitio web, consideramos que no se ha aprovechado la potencialidad que el documento posee y el valor agregado que supone al tratarse de un proceso colectivo y compartido que podría haberse socializado con más énfasis. No sólo al interior del territorio 
sino también con otros espacios de gestión de gobiernos locales, nacionales y organismos en general que en forma permanente se contactan con el Instituto para intercambiar experiencias o incluso para visitar, por ejemplo, el Parque Tecnológico de Reciclado. Incluso hay un actor clave en este sentido que son los organismos de financiamiento que pueden ser un destinatario muy relevante para la obtención de fondos y la presentación a convocatorias, que suelen ser muy habituales respecto a prácticas innovadoras en materia ambiental en las que la ciudad de Rafaela es absolutamente pionera en la región y en el país.

De todas formas, más allá de que consideramos que este momento no ha sido del todo aprovechado y potenciado, encontramos dos señales que nos alientan a seguir trabajando en esta dirección y profundizando los esfuerzos hacia la comunicación de la experiencia. La primera tiene que ver con la valoración de la sistematización por quienes han formado parte de la misma y la propia red de comunicación que ellos y ellas mismos generaron al interior de sus organizaciones e instituciones. La segunda se dio recientemente en donde a raíz del cambio de gestión, si bien fue reelecto el intendente Luis Castellano parte de su gabinete se ha modificado, en un diálogo casual con quien fuera la directora del Instituto para el Desarrollo Sustentable, María Paz Caruso, que acaba de asumir como Secretaria de Ambiente y Movilidad de la Municipalidad de Rafaela, nos expresa que deberíamos retomar y realizar una nueva sistematización, ya habiendo transcurrido un período de gestión del Instituto, para analizar en qué medida se ha consolidado y/o transformado. Este, para nosotros y nosotras, constituye un indicador de que el proceso ha sido significativo.

Finalmente, más allá de las etapas metodológicas y su puesta en práctica que no es de ninguna manera lineal y que ha generado tensiones y contradicciones, nos parece central concluir en la fortaleza política que posee la sistematización de experiencias como herramienta en procesos de desarrollo territorial donde la construcción de capacidades ocupa un lugar importante. Con esto nos referimos a la importancia de incorporarla, casi como un "hábito", en la gestión de las políticas públicas locales.

Para ello sería deseable un proceso de formación referido a los marcos conceptuales y metodológicos, pero también sobre lo que implica la facilitación de espacios de diálogo y comunicación para que puedan tener real incidencia en la construcción de proceso colectivos, que no sólo documenten las acciones sino que permitan mirar hacia el futuro, tomando decisiones que no estén solamente basadas en las evaluaciones tradicionales, que ponen el eje (en la mayoría de los casos) en visiones resultadistas y cuantitativas.

La potencia de la sistematización como ejercicio colectivo nos invita a reconstruir nuestras identidades, nuestros haceres juntos y juntas, recuperando las miradas críticas sobre los procesos, identificando quienes no están teniendo voz y protagonismo en la palabra pública y debería estar discutiendo los temas que nos involucran y planificando nuestro futuro. Lejos de ser una mirada romántica de la práctica es una invitación a profundizar otros modos comunicativos de construir relatos de nuestras comunidades, especialmente en lo que se refiere a la gestión de una política pública de estado, como es este caso, que involucra a sectores diversos. 


\section{Aprendizajes vinculados a los diálogos con la academia}

Otro elemento, en términos de aprendizajes, que nos gustaría retomar en este apartado es la vinculación de los aprendizajes surgidos de la sistematización con los espacios académicos. Como ya lo hemos mencionado, recuperando la perspectiva de la Investigación Acción Participativa (IAP) es importante y relevante compartir estos procesos de acción, reflexión, acción en el marco no sólo del aula sino también en los ámbitos de discusión de la producción de conocimiento. Poniendo el énfasis en que "la academia" es un actor más del proceso de construcción colectiva y bajo la apuesta de ir proponiendo y "dando batalla" sobre la importancia que poseen otros modos de construcción de conocimiento y de investigación que vienen estando en los márgenes, al menos en los temas del desarrollo territorial, como es el caso de la sistematización de experiencias y la investigación acción.

En este sentido también se ha constituido como un desafío para este trabajo propiciar y alentar la construcción de otros modos de producir conocimientos, otras metodologías para poner en diálogo las experiencias con los marcos conceptuales como es el caso de la sistematización, generando también disputas al interior de la propia academia, proponiendo otros enfoques para revisar las propias prácticas como docentes e investigadores.

Esta situación sigue siendo un espacio de tensión y la hemos vivenciado claramente cuando nos propusimos publicar una versión reducida del documento de sistematización en una prestigiosa revista académica de otro país dedicada específicamente al campo del desarrollo territorial. Allí, como se realiza habitualmente, enviamos nuestro trabajo, pero tuvimos devoluciones para la publicación orientados a revisar la metodología como si la metodología estuviera divorciada de los conceptos, de las experiencias. Por lo cual justificamos algunas observaciones, pero en el caso de otras debimos incorporar precisiones concretas y autores sobre metodologías cualitativas para poder ser publicados. Esta cuestión nos muestra como aún estas propuestas siguen estando en los bordes de la producción de conocimiento, por lo cual es importante redoblar los esfuerzos para profundizar otros modos de investigar en ciencias sociales, más allá de los hegemónicos.

Es interesante señalar que como experiencia de aprendizaje colectivo esta sistematización también contribuyó a la revisión y reforma del plan de estudios de la Maestría en Desarrollo Territorial que se cristalizan en dos espacios curriculares, como lo son el "Taller de Reflexión sobre la Praxis I y II" que pretenden abordar estas temáticas y trascender aún la sistematización para generar propuestas de formación que se articulen con el territorio, promoviendo acciones transformadoras de las problemáticas de las comunidades, recuperando como ejes centrales y como perspectiva política al diálogo y la co - construcción con las y los actores de esas comunidades.

Asimismo, también a partir de nuestros aprendizajes, introducimos modificaciones en el abordaje de los contenidos y metodologías de las clases de los mencionados Talleres de Praxis, como por ejemplo la conformación del equipo de sistematización en donde las y los 
estudiantes tienen como condición para el inicio del proceso conformar un equipo con las y los actores de la experiencia a sistematizar, eso implicaba que deben darse el tiempo para trabajar en un espacio de negociación conjunta.

Lo mismo sucede con la definición del eje de la sistematización, antes se realizaba desde el espacio áulico a partir de la identificación que realizaba el grupo de estudiantes en diálogo con nosotros y nosotras, sus docentes. Ahora el eje se aborda en conjunto con las y los actores protagonistas de la experiencia, recuperando cual es el sentido para ellos y ellas de darle valor a un tema, problemática o dimensión de la propia práctica. Esto parece sencillo, pero necesita de una gran energía por la resistencia que genera, en algunos casos, salir de aula e involucrarse en el territorio especialmente en el ámbito de la formación de posgrado y la multiplicidad de las lógicas disciplinares de las y los maestrandos.

Si bien desde la dimensión pedagógica esto ha sido complejo, porque requiere de un proceso que a veces no va de la mano con los tiempos de la academia, se ha transformado en un horizonte político dando un giro en el modo de construir conocimiento, en este caso, con otros y otras personas que pertenecen a organizaciones e instituciones de la dinámica territorial. Además estas sistematizaciones contribuyen a generar un proceso reflexivo y un ida y vuelta entre los espacios formativos / académicos y la comunidad (a través de una diversidad de entidades talos como los organismos del estado local, sindicatos, gremiales empresarias, organizaciones sociales, instituciones del ámbito educativo y científico - tecnológico, entre otros).

Otra de las modificaciones que realizamos, además de las metodológicas, fue en relación a los contenidos en donde introducimos una unidad sobre la perspectiva de Paulo Freire. Si bien lo veníamos trabajando más metodológicamente, entrar en el corazón del pensamiento freireano referido a las nociones de educación problematizadora, universo vocabular, diálogo y praxis, así como también el sentido político, nos abrió nuevos espacios de conversación y de acción con nuestros y nuestras estudiantes que poseen trayectorias laborales, pertenencias institucionales, franjas etarias y formaciones disciplinares de lo más diversas. Muchos y muchas de ellas habían leído a Freire, para otros y otras era un autor desconocido, pero nos animamos a decir que para todas y todos fue una lectura significativa que adquirió sentido en sus prácticas y biografías y que se transformó, al menos, en un norte en el proceso de sistematización. Contribuyó también a esta mirada la perspectiva de Comunicación / Educación de Jorge Huergo que enriqueció el debate y la vinculación con el enfoque pedagógico del Desarrollo Territorial.

\section{Aprendizajes vinculados a la planificación y gestión de políticas públicas socioambientales.}

Finalmente, nos gustaría compartir algunas dimensiones que pudimos visualizar respecto a la planificación y gestión de políticas públicas socioambientales, mencionando algunas cuestiones generales que recuperamos del proceso de sistematización, pero poniendo el énfasis especialmente en la dimensión comunicativa. 
Una primera reflexión que surge del proceso es la reducción de lo ambiental a la temática exclusiva de los residuos. Esto lo hemos identificado principalmente en los diálogos con las y los participantes del Consejo Ambiental. Se entiende que la gestión integral de residuos sólidos urbanos ha sido "punta de lanza" para instalar las temáticas ambientales, en las que además el municipio ha sido pionero con una tasa de separación domiciliaria en origen superior al $80 \%$. Pero hay otro conjunto de dimensiones en el marco de la agenda ambiental que son estratégicas y que representan una oportunidad respecto a la mirada a futuro y que hoy se presentan más en el plano de lo intangible pero que sería importante atender; con ello nos referimos por ejemplo a la discusión del modelo mismo de producción y consumo. Significa un horizonte innovador como política a largo plazo que involucra un conjunto de acciones que hoy mismo pueden comenzar a abordarse como política pública en diálogo con la comunidad local.

El proceso de conformación del Instituto para el Desarrollo Sustentable sin ningún lugar a dudas marca un hito en la consolidación de una política pública, asegurando y garantizando su continuidad como política de Estado, independientemente de las gestiones de gobierno y eso significa un salto cualitativo y una oportunidad a futuro. Es relevante y llamativa la valoración de este espacio aún desde los sectores opositores al gobierno local, que, si bien manifiestan sus críticas, recuperan la importancia de un ente autárquico con presupuesto propio y capacidad en la toma de decisiones. Hay un consenso explícito respecto a la relevancia de la política ambiental, pero, desde nuestro punto de vista, es importante fortalecer los mecanismos colectivos que le dan respaldo a esas políticas.

Con ello nos referimos a que existe un enorme potencial para generar instancias de intercambio y efectiva participación para la toma de decisiones, más que espacios de validación y aprobación de las acciones definidas con anterioridad. Y es hacia allí hacia donde debería redefinirse el rol del Consejo Ambiental y la ampliación hacia otros sectores que hoy no están sentados en la mesa de discusión de temáticas que las y los afectan directamente. En este punto consideramos que nuestro trabajo ha podido hacer un aporte interesante.

Por otro lado, es importante reconocer que sin decisión política y sin un rol activo y protagónico del estado local este tipo de iniciativas con la fuerza que poseen no hubieran sido posibles ni viables. El liderazgo en este sentido es clave teniendo en cuenta que, en la mayoría de los casos, se requieren además de inversiones presupuestarias que no tienen alta visibilidad (como por ejemplo es el caso de las obras de infraestructura y servicios) y que suponen apuestas a futuro con iniciativas que poseen resultados recién a mediano y largo plazo y que requieren de otros tiempos que, generalmente, no son los tiempos de la política. En este marco, el rol del estado es un tema de suma importancia.

Si bien los temas ambientales no son nuevos, sino que tienen una tradición en el territorio y que fueron configurando el escenario de lo que es hoy el Instituto para el Desarrollo Sustentable, se trata de un espacio reciente que como toda nueva institucionalidad territorial 
necesita afianzarse y consolidarse en el tiempo. A estos desafíos se suma que la conducción de este espacio está cargo de una mujer, joven, con todas las implicancias, complejidades y adversidades que existen para las mujeres en espacios de gestión y decisión política en un terreno que ha sido casi exclusivo de varones, en donde nosotras hemos tenido que hacernos lugares derribando mitos y conquistando derechos, para acceder a las áreas que además no son las que históricamente nos han habilitado. Pensando en que, en la mayoría de los casos, venimos ocupando espacios vinculados con los tradicionales roles de cuidado, casi como una extensión del maternaje (como es el caso de educación, desarrollo o acción social, ni hablar de las denominadas "secretarías o áreas de la mujer").

Un aspecto que puede contribuir en este proceso de consolidación, de un espacio de gestión de política que no es tradicional por el modo en que se ha conformado, es el abordaje de la comunicación desde la perspectiva PLANGESCO que supone ir más allá de las dimensiones de tipo instrumentales para avanzar hacia una lectura de los procesos sociales, la identificación de problemáticas, de interpelaciones en los territorios en donde intervienen sujetos y sujetas que construyen prácticas de producción de sentidos de diversa índole. Por ello la comunicación es una clave de lectura y una mirada estratégica de la intervención.

Cabe entonces retomar la pregunta por la comunicación en procesos de Desarrollo Territorial, y que dimensiones implica. Porque pareciera que siguen primando las lógicas de los productos por sobre los procesos, por sobre las reflexiones sobre el cómo, por sobre la generación o el fortalecimiento de capacidades comunicativas en las y los actores y facilitadores. No se trata de ningún modo de abandonar los espacios de producción comunicativa, tales como las redes sociales, ni los productos de difusión sino lo que se trata es de poder crear y recrear otras experiencias comunicativas que contribuyan a recuperar el diálogo como modo colectivo de gestar y gestionar sumando gente que facilite procesos también en este sentido.

Para culminar, o quizás para un nuevo empezar, nos parece relevante mencionar el valor que ha tenido para nosotras y nosotros el proceso de sistematización de experiencias como práctica formativa, como horizonte político, como espacio de comunicación, como narrativa común. En tiempos fugaces, efímeros e impersonales la dinámica del diálogo, el tiempo del encuentro entre mate y mate con quienes nos abrieron la puerta de sus casas, en alguna oficina, en el aula, en el barrio y en tantos otros recorridos, nos señala un horizonte que nos invita cada vez más a involucrarnos y comprometernos para andar juntos y juntas. 



\section{Bibliografía:}

- Alburquerque, F. (2013): Economía del Desarrollo y Desarrollo Territorial. Programa ConectaDEL. Buenos Aires. Argentina.

- Alburquerque, F. (2010). "La experiencia de Desarrollo Local de Rafaela, Argentina". Septiembre.

- Alburquerque, F. y Pérez Rozzi, S. (2012): El desarrollo territorial: enfoque, contenido y políticas. Mesa de Programas, Buenos Aires. http://www.conectadel.org/wp-content/uploads/ downloads/2013/09/EL-ENFOQUE-SOBRE-EL-DESARROLLO-TERRITORIAL-doc-Mesa-deProgramas.pdf

- Alburquerque F., Costamagna P. y Ferraro C. (2008) Desarrollo económico local, descentralización y democracia. Ideas para un cambio. San Martín. UNSAM Edita.

- Álvarez Álvarez, C. (2008). La etnografía como modelo de investigación en educación. Gazeta de Antropología. 24 (1). 1-15.

- Amaya Sierra, A. (2017). La investigación-acción participativa como pedagogía crítica. un acercamiento. Ediciones Noria.

- Barnechea, M., González, E. y Morgan Tirado, M. (2005): La producción de conocimientos en sistematización. Ponencia presentada en el Seminario Latinoamericano de Sistematización.

- Berdegué, J.; Ocampo, A. y Escobar, G. (2007): Sistematización de experiencias locales de desarrollo rural. Guía Metodológica. Fondo Internacional de Desarrollo Agrícola (FIDA).

- Calderón, J. y López Cardona, D. (2016). Orlando Fals Borda y la investigación acción participativa: aportes en el proceso de formación para la transformación. En: Primer Encuentro hacia una Pedagogía Emancipatoria en Nuestra América. Buenos Aires.

- Cerro, G. y Rearte, M. (2007). Concepciones acerca de la sistematización. Centro Provincial de Investigación y Prospectiva Educativa. Dirección General de Cultura y Educación de la Provincia de Buenos Aires.

- Centro de Estudios para la Educación Popular, CEPEP (2010). La Sistematización de experiencias: un método para impulsar procesos emancipadores. Editorial El Perro y la Lana. Caracas.

- Costamagna, P. (2015). Política y formación en el Desarrollo Territorial. Aportes al enfoque pedagógico y la investigación acción con casos de estudio en Argentina, Perú y País Vasco (1era edición). San Sebastián: Orkestra Deusto Publicaciones. 
- Costamagna, P. y Larrea, M. (2015). El Enfoque Pedagógico y la Investigación Acción para el Desarrollo Territorial. En: Costamagna, P y Pérez Rozzi, S. Enfoque, estrategias e información para el desarrollo territorial. Los aprendizajes de ConectaDEL FOMIN-BID (123) (1era Edición). Buenos Aires: Programa ConectaDEL. .

- Costamagna, P. y Ferraro, C. (2000). “Entorno institucional y desarrollo productivo local. La importancia del ambiente y las instituciones para el desarrollo empresarial. El caso de Rafaela." CEPAL.

- Costamagna, P; Pérez, R y Spinelli, E. (2015). Elementos de un Enfoque Pedagógico para el Desarrollo Territorial. Buenos Aires: Programa ConectaDEL.

- Costamagna, P. y Jurado, A. (2011). Programa Rafaela Más Sustentable (1era Edición). Rafaela: ICEDeL. Municipalidad de Rafaela.

- Costamagna, P. y Spinelli, E. (2013): Formadores - Facilitadores de procesos de Desarrollo Territorial. Programa ConectaDEL.

- Díaz Bordenave, J. (2008). “Comunicación y Desarrollo”. Revista Chasqui. Nro 77. Quito. Ecuador.

- Fals Borda, O. y Rodríguez Brandao, C. (1987).Investigación Participativa, Montevideo: De la Banda Oriental.

- Freire, P. (ed. 1999): Pedagogía del Oprimido. Editorial Siglo XXI.

- Freire, P. (1995). Educación como práctica de la libertad. Editorial: Siglo XXI.

- Freire, P. (1985). La importancia del acto de leer. Trabajo presentado en la apertura del Congreso Brasileño de Lectura, Campinas, Sao Paulo.

- Guber, R. (2011). La Etnografía. Método, campo y reflexividad. $1^{\circ}$ Edición. Buenos Aires: Siglo XXI Editores.

- Greenwood, D.J. y Levin, M. (2007) Introduction to action research: Social research for social change. Sage Publications, Thousand Oaks.

- Gumucio Dagron, A. (2012). Comunicación para el cambio social: clave del desarrollo participativo. Signo y pensamiento.

- Gustavsen, B. (1992). Dialogue and Development. Theory of Communication, Action Research and the Restructuring of Working Life. Assen: Van Gorcum.

- Huergo, J. (2002). Espacios discursivos. Lo educativo, las culturas y lo político. II Coloquio Nacional de Investigadores en Estudios del Discurso. La Plata. 
- Huergo, J. (2003). El reconocimiento del Universo Vocabular y la Prealimentación de Acciones Estratégicas. Centro de Comunicación y educación. FPyCS. La Plata.

Huergo, J. (2004). La formación de sujetos y los sentidos político-culturales de Comunicación/ Educación. En: DEBATES SOBRE EL SUJETO. Perspectivas contemporáneas. María Cristina Laverde Toscano, Gisela Daza Navarrete y Mónica Zuleta Pardo (dir.). Editorial Siglo del Hombre. Bogotá.

- Jara, O. (1994). Para sistematizar experiencias. Alforja, San José de Costa Rica.

- Jara, O. (sin fecha de publicación): El desafío político de aprender de nuestras prácticas. Centro de Estudios y Publicaciones Alforja. Costa Rica.

- Jara, O. (sin fecha de publicación): Como sistematizar (una propuesta en cinco tiempos. CEP - Alforja. Costa Rica.

Jurado, A. (2011). Economía verde y calidad ambiental. Revista Café de las ciudades. Año 10. Nro. 109.

- Kaplún, M. (2002). Una Pedagogía de la Comunicación: El Comunicador Popular. Editorial Caminos. La Habana. Cuba.

- Manzanal, M. (2017). Desarrollo, territorio y políticas públicas. Una perspectiva desde el desarrollo rural y territorial. Revista Interdisciplinaria de Estudios Agrarios $N^{\circ} 46$. Buenos Aires. Madoery, O. (2005). El valor de la política de Desarrollo Local. Universidad de San Martin. Buenos Aires.

- Mata, MC. (1984). Nociones para pensar la comunicación y la cultura masiva. Centro de Comunicación educativo La Crujía. Curso de especialización Educación para la comunicación.

- Messina, G. (2005). La Sistematización: acerca de su especificidad. Rieda (Revista internacional de educación de adultos). Año 27 / Nº 2 .

- Muñoz, M. y Spinelli, E. (2015). Comunicación y Sistematización de experiencias. En: Costamagna, P y Pérez Rozzi, S. Enfoque, estrategias e información para el desarrollo territorial. Los aprendizajes de ConectaDEL FOMIN-BID (1era Edición). Buenos Aires: Programa ConectaDEL.

- Lois, I. (2017). La Investigación-Acción (I+A) y la Investigación Acción Participativa (IAP): un recorrido posible entre el conocimiento y la praxis. Universidad de Buenos Aires.

- Obregón, A. y Botero, R. (2011). Un análisis crítico de las perspectivas de diálogo en la literatura sobre comunicación para el desarrollo y cambio social: abordajes y desafíos. Revista Signo y

- Pensamiento 58 · Documentos de Investigación I pp 190-205 · volumen XXX. Colombia. 
- Ortiz, R. (2004). Taquigrafiando lo social. Buenos Aires: Siglo XXI Editores.

- Palma. D. (1992). La sistematización como estrategia de conocimiento en la educación popular: El estado de la cuestión en Latino América. CEEAL. Chile.

- Peiretti, D. (2017) La Sistematización de Experiencias en Desarrollo Territorial bajo el enfoque del Instituto PRAXIS y la Maestría en DT. Instituto Praxis. UTN. Facultad Regional Rafaela.

- PLANGESCO (sin fecha de publicación). Documento Proyecto curricular y plan de estudios.

- Maestría en Planificación y Gestión de Procesos Comunicacionales. Facultad de Periodismo y Comunicación Social. Universidad Nacional de La Plata.

- Porto Concalves, C. (2006): El desafío ambiental. Programa de Naciones Unidas para el medio Ambiente, México. Primera edición en español. (Parte I: La naturaleza de la globalización y la globalización de la naturaleza).

- Sautu, R. (2005). Todo es teoría: objetivos y métodos de investigación. 1ra ed. Buenos Aires: Lumiere.

- Sirvent, M. (2018). De la Educación Popular a la Investigación Acción Participativa. Perspectiva pedagógica y validación de sus experiencias. InterCambios. Dilemas y transiciones de la Educación Superior 5(1), 12-29.

- Spinelli, E. (2015). Apuntes para pensar los procesos de sistematización de experiencias en desarrollo territorial. Buenos Aires: Programa CONECTA DEL.

- Spinelli, E. (2013). Aportes de la comunicación a los procesos de desarrollo territorial. Presentación en el Taller de Investigación Acción para el Desarrollo Territorial. Programa ConectaDEL.

Spinelli, E. (2004). Los modelos de comunicación. En: Módulo de comunicación para las organizaciones públicas. IPAP.

- Stevens, C.; Morey, F.; Lobo, L y Beduschi, C. (2012). Metodología para la sistematización de experiencias. Programa España FAO.

- Taylor, S. y Bogdan, R. (1986). Introducción: ir hacia la gente, en Introducción a los métodos cualitativos de investigación.

- Vasallo de López, M. (2012). La investigación de la comunicación: cuestiones epistemológicas, teóricas y metodológicas. Revista Diálogos de la Comunicación (FELAFACS). pp. 12-27. 


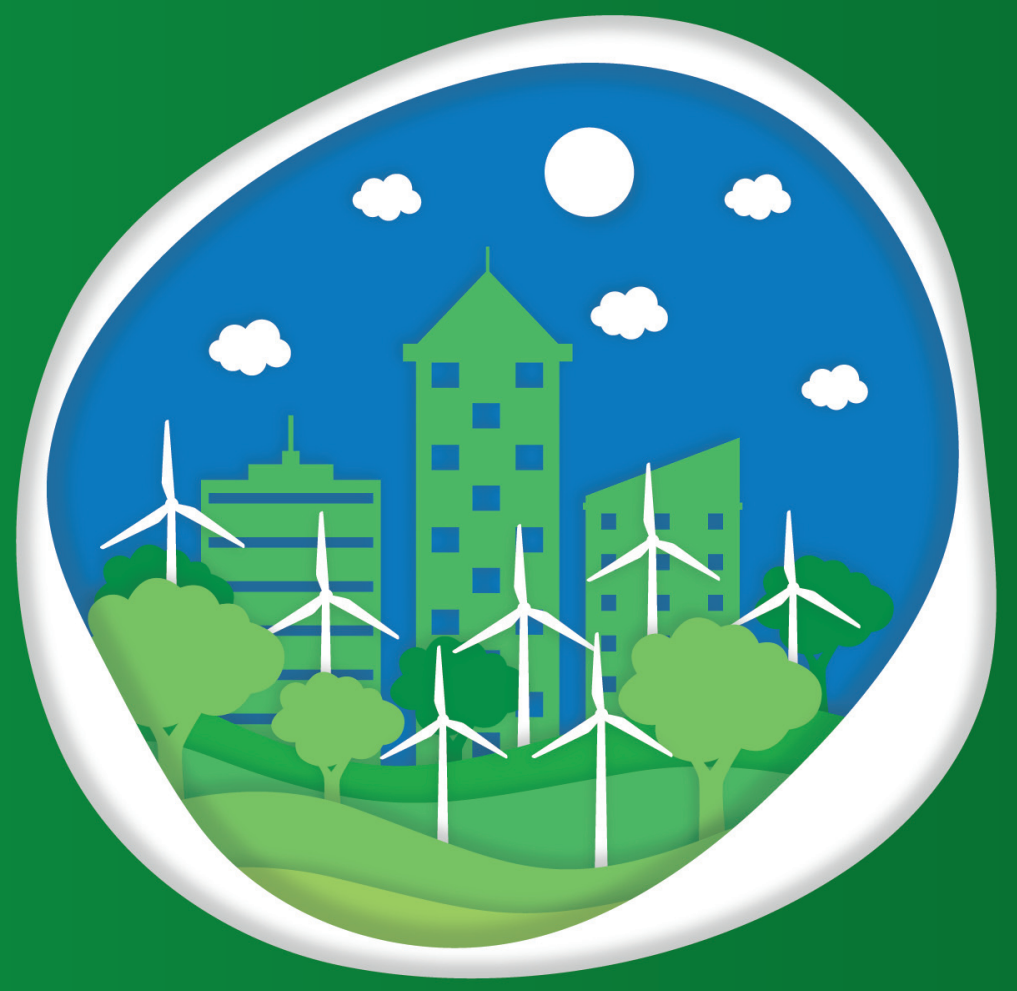

Comunicación y Sistematización de experiencias:

aprendizajes sobre una política ambiental territorial, Rafaela Más Sustentable 